SILVANIA DA SILVA TEIXEIRA

\title{
MECANISMOS ENVOLVIDOS NA AÇÃO NÃO GENÔMICA DO HORMÔNIO TIREOIDIANO SOBRE A EXPRESSÃO E TRANSLOCAÇÃO \\ DA ISOFORMA 4 DO TRANSPORTADOR DE GLICOSE (GLUT4): ESTUDO NO TECIDO MUSCULAR ESQUELÉTICO E ADIPOSO
}

Tese apresentada ao Programa de Pós-Graduação em Fisiologia Humana do Instituto de Ciências Biomédicas da Universidade de São Paulo, para obtenção do Título de Doutor em Ciências. 
SILVANIA DA SILVA TEIXEIRA

\section{MECANISMOS ENVOLVIDOS NA AÇÃO NÃO GENÔMICA DO HORMÔNIO TIREOIDIANO SOBRE A EXPRESSÃO E TRANSLOCAÇÃO \\ DA ISOFORMA 4 DO TRANSPORTADOR DE GLICOSE (GLUT4): ESTUDO NO TECIDO MUSCULAR ESQUELÉTICO E ADIPOSO}

Tese apresentada ao Programa de Pós-Graduação em Fisiologia Humana do Instituto de Ciências Biomédicas da Universidade de São Paulo, para obtenção do Título de Doutor em Ciências.

Área de concentração: Fisiologia Humana Orientador: Maria Tereza Nunes 
DADOS DE CATALOGAÇÃO NA PUBLICAÇÃO (CIP)

Serviço de Biblioteca e Informação Biomédica do

Instituto de Ciências Biomédicas da Universidade de São Paulo

reprodução não autorizada pelo autor

Teixeira, Silvania da Silva.

Mecanismos envolvidos na ação não genômica do hormônio tireoidiano sobre a expressão e translocção da isoforma 4 do transportador de glicose (GLUT4): estudo no tecido muscular esquelético e adiposo / Silvania da Silva Teixeira. -- São Paulo, 2010.

Orientador: Maria Tereza Nunes.

Tese (Doutorado) - Universidade de São Paulo. Instituto de Ciências Biomédicas. Departamento de Fisiologia e Biofísica. Área de concentração: Fisiologia Humana. Linha de pesquisa: Bases moleculares da ação de hormônios tireoidianos, substratos metabólicos e ío

Versão do título para o inglês: Mechanisms involved in the nongenomic action of thyroid hormone on the expression and translocation of the isoform of glucose transporter 4 (GLUT4)a study in skeletal muscle and adipose tissue.

Descritores: 1. Hormônio da tireóide 2. Glicose 3. Músculo esquelético 4. Tecido adiposo I. Nunes, Maria Tereza

II. Universidade de São Paulo. Instituto de Ciências Biomédicas.

Programa de Pós-Graduação em Fisiologia Humana. III. Título. 
Candidato(a):

Título da Tese:

Orientador(a):
Silvania da Silva Teixeira.

Mecanismos envolvidos na ação não genômica do hormônio tireoidiano sobre a expressão e translocção da isoforma 4 do transportador de glicose (GLUT4) estudo no tecido muscular esquelético e adiposo.

A Comissão Julgadora dos trabalhos de Defesa da Tese de Doutorado, em sessão pública realizada a I................................., considerou

\section{( ) Aprovado(a) \\ ( ) Reprovado(a)}

\begin{tabular}{|c|c|}
\hline Examinador(a): & $\begin{array}{l}\text { Assinatura } \\
\text { Nome: ...... } \\
\text { Instituição: }\end{array}$ \\
\hline Examinador(a): & $\begin{array}{l}\text { Assinatura } \\
\text { Nome: ....... } \\
\text { Instituição: }\end{array}$ \\
\hline Examinador(a): & $\begin{array}{l}\text { Assinatura } \\
\text { Nome: ....... } \\
\text { Instituição: }\end{array}$ \\
\hline Examinador(a): & $\begin{array}{l}\text { Assinatura } \\
\text { Nome: ...... } \\
\text { Instituição: }\end{array}$ \\
\hline Presidente: & $\begin{array}{l}\text { Assinatura } \\
\text { Nome: ...... } \\
\text { Instituição: }\end{array}$ \\
\hline
\end{tabular}




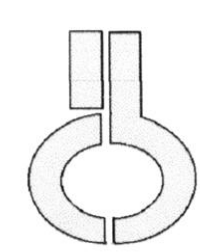

UNIVERSIDADE DE SÃO PAULO INSTITUTO DE CIÊNCIAS BIOMÉDICAS

\section{Certificado}

Certificamos que o protocolo registrado sob $\mathrm{n}^{\circ} 098$ nas fls. 35 do livro 2 para uso de animais em experimentação, sob a responsabilidade de Maria Tereza Nunes, Coordenador(a) da Linha de pesquisa "Mecanismos envolvidos na ação não genômica do hormônio tireoideano sobre a expressão e translocação da isoforma 4 do transportador de glicose (glut4): estudo no tecido muscular esquelético e adiposo" do qual participou(aram) o(s) alunos Silvania da Silva Teixeira, está de acordo com os Principios Éticos de Experimentação Animal adotado pelo Colégio Brasileiro de Experimentação Animal (COBEA) e foi aprovado pela COMISSÃO DE ÉTICA EM EXPERIMENTAÇÃO ANIMAL (CEEA) em 17.08.2006.

Săo Paulo, 17 de agosto de 2006.
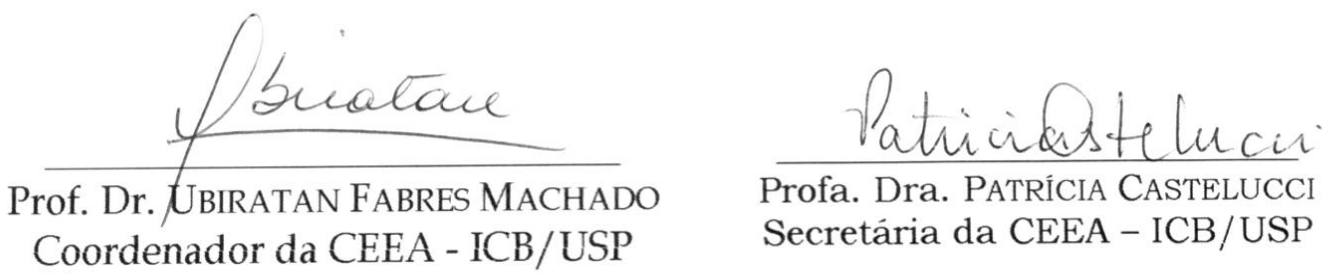

Profa. Dra. PATRÍCIA CASTELUCCI Secretária da CEEA - ICB/USP 
Dedico esta tese a Deus pela sua ajuda, direção e provisão e à minha mãe, que é um exemplo de vida, força, coragem, caráter, dignidade e sabedoria. 


\section{AGRADECIMENTOS}

A Deus por me amparar nos momentos difíceis, me dar força interior para superar as dificuldades, mostrar os caminho nas horas incertas e me suprir em todas as minhas necessidades.

À minha família, por todo apoio e confiança em mim depositada, o que tornou possivel a realização deste sonho.

À minha orientadora Maria Tereza Nunes, pelo carinho, confiança, orientação e dedicação.

À amiga e técnia de laboratório Leonice Lourenço Poyares, pela força e incentivo nos momentos de desânimo, por sempre torcer por mim, pelo carinho $e$ amizade.

A todos os colegas do Laboratório de Fisiologia Endócrina, em especial a Caroline, Jamile, Janaina e Thais, pela amizade e companheirismo.

Às moradoras do Apto $112 \mathrm{D}$, pelo carinho, força e incentivo. Obrigada por fazerem parte da minha vida e, assim, torná-la mais feliz.

Aos meus amigos Camilo e Daniella por todos os momentos que tornaram essa conquista mais divertida.

À Fundação de Amparo à Pesquisa do Estado de São Paulo (FAPESP) pelo apoio financeiro.

Enfim a todos que contribuíram para a realização deste trabalho.

Obrigada por tudo! 
"O conhecimento torna a alma jovem $e$ diminui a amargura da velhice, colhe pois, a sabedoria. Armazena a suavidade para a vida." 


\section{RESUMO}

TEIXEIRA, S. S. Mecanismos envolvidos na ação não genômica do hormônio tireoidiano sobre a expressão e translocação da isoforma 4 do transportador de glicose (GLUT4): estudo no tecido muscular esquelético e adiposo. 2010. 106 f. Tese (Doutorado em Fisiologia Humana) - Instituto de Ciências Biomédicas, Universidade de São Paulo, São Paulo, 2010.

O hormônio tireoidiano (HT) participa do controle de funções essenciais do organismo. A maioria dos seus efeitos é mediada pela modulação da transcrição gênica e se manifesta em um período longo o suficiente para permitir a transcrição de genes específicos. Por outro lado, são crescentes na literatura as evidências de que o HT também promove efeitos que ocorrem em um curto espaço de tempo e que se manifestam mesmo na presença de inibidores da transcrição gênica. O GLUT4 é o principal transportador de glicose presente no músculo esquelético, no cardíaco e no tecido adiposo. O seu processo de translocação e inserção na membrana plasmática resulta da ativação de vias de sinalização que ocorre a partir da interação da insulina com seus receptores de membrana. No músculo esquelético e cardíaco, uma segunda via que aciona o mecanismo de translocação do GLUT4 envolve a ativação da AMPK, processo desencadeado pela contração muscular. O presente estudo teve como objetivo avaliar: (i) no modelo in vivo (ratos Wistar), se o T3 e o T4 provocam agudamente a translocação do GLUT4 para a membrana plasmática; (ii) no modelo in vitro (células musculares L6 e adipócitos 3T3-L1), se o T3 e o T4 provocam o efeito descrito acima; e (iii) se esse efeito ocorre por ativação das vias de sinalização da insulina e/ou da contração muscular. Nossos estudos in vivo demonstram que a administração de T3 rapidamente aumentou o conteúdo de GLUT4 na fração correspondente à membrana plasmática no músculo esquelético e no tecido adiposo. No entanto, essa ação foi independente da ativação da PI3-K e da AMPK. Os estudos in vitro, mostraram que o T3 promove, rapidamente, um aumento na captação de glicose nas células L6 sem, contudo, alterar o conteúdo de GLUT4 presente na membrana. Esses resultados sugerem que essa ação do T3 ocorra devido a ativação do GLUT4 já presente na membrana ou devido a algum processo independente dessa proteína. Nossos resultados demonstram que ao lado das suas reconhecidas ações genômicas, o HT atua por mecanismos não genômicos regulando a translocação do GLUT4. Além disso, sugerem fortemente que o T3 participe, também por mecanismos não genômicos, do processo de ativação do GLUT4 já inserido na membrana.

Palavras-chave: Hormônio Tireoideano. Ações não Genômicas. GLUT4. Captação de Glicose. 


\begin{abstract}
ABSTRAT
TEIXEIRA, S.S Mechanisms involved in the nongenomic action of thyroid hormone on the expression and translocation of the isoform of glucose transporter 4 (GLUT4): a study in skeletal muscle and adipose tissue. 2010. 106 p. Ph. D. Thesis (Human Physiology) - Instituto de Ciências Biomédicas, Universidade de São Paulo, São Paulo, 2010.
\end{abstract}

The thyroid hormone (TH) participates in the control of essential functions of the organism. Most of its effects are mediated by modulation of gene transcription and take place over a long enough period of time to allow the transcription of specific genes. On the other hand, evidence that TH also promotes the effects that occur in a short period of time and which manifest even in the presence of inhibitors of gene transcription have been increasingly found in literature. GLUT4 is the main transporter of glucose in skeletal muscle, the heart and adipose tissue. Its translocation and insertion in the plasma membrane result from the activation of signaling pathways triggered by the interaction of insulin with membrane receptors. In skeletal muscle and the heart, a second pathway that activates the mechanism of GLUT4 translocation involves the activation of AMPK, a process triggered by muscle contraction. This study aimed at evaluating: (i) in the in vivo model (Wistar rats), if T3 and T4 acutely cause translocation of GLUT4 to the plasma membrane, (ii) in the in vitro model (L6 muscle cells and adipocytes 3T3 -L1), if T3 and T4 cause the effect described above; and (iii) whether this effect occurs by activation of the signaling pathways of insulin and/or muscle contraction. Our in vivo studies demonstrate that administration of T3 rapidly increased the amount of GLUT4 in the fraction corresponding to the plasma membrane in skeletal muscle and adipose tissue. However, this action did not depend on the activation of PI3-K and AMPK. In vitro studies showed that T3 quickly increases the glucose uptake in L6 cells, but without changing the amount of GLUT4 present in the membrane. These results suggest that this action of T3 occurs due to activation of GLUT4 already present in the membrane or due to some process which does not depend on this protein. Our results demonstrate that other than its known genomic actions, TH acts through nongenomic mechanisms regulating GLUT4 translocation. In addition, they strongly suggest that T3 participates, also through non-genomic mechanisms, in the activation process of GLUT4 already inserted in the membrane.

Keywords: Thyroid Hormone. Nongenomic Actions. GLUT4. Glucose Uptake. 


\section{LISTA DE FIGURAS}

Figura 1 - Representação gráfica da dosagem sérica de TSH e de T4 dos ratos eutireoideos e hipotireoideos

Figura 2 - Representação gráfica da dosagem sérica de T3 dos ratos hipotireoideos antes e após administração de T3.

Figura 3 - Representação gráfica do conteúdo total de GLUT4 no músculo EDL, Soleus e tecido adiposo dos ratos eutireoideos e hipotireoideos.

Figura 4 - Representação gráfica do conteúdo da proteína GLUT4 na membrana plasmática do músculo EDL, Soleus e tecido adiposo de ratos eutireoideos e hipotireoideos................................ 42 Figura 5 - Representação gráfica do conteúdo total de GLUT4 no músculo EDL, Soleus e tecido adiposo de ratos hipotireoideos e hipotireoideos que receberam T4.

Figura 6 - Representação gráfica do conteúdo da proteína GLUT4 na membrana plasmática no músculo EDL, Soleus e tecido adiposo de ratos hipotireoideos e hipotireoideos que receberam T4.

Figura 7 - Representação gráfica do conteúdo total de GLUT4 no músculo EDL, Soleus e tecido adiposo de ratos hipotireoideos e hipotireoideos que receberam T3.

Figura 8 - Representação gráfica do conteúdo da proteína GLUT4 na membrana plasmática no músculo EDL, Soleus e tecido adiposo de ratos hipotireoideos e hipotireoideos que receberam T3.

Figura 9 - Representação gráfica da fosforilação do receptor de insulina (IR) no músculo EDL e Soleus de ratos hipotiroideos antes e após administração de T3. 51

Figura 10 - Representação gráfica da fosforilação do substrato do receptor de insulina (IRS1/2) no músculo EDL e Soleus de ratos hipotiroideos antes e após administração de T3..................... 52

Figura 11 - Representação gráfica do conteúdo da proteína p85 no músculo EDL e Soleus de ratos hipotiroideos antes e após administração de T3.

Figura 12 - Representação gráfica do conteúdo da proteína p110 no músculo EDL e Soleus de ratos hipotiroideos antes e após administração de T3.

Figura 13 - Representação gráfica da fosforilação da AKT em serina no músculo EDL e Soleus de ratos hipotiroideos antes e após administração de T3.

Figura 14 - Representação gráfica da fosforilação da AMPK $\alpha$ em Thr no músculo EDL e Soleus de ratos hipotiroideos antes e após administração de T3 
Figura 15 - Representação gráfica da fosforilação da AMPK $\beta$ em serina no músculo EDL e Soleus de ratos hipotiroideos antes e após administração de T3 ..................................................... 57

Figura 16 - Representação gráfica da concentração sérica de insulina nos animais eutiroideos, hipotiroideos e nos hipotiroideos 30 minutos após a administração de T3................................. 58

Figura 17 - Imagem das células L6........................................................................................ 59

Figura 18 - Representação gráfica do conteúdo total de GLUT4 nas células L6 controle e

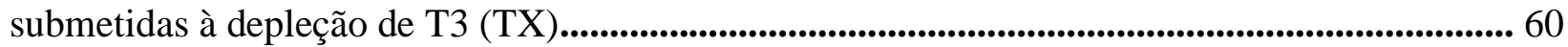

Figura 19 - Representação gráfica do conteúdo de GLUT4 na membrana plasmática das células L6 controle e submetidas à depleção de T3 (TX)....................................................................... 61

Figura 20 - Representação gráfica do conteúdo total de GLUT4 nas células L6 submetidas à depleção de T3 (TX) e no grupo TX que recebeu T3 ............................................................ 61

Figura 21 - Representação gráfica do conteúdo de GLUT4 na membrana plasmática das células L6 submetidas à depleção de T3 (TX) e no grupo TX que recebeu T3............................................ 62

Figura 22 - Representação gráfica do conteúdo de GLUT4myc presente na membrana plasmática das células L6-GLUT4myc controle e nas células submetidas à depleção de T3 (TX).

Figura 23 - Representação gráfica do conteúdo de GLUT4myc presente na membrana plasmática das células L6-GLUT4myc submetidas à depleção de T3 (TX) e no grupo TX que recebeu T3. 64

Figura 24 - Representação gráfica da captação de glicose nas células L6-GLUT4myc controle e nas células submetidas à depleção de T3 (TX).

Figura 25 - Representação gráfica da captação de glicose no grupo de células L6-GLUT4myc submetidas à depleção de T3 (TX) e no grupo TX que recebeu T3 nas doses $10^{-9}, 10^{-8}, 10^{-7}$ e $10^{-6}$ $\mathrm{M}$ por 30 minutos............................................................................................................................................... 65

Figura 26 - Representação gráfica da captação de glicose no grupo de células L6-GLUT4myc submetidas à depleção de T3 (TX) e no grupo TX que recebeu T3 na dose $10^{-8} \mathrm{M}$ por 10, 20, $30 \mathrm{e}$

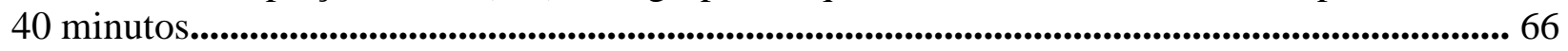

Figura 27 - Representação gráfica da captação de glicose nas células L6-GLUT4myc que foram submetidas à depleção de T3 (TX) e receberam insulina nas doses de 10, 20 e $100 \mathrm{nM}$ na ausencia ou presença de T3 na dose $10^{-8} \mathrm{M}$......

Figura 28 - Representação gráfica do conteúdo de GLUT4myc presente na membrana plasmática das células L6-GLUT4myc que foram submetidas à depleção de T3 (TX) e receberam insulina nas doses de 10, 20 e $100 \mathrm{nM}$ na ausencia ou presença de T3 na dose $10^{-8} \mathrm{M}$ 
Figura 29 - Representação gráfica da captação de glicose na ausência ou presença de $100 \mu \mathrm{M}$ de indinavir nas células L6-GLUT4myc controle, nas células submetidas à depleção de T3 (TX) e nas células TX que receberam $10^{-8} \mathrm{M}$ de T3 por 30 minutos... 68

Figura 30 - Representação gráfica da porcentagem de inibição da captação de glicose pelo indinavir nas células L6-GLUT4myc controle, nas células submetidas à depleção de T3 (TX) e nas células TX que receberam $10^{-8} \mathrm{M}$ de T3 por 30 minutos.

Figura 31 - Representação gráfica da captação de glicose nas células L6-GLUT1myc controle e nas células submetidas à depleção de T3 (TX).

Figura 32 - Representação gráfica do conteúdo de GLUT1myc presente na membrana plasmática das células L6-GLUT1 myc controle e nas células submetidas à depleção de T3 (TX)................. 70

Figura 33 - Representação gráfica da captação de glicose no grupo de células L6-GLUT1myc submetidas à depleção de T3 (TX) e no grupo TX que recebeu T3 na dose $10^{-8} \mathrm{M}$ por 10, 20, $30 \mathrm{e}$ 40 minutos.

Figura 34 - Representação gráfica do conteúdo de GLUT1 myc presente na membrana plasmática das células L6-GLUT1 myc submetidas à depleção de T3 (TX) e no grupo TX que recebeu T3 na dose $10^{-8}$ M por $10,20,30$ e 40 minutos.

Figura 35 - Representação gráfica do conteúdo da AKT total e do conteúdo da AKT fosforilada em serina nas células L6-GLUT4myc controle e nas células submetidas à depleção de T3 (TX) 73

Figura 36 - Representação gráfica do conteúdo da AKT total e do conteúdo da AKT fosforilada em serina no grupo de células L6-GLUT4myc submetidas à depleção de T3 (TX) e no grupo TX que recebeu T3 na dose $10^{-8} \mathrm{M}$ por 10, 20 e 30 minutos................................................................. 74

Figura 37 - Representação gráfica do conteúdo da proteína AS160 fosforilada nas células L6GLUT4myc controle e nas células submetidas à depleção de T3 (TX).......................................... 75

Figura 38 - Representação gráfica do conteúdo da protein AS160 fosforilada no grupo de células L6GLUT4myc submetidas à depleção de T3 (TX) e no grupo TX que recebeu T3 na dose $10^{-8} \mathrm{M}$ por $10,20 \mathrm{e}$ 30 minutos.............................................................................................................................................. 75

Figura 39 - Representação gráfica do conteúdo da AMPKa fosforilada nas células L6GLUT4myc controle e nas células submetidas à depleção de T3 (TX)........................................... 76

Figura 40 - Representação gráfica do conteúdo da AMPKa fosforilada no grupo de células L6GLUT4myc submetidas à depleção de T3 (TX) e no grupo TX que recebeu T3 na dose $10^{-8} \mathrm{M}$ por 10,20 e 30 minutos................................................................................................................................. 76

Figura 41 - Representação gráfica do conteúdo da p38 total e do conteúdo da p38 fosforilada nas células L6-GLUT4myc controle e nas células submetidas à depleção de T3 (TX). 
Figura 42 - Representação gráfica do conteúdo da proteína p38 total e do conteúdo da proteína p38 fosforilada no grupo de células L6-GLUT4myc submetidas à depleção de T3 (TX) e no grupo TX que recebeu T3 na dose $10^{-8} \mathrm{M}$ por 10, 20 e 30 minutos............................................................... 78

Figura 43 - Imagem das células 3T3-L1 ......................................................................... 79

Figura 44 - Representação gráfica do conteúdo total de GLUT4 nas células 3T3-L1 controle e

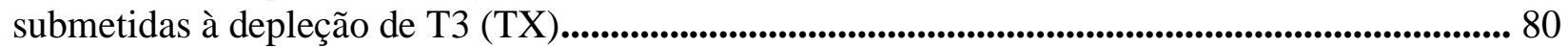

Figura 45 - Representação gráfica do conteúdo de GLUT4 na membrana plasmática das células 3T3-L1 controle $(\mathrm{C})$ e submetidas à depleção de T3 (TX)...................................................... 81

Figura 46 - Representação gráfica do conteúdo total de GLUT4 nas células 3T3-L1 submetidas à depleção de T3 (TX) e no grupo TX que recebeu T3 nas doses $10^{-9}, 10^{-8}, 10^{-7}$ e $10^{-6} \mathrm{M}$ de T3 por 30 minutos. 81

Figura 47 - Representação gráfica do conteúdo de GLUT4 na membrana plasmática das células 3T3-L1 submetidas à depleção de T3 (TX) e no grupo TX que recebeu T3 nas doses $10^{-9}, 10^{-8}$, $10^{-7}$ e $10^{-6} \mathrm{M}$ de T3 por 30 minutos.

Figura 48 - Representação gráfica do conteúdo total de GLUT4 no grupo de células 3T3-L1 submetido a depleção de T3 (TX), no grupo TX que recebeu T3 nas doses $10^{-9} \mathrm{M}$ por 30 minutos (T3), no grupo TX que recebeu $1 \mathrm{~h}$ antes da administração de T3 $2 \mu \mathrm{g} / \mathrm{ml} \operatorname{de}$ ActD (T3+ActD) e $\mathrm{CHX}(\mathrm{T} 3+\mathrm{CHX})$ respectivamente.

Figura 49 - Representação gráfica do conteúdo de mRNA do GLUT4 nas células 3T3-L1 controle e submetidas à depleção de T3 (TX).

Figura 50 - Representação gráfica do conteúdo de mRNA de GLUT4 nas células 3T3-L1 submetidas a depleção de T3 (TX) no grupo TX que recebeu T3 nas doses $10^{-9} \mathrm{M}$ por 30 minutos (T3) e no grupo TX que recebeu $1 \mathrm{~h}$ antes da administração de T3 $2 \mu \mathrm{g} / \mathrm{ml}$ de AcTD (T3+ActD)

Figura 51 - Representação gráfica do conteúdo total de GLUT4 no grupo de células 3T3-L1 submetido a depleção de T3 (TX), no grupo TX que recebeu $10^{-9} \mathrm{M}$ de T3 por 30 minutos (T3) e no grupo TX que recebeu $10^{-9} \mathrm{M}$ de GC1 por 30 minutos. 


\section{SUMÁRIO}

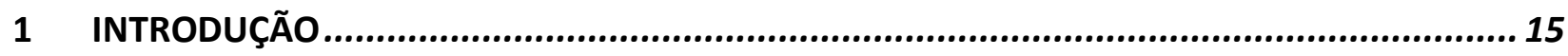

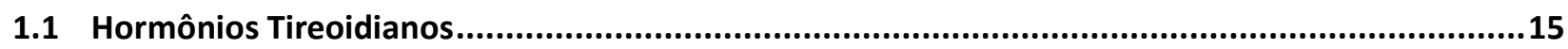

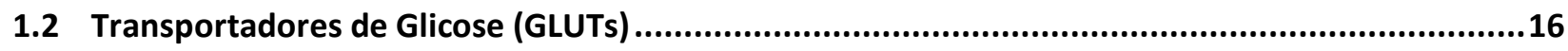

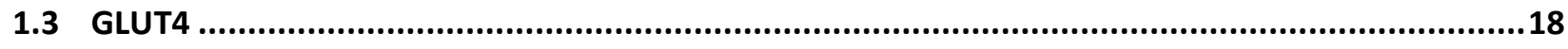

1.4 Hormônios Tireoidianos e GLUT4 ......................................................................................21

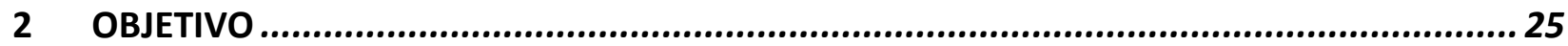

3 MATERIAL E MÉTODOS................................................................................ 26

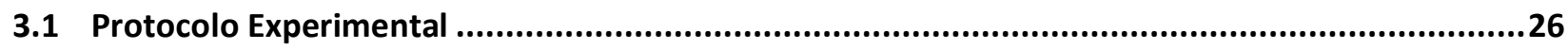

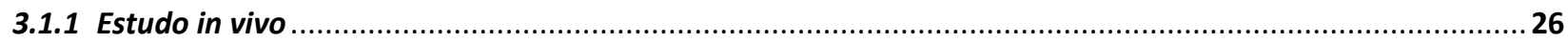

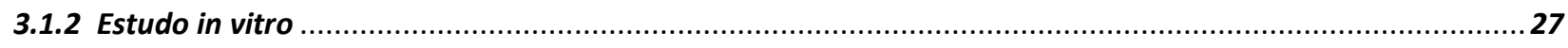

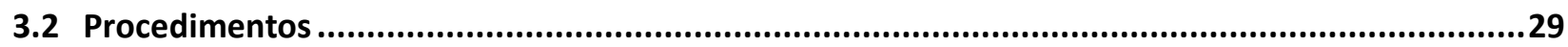

3.2.1 Avaliação do Grau de Diferenciação das Células 3T3L1 e L6 ..........................................................29

3.2.2 Preparo do soro fetal bovino (SFB) depletado de Hormônios Tireoidianos ...............................................29

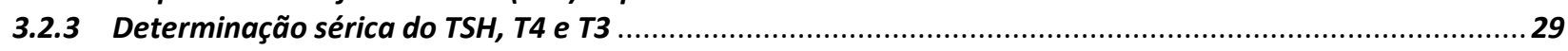

3.2.4 Extração das Proteínas Microssomais e de Membrana Plasmática (GLUT4) ................................................29

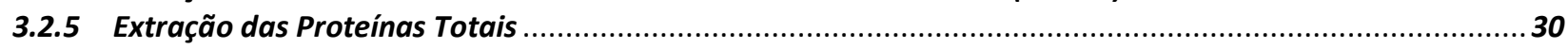

3.2.6 Dosagem das Proteínas pelo Método de Bradford .................................................................................... 31

3.2.7 Preparo das Amostras e Eletroforese em Gel de Poliacrilamida - SDS (SDS- PAGE)................................... 31

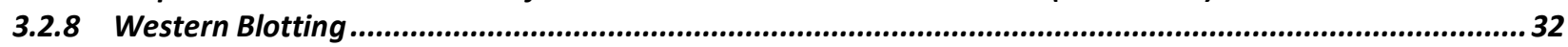

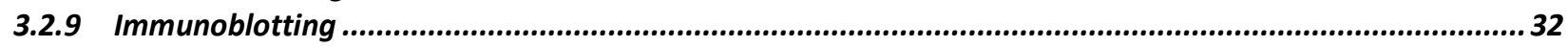

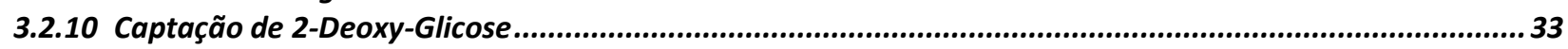

3.2.11 Deteç̧ão Óptica do Conteúdo de GLUT4myc na Superfície da Membrana Plasmática............................... 33

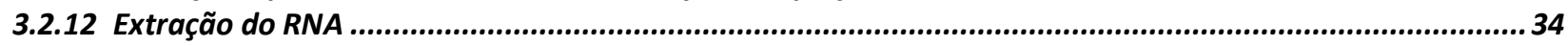

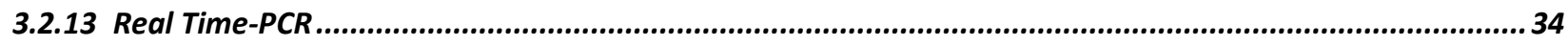

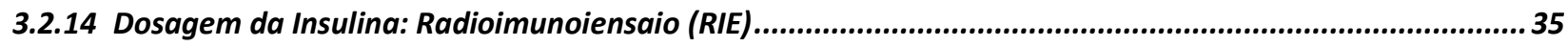

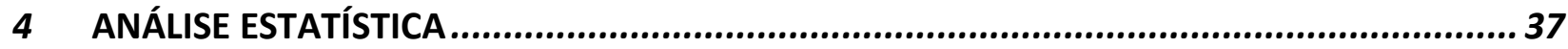

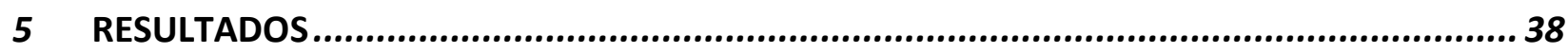

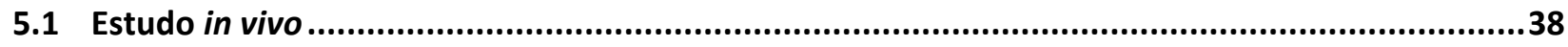

5.1.1 Avaliação da eficiência dos procedimentos experimentais realizados.........................................................38

5.1.2 Efeito da tireoidectomia sobre o conteúdo de GLUT4 no tecido muscular esquelético e adiposo..................40

5.1.3 Efeito da administração aguda (30 minutos) de T4 sobre o conteúdo de GLUT4 no tecido muscular esquelético e adiposo........................................................................................................................................................ 43

5.1.4 Efeito da administração aguda (30 minutos) de T3 sobre o conteúdo de GLUT4 no tecido muscular

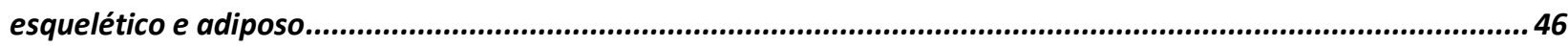
5.1.5 Efeito da administração aguda de T3 sobre o grau de fosforilação de proteínas classicamente envolvidas na translocação do GLUT4 para a membrana plasmática ......................................................................................... 49 5.1.6 Efeito da administração aguda de T3 sobre a concentração sérica de insulina ...........................................58

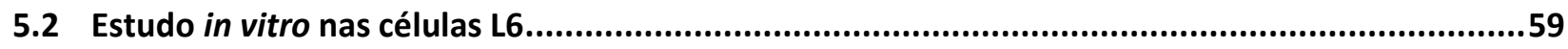

5.2.1 Aspectos morfológicos do cultivo das células $L 6$................................................................................59

5.2.2 Efeito do T3 sobre o conteúdo da proteína GLUT4 nas células $L 6$...........................................................59

5.2.3 Efeito do T3 sobre o conteúdo de GLUT4myc presente na MP das células L6-GLUT4myc ............................62

5.2.4 Efeito do T3 sobre a captação de glicose nas células L6-GLUT4myc..........................................................64 
5.2.5 Efeito do T3 sobre a resposta insulínica nas células L6-GLUT4myc

5.2.6 Efeito do tratamento com indinavir sobre a ação aguda de T3 nas células L6-GLUT4myc...........................68

5.2.7 Efeito do T3 sobre o conteúdo de GLUT1myc presente na MP das células L6-GLUT1myc ...........................69

5.2.8 Efeito do tratamento agudo com T3 sobre o conteúdo total e a fosforilação de proteínas classicamente envolvidas na translocação do GLUT4 para a membrana plasmática em células L6-GLUT4myc .......................... 72

5.3 Estudo in vitro nas células 3T3-L1 ...........................................................................79

5.3.1 Aspectos morfológicos do cultivo das células 3T3-L1 ............................................................................ 79

5.3.2 Efeito da depleção e da administração aguda de T3 sobre o conteúdo da proteína GLUT4 nas células 3T3-L1

5.3.3 Efeito do tratamento agudo com T3 no conteúdo total de GLU4 de células 3T3-L1 previamente tratadas com actinomicina $D$ (bloqueador da transcrição) e cicloheximide (bloqueador da tradução) .................................82 5.3.4 Efeito da depleção e da administração aguda de T3 sobre o conteúdo do mRNA do GLUT4 nas células 3T3-L1

5.3.5 Efeito da administração aguda de GC1 sobre o conteúdo da proteína GLUT4 nas células 3T3-L1 ................85

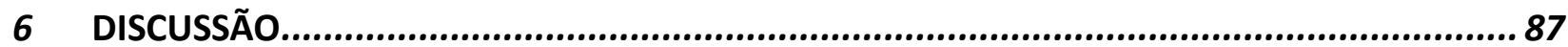

7 CONCLUSÃO

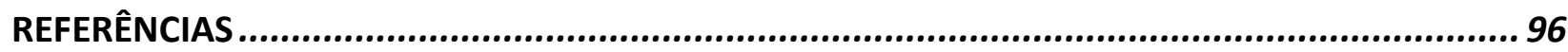




\section{INTRODUÇÃOO}

\subsection{Hormônios Tireoidianos}

Os hormônios tireoidianos (HTs) possuem um importante papel na diferenciação, no crescimento e no metabolismo. Suas ações são necessárias para o funcionamento normal de todos os tecidos, participando principalmente da regulação do consumo de oxigênio e da taxa metabólica (OPPENHEIMER et al., 1987).

Os hormônios tireoidianos, T4 e T3 são sintetizados na glândula tireóide e podem exercer seus efeitos em vários locais, agindo principalmente na regulação da transcrição de genes alvos. As ações genômicas dos HTs decorrem basicamente da interação do T3 com seu receptor nuclear (TR), proteína que tem afinidade cerca de 10 vezes maior pelo T3 que pelo T4. Os TRs estão intimamente associados com o DNA e ligam com alta afinidade e especificidade o T3. A ligação do T3 ao seu TR é um processo complexo e envolve a participação de proteínas co-ativadoras e co-repressoras, que se associam ou se dissociam dos TRs, e disso resulta a indução ou redução da síntese de proteínas específicas, responsáveis pelos efeitos biológicos do T3 (JEPSEN et al., 2002; FONDELL et al., 1999). Dessa forma, as ações genômicas dos HTs se manifestam em um período de tempo longo o suficiente para permitir a transcrição de genes específicos, o processamento do mRNA até a sua forma madura e a tradução subsequente em proteínas.

Por outro lado, são crescentes na literatura as evidências de que os HTs também

promovem efeitos que ocorrem em um curto espaço de tempo (poucos minutos) e que se manifestam mesmo na presença de inibidores da transcrição gênica, o que demonstra que algumas ações dos HTs não dependem da interação do hormônio com o seu receptor nuclear associado ao TRE (elemento responsivo ao HT), e ocorrem por intermédio de outro mecanismo que não o nuclear, sendo, portanto, conhecidas como ações não genômicas ou extranucleares (CAO et al., 2005; MEZOSI et al., 2005; DAVIS et al., 1996). Outra particularidade das ações não genômicas é que elas podem ser desencadeadas também pelo T4, rT3 e T2, bem como pelo T3; ao contrário das ações nucleares que são protagonizadas basicamente pelo T3, conforme salientado (MEZOSI et al., 2005).

Há evidências de ações não genômicas dos HTs: (a) na membrana plasmática, onde são descritos efeitos estimulantes do HT sobre o transporte de glicose, $\mathrm{Ca}^{++}$e $\mathrm{Na}^{+}$(DAVIS et al.,1996; SEGAL et al., 1989 b; INCERPI et al., 1999); (b) em várias organelas celulares, como na mitocôndria, onde facilitaria o transporte de ADP para o seu interior e a formação de ATP 
(DAVIS; DAVIS, 1996) e no retículo sarcoplasmático, onde aumentaria a atividade da bomba de cálcio (SERCA) (ZINMAN et al., 2006), efeito que se somaria a sua ação transcricional bastante conhecida sobre a expressão gênica da SERCA; (c) no citoesqueleto, promovendo polimerização da actina em células gliais (LEONARD et al., 1990), ósseas (LUEGMAYR et al., 1996) e hipofisárias (GOULART-SILVA et al., 2006); (d) sobre a atividade de quinases específicas, como a proteína quinase $\mathrm{C}$ (PKC), a (PKA), a piruvato quinase M2 (PKM2) e a mitogen activated protein Kinase (MAPK), que parecem ser as mediadoras dos efeitos não genômicos desses hormônios (DAVIS; DAVIS, 1996; DAVIS et al., 2000; LIN et al.,1999), e (e) em mRNAs específicos, alterando sua estabilidade e sua taxa de tradução (DAVIS; DAVIS, 1996), entre outras.

O músculo esquelético é um importante alvo da ação do HT. Neste tecido o HT induz a expressão de genes envolvidos com o controle do metabolismo, assim como daqueles relacionados à sua atividade mecânica. No primeiro grupo podemos incluir o gene da Mioglobina (SANTOS; GIANNOCCO; NUNES, 2001; CLÉMENT et al., 2002) e do GLUT-4 (WEINSTEIN et al., 1994; CASLA; ROVIRA; WELLS, 1990) e, no segundo, o gene que codifica a isoforma II da cadeia pesada da miosina (MHCII) (FITTS et al., 1980; SANTOS; GIANNOCCO; NUNES, 2001) e o da bomba de cálcio do retículo sarcoplasmático (SERCA) (NUNES et al., 1985; ROHER et al.,1988). Em paralelo às suas ações nucleares, ações extranucleares também têm sido descritas neste tecido, como a elevação da atividade da SERCA e da captação de glicose, fenômenos observados em células em cultura (SEGAL et al., 1989a; ZINMAN et al., 2006).

No tecido adiposo, efeitos nucleares do HT também são descritos, como o aumento da transcrição do gene que codifica o receptor $\beta$ adrenérgico, do qual resulta o conhecido efeito lipolítico deste hormônio (VIGUERIE et al., 2002).

\subsection{Transportadores de Glicose (GLUTs)}

A glicose é um combustível essencial em mamíferos e um substrato metabólico de grande importância. Ela é obtida diretamente a partir da dieta, principalmente após a hidrólise dos dissacarídeos e polissacarídeos ingeridos ou pela síntese endógena a partir de outros substratos como o glicerol e o piruvato. A glicose proveniente da dieta é transferida do lúmen do intestino delgado para os enterócitos e, juntamente com a glicose endógena, deve ser transportada da circulação para células alvo. Esse processo envolve a transferência da glicose através da 
membrana plasmática e isso ocorre via proteínas integrais da membrana. Estas proteínas compreendem dois grupos estrutural e funcionalmente distintos de transportadores de glicose, identificados há mais de duas décadas: o co-transportador glicose/sódio (SGLT, membro de uma grande família de transportadores de glicose dependentes de sódio, nome do gene SLC5A) e o transportador de glicose sódio independente (GLUT, nome do gene SLC2A) (WRIGHT et al., 2001; MUECKLER et al., 1994; JOOST E THORENS et al., 2001).

Os transportadores de glicose (GLUTs) apresentam 12 domínios transmembrânicos com as regiões amino terminal e carboxi terminal localizadas no citosol. Possuem ainda um grande domínio extracelular entre os segmentos transmembranicos 1 e 2 , o qual contém um sitio de glicosilação (MUECKLER et al., 1985).

Os GLUTs permitem o fluxo de glicose e outros açúcares através da membrana plasmática por difusão facilitada (gradiente de concentração) e diferem entre si em relação à especificidade pelo substrato, propriedades cinéticas e expressão tecidual.

Os transportadores de glicose (GLUTs) são divididos em 3 classes, de acordo com as suas características estruturais (SCHEEPERS; JOOST; SCHURMANN, 2004; MACHADO; SCHAAN; SERAPHIM, 2006; ULDRY et al., 2004). A classe I dos transportadores de glicose compreende os GLUTs 1-4, os quais têm sido amplamente caracterizados segundo sua estrutura, função e distribuição nos tecidos. O GLUT1 é expresso em todos os tecidos e apresenta um baixo $\mathrm{Km}$, sendo, portanto, o principal transportador de glicose quando esta se encontra em níveis fisiológicos na corrente sanguínea; desta forma, garante o transporte basal de glicose a todos os tecidos (GOROVITS et al., 2003). O GLUT2 é expresso, predominantemente, nos hepatócitos e nas células $\beta$ pancreáticas; apresenta alto $\mathrm{Km}$, tendo, portanto, maior capacidade de transportar a glicose quando esta se encontra elevada na corrente sanguínea. Ele é importante para garantir o armazenamento de glicose, ou o seu efluxo, no tecido hepático e a secreção de insulina (GOROVITS et al., 2003). O GLUT 3 tem alta afinidade por glicose e está presente em tecidos que demandam grande quantidade de glicose, como o cérebro e o tecido muscular (HABER et al., 1993; STUART; WEN; JIANG, 1999). O GLUT4 é expresso no tecido muscular esquelético, cardíaco e adiposo branco e marrom. Tal qual o GLUT2, o GLUT4 apresenta elevado Km, sendo a única isoforma cuja translocação e inserção à membrana plasmática é induzida pela insulina.

A classe II dos transportadores de glicose abrange o GLUT5, GLUT7, GLUT9 e o GLUT11. O GLUT5, que possui alta especificidade pela frutose, é expresso predominantemente 
no intestino delgado, testículos e rins. O GLUT7 é o mais recente membro da família dos GLUTs a ser caracterizado. Ele é expresso na membrana apical do intestino delgado e grosso e tanto a glicose quanto a frutose parecem ser seus substratos (CHEESEMAN et al., 2008). O GLUT9 é expresso no fígado e rins e apresenta como substrato a glicose e o ácido úrico (PHAY; HUSSAIN; MOLEY, 2000; AUGUSTIN et al., 2004; DOBLADO et al., 2009). O GLUT 11 apresenta duas formas (uma curta e outra longa), sendo o transportador de glicose que exibe a maior similaridade com o transportador de frutose GLUT5. É expresso no coração, músculo esquelético, tecido adiposo, rins e pâncreas e transporta glicose quando esta se encontra em altas concentrações na corrente sanguínea, sendo que este transporte é inibido pela frutose (DOEGE et al., 2001; SCHEEPERS et al., 2005).

A classe III dos transportadores de glicose compreende 5 membros: GLUT6, GLUT8, GLUT10, GLUT12 e o HMIT (Transportador de $\mathrm{H}^{+}$ligado ao mio-inositol). O GLUT6 apresenta baixa afinidade por glicose e é expresso no cérebro, leucócitos e baço, enquanto que o GLUT 8 apresenta alta afinidade por glicose e é expresso principalmente nos testículos (DOEGE et al., 2000). O GLUT 10 é predominantemente expresso no fígado e pâncreas e está associado com o diabetes do tipo 2 (DAWSON et al., 2001; MCVIE-WYLIE et al., 2001). O GLUT 12 é expresso predominantemente no coração e próstata; o HMIT no cérebro (WOOD et al., 2003; SCHEEPERS; JOOST; SCHURMANN, 2004).

\subsection{GLUT4}

O GLUT4 foi descoberto em meados da década de 90, quando pesquisadores de grupos distintos clonaram e caracterizaram uma proteína transportadora de glicose sensível à insulina; desde então, o GLUT4 tem recebido mais atenção do que qualquer outro membro desta família (JAMES; STRUBE; MUECKLER, 1989; CHARRON et al., 1989; BIRNBAUM et al., 1989).

O GLUT4 é responsável pela captação de glicose quando esta se encontra em concentrações elevadas na circulação sanguínea, situação em que ocorre aumento da secreção de insulina. Essa proteína vem sendo alvo de muitos estudos, considerando o aumento alarmante da incidência da resistência insulínica na população mundial, o que predispõe ao Diabetes tipo II. O GLUT4 encontra-se inserido na membrana de vesículas intracelulares, presentes na região perinuclear e no citoplasma das células. Essas vesículas, sob estímulo específico, deslocam-se para a membrana plasmática, onde se fundem. Esse processo resulta na incorporação de várias 
moléculas de GLUT4 na membrana plasmática, possibilitando assim o influxo de glicose nas células que as expressam (GOROVITS et al., 2003).

A translocação do GLUT4 para a membrana plasmática é estimulada por alguns fatores, entre eles, a insulina e o exercício físico. A insulina desencadeia seus efeitos biológicos mediante a fosforilação de proteínas, promovendo, entre outras ações, o aumento do transporte da glicose para as células (NYSTROM et al., 1999). Para realizar esses efeitos a insulina interage com seu receptor, o qual se encontra na superfície das células dos tecidos alvos. O receptor da insulina (IR) é uma proteína heterotetramérica, que possui uma atividade tirosina cinase intrínseca. Essa proteína é composta de duas subunidades $\alpha$ extracelulares, as quais contêm o sítio de ligação para a insulina; e duas subunidades $\beta$ transmembrana. É na porção intracelular da subunidade $\beta$, que se encontram os domínios tirosina cinase. A ligação da insulina à subunidade $\alpha$ provoca uma alteração conformacional que resulta na autofosforilação da subunidade $\beta$ do receptor, aumentando a atividade cinase dessa proteína (WATSON et al., 2001; CARVALHEIRA; ZECCHIN; SAAD, 2002). Uma vez ativado, o receptor da insulina (IR) fosforila vários substratos proteicos, entre eles a família de substratos para o receptor de insulina (IRS 1-4), Shc, Gab-1, p60doc, Cbl, JAK2 e APS. Após a fosforilação dos IRS em resíduos de tirosina, estes substratos servem como local de ancoragem para proteínas que possuem o domínio SH2. Muitas destas proteínas são moléculas adaptadoras tais como a subunidade regulatória p85 da fosfatidilinositol-3 cinase (PI3-K), (SALTIEL et al., 2001; WATSON et al., 2001; CARVALHEIRA; ZECCHIN; SAAD, 2002).

A PI3-K é uma enzima de fundamental importância na regulação das ações metabólicas da insulina. Esta proteína é formada por uma subunidade regulatória (p85) e uma subunidade catalítica (p110), a qual catalisa a fosforilação dos fosfoinositídeos na posição 3 do anel inositol produzindo fosfatidilinositol-3-fosfato, fosfatidilinositol-3,4-difosfato e fosfatidilinositol-3,4,5trifosfato. A fosforilação na posição 3 recruta proteínas como a PDK-1 (proteína cinase 1 dependente de PI-3K) e a AKT (SALTIEL et al., 2001; CARVALHEIRA; ZECCHIN; SAAD, 2002; KHAN et al., 2002; KROOK; WALLBERG-HENRIKSSON; ZIERATH, 2004). Em seguida, PDK-1 fosforila e ativa a AKT e isoformas da proteína cinase $\mathrm{C}(\mathrm{PKC})$ atípica $(\zeta, \lambda)$. Um dos mais importantes resultados da ativação da AKT é a elevação da captação de glicose através do aumento da translocação do GLUT 4 (ŽDYCHOVÁ et al., 2005). Da mesma forma, 


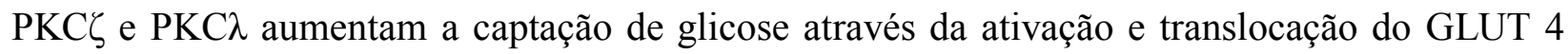
(KHAN et al., 2002; LIU et al., 2006).

Além da ativação da PI3-K, outros sinais também estão envolvidos no transporte de glicose estimulado pela insulina. Um desses sinais envolve a fosforilação do protooncogene Cbl. Na maioria dos tecidos sensíveis à insulina, o Cbl está associado com a proteína adaptadora CAP. Após a fosforilação, o complexo Cbl-CAP migra para a membrana celular e interage com a proteína CrkII, que também está associada com a proteína C3Gl. A C3Gl é uma proteína trocadora de nucleotídeos que catalisa a troca de GDP por GTP da proteína TC10 ativando-a. Uma vez ativada, TC10 causa um segundo sinal para a translocação da proteína GLUT-4, em paralelo à ativação da via da PI3-K (KHAN et al., 2002; ISHIKI et al., 2005).

Além da insulina é sabido que o exercício físico também aumenta a translocação do GLUT4 para a membrana plasmática. Estudos demonstram que homens que participam regularmente de esportes competitivos apresentam uma melhora da tolerância à glicose e níveis de insulina menores, quando comparados aos seus controles. Outros estudos mostram ainda que mulheres hiperinsulinêmicas e obesas apresentaram níveis de insulina no plasma diminuídos após 6 semanas de treinamento físico (BJORNTORP et al., 1970, 1972). Esses estudos sugerem que o exercício físico regular aumenta a sensibilidade à insulina no músculo e em outros tecidos (MONDON; DOLKAS; REAVEN, 1980).

Vários experimentos demonstram um aumento significante na atividade da AMPK (AMPactivated protein kinase) após a contração muscular por estimulação elétrica in situ (VAVVAS et al., 1997; HAYASHI et al., 2000) e após a contração isolada do músculo de ratos in vitro (FUJII et al., 2000; MUSI et al., 2005). A AMPK é uma proteína heterotrimérica formada por uma subunidade catalítica $(\alpha)$, que apresenta duas isoformas $\left(\begin{array}{llll}\alpha & 1 & \alpha & 2\end{array}\right)$ e duas subunidades regulatórias $(\beta$ e $\gamma$ ), que possuem as seguintes isoformas ( $\beta 1, \beta 2, \gamma 1, \gamma 2$ e $\gamma 3$ ) (HARDIE et al., 1997). A AMPK é ativada quando ocorre a fosforilação no resíduo de treonina 172 na alça de ativação da subunidade $\alpha$ (HARDIE et al., 1997). A ativação é promovida quando ocorre uma alteração no estado energético da celula, assim, quando a relação AMP:ATP está aumentada, ocorre uma alteração conformacional na proteína, deixando-a suscetível a fosforilação e ativação pela AMPK cinase (AMPKK) (HARDIE et al., 2003). A AMPK fosforilada ativa vias que causam o aumento de ATP, tais como as da oxidação de ácidos graxos, e também inibe vias anabólicas que consomem o ATP, tais como a síntese de ácidos graxos. O aumento da atividade 
da AMPK, em consequência do maior consumo de ATP durante o exercício físico, causa a translocação das vesículas contendo GLUT4, promovendo assim, o transporte de glicose para o músculo, de modo semelhante à insulina, embora por vias de sinalização independentes (MCGEE et al., 2003).

Após a translocação, o GLUT4 precisa ser inserido na membrna plasmática (MP); esse processo envolve alguns passos, entre eles a ancoragem e a fusão do GLUT4 à MP (ZAID et al., 2008). Durante a translocação e posterior fusão do GLUT4 à MP, há envolvimento de dois grupos de proteínas: as v-SNAREs e as t-SNAREs. Algumas dessas proteínas (VAMP2, sintaxin4, SNAP23 e munc18) controlam a fusão das vesículas contendo o GLUT4 com a MP. A insulina recruta as vesículas contendo o GLUT4 através da fosforilação da VAMP2, que por sua vez interage com SNAP23 e sintaxin4 formando um complexo ternário. Simultaneamente à formação desse complexo ocorre a dissociação da proteína synip da sintaxin 4 e a alteração conformacional da munc18c expondo o domínio de ligação do complexo ternário e, dessa forma, promovendo a fusão das vesículas contendo o GLUT4 com a MP (WATSON et al., 2001; HE et al., 2007).

\subsection{Hormônios Tireoidianos e GLUT4}

Já é bastante conhecido que nos estados de hipertireoidismo ocorre um aumento da utilização de glicose pelas células. Esse efeito tem sido descrito como decorrente de ações que alteram a atividade das enzimas envolvidas com a via glicolítica e oxidativa, promovendo a ativação do metabolismo da glicose, o que reduziria o conteúdo intracelular de glicose, gerando um gradiente que favoreceria sua entrada nas células (CHEN-ZION; BASSUKEVITZ; BEITNER, 1995). Soma-se a essas ações o efeito transcricional do HT sobre a expressão do gene SLC2A4 (SHIMIZU et al., 2002).

Nosso laboratório vem investigando o papel do hormônio tireoidiano na expressão do gene SLC2A4, não só no músculo esquelético, mas também no músculo cardíaco e tecido adiposo. Nossos estudos dão suporte aos trabalhos da literatura que demonstraram que, nesses tecidos, cuja expressão do GLUT4 é normalmente bastante elevada, o tratamento crônico com T3 provoca aumento ulterior da mesma, ocorrendo o contrário nos estados de hipotireoidismo (CASLA; ROVIRA; WELLS, 1990; GOSTELI-PETER; SCHMID; ZAPF, 1996; TORRANCE et al.,1997a; SHIMIZU et al., 2002). Estudos recentes indicam ainda, que o T3 aumenta a 
translocação de GLUT3, mecanismo pelo qual o T3 poderia também promover aumento da captação de glicose (DIMITRIADIS et al., 2005). Esses achados colocam o T3 como um hormônio importante para a regulação da homeostase glicêmica.

Nesse sentido, o tecido muscular esquelético torna-se um importante alvo da ação do T3, uma vez que ele se destaca dos demais como o principal tecido responsável pela utilização da glicose, já que $40 \%$ da massa corporal correspondem aos músculos esqueléticos. O músculo esquelético é formado por uma mistura de diferentes tipos de fibras (NEMETH e PETTE, 1981) que são geralmente classificadas por suas características contráteis e metabólicas, bem como por sua coloração. Dessa forma, as fibras musculares vermelhas possuem elevada capacidade oxidativa, e podem ser de contração rápida ou lenta, dependendo se expressam predominantemente MHCII ou I, respectivamente, ao passo que as fibras brancas são glicolíticas e de contratação rápida, pois expressam predominantemente MHCII. A sensibilidade à insulina e a taxa máxima de transporte de glicose são também diferentes entre as fibras musculares vermelhas e brancas, de forma que as brancas são menos sensíveis à insulina em relação às vermelhas (JAMES; JENKINS; KRAEGEN, 1985; RICHTER; HANSEN; HANSEN, 1988).

Estudos em andamento no nosso laboratório têm demonstrado que além de induzir a expressão do GLUT4, o T3 é capaz de promover a translocação dessa proteína em direção à membrana plasmática (BRUNETTO et al., 2006; GIANNOCCO et al., 2006). Esses estudos foram desenvolvidos em tecido muscular esquelético e cardíaco, e mostraram que ratos previamente tireoidectomizados apresentam incremento da taxa de translocação de GLUT4 30 minutos após a administração de doses suprafisiológicas de T3 (100 $\mu \mathrm{g} / 100$ g, PC), o que sugere fortemente uma ação não genômica do HT. Esses dados corroboram estudos in vitro, relatados na literatura, que demonstraram que o HT induz, em um curto espaço de tempo, o aumento da captação de glicose por miócitos mantidos em meio de incubação contendo glicose marcada (SEGAL et al., 1989a). Além disso, estudos mostram a presença de um elemento responsivo ao HT (TRE) na região promotora do gene SLC2A4, bastante diferente dos TREs presentes em outros tecidos, já que possui baixa afinidade pelo receptor do HT, o que sugere que outro mecanismo, além do transcricional, possa estar envolvido nas ações promovidas pelo hormônio tireoidiano sobre a expressão deste gene (TORRANCE et al., 1997b).

Contudo, o mecanismo pelo qual essas ações não genômicas do HT são estabelecidas ainda não está totalmente esclarecido, sendo motivo de vários estudos. Sabe-se que algumas 
cinases participam como intermediárias dessas ações não genômicas. Assim, tem-se que o HT promove, por via extranuclear, a fosforilação da isoforma $\beta$ do receptor de HT, o TR $\beta$, por meio da ativação da MAPK. Em outras palavras, descreveu-se uma ação não genômica do HT precedendo a sua ação genômica. Essa via de sinalização também está envolvida na angiogênese induzida não genomicamente pelo T3. Já o aumento da atividade do trocador $\mathrm{Na}^{+} / \mathrm{H}^{+}$induzido pelo T3 parece depender da ativação da PKC (DAVIS; DAVIS; 1996; DAVIS; DAVIS; CODY, 2005).

Mais recentemente foi evidenciado que tanto o T4 quanto o T3 se ligam à isoforma da integrina $\alpha \mathrm{V} \beta 3$, mecanismo pelo qual ocorreria a ativação da PKC e MAPK (DAVIS; DAVIS; CODY, 2005). Sabe-se, ainda, que a integrina, que é uma proteína de matriz extracelular, exerce um papel estrutural muito importante, já que conecta a matriz extracelular ao citoesqueleto de actina das células. Além disso, sabe-se que o tráfego de vesículas para a membrana plasmática depende de um citoesqueleto altamente organizado, uma vez que agentes que impedem o remodelamento da actina, impedem a translocação do GLUT4 para a membrana plasmática (BROZINICK et al., 2004). O HT participa do controle da expressão de genes envolvidos na manutenção da arquitetura celular; Também exerce efeitos não genômicos sobre a polimerização da actina do citoesqueleto, os quais foram descritos em células gliais, osteoblásticas e hipofisárias; e são mecanismos pelos quais ele poderia influenciar no tráfego de vesículas intracelulares e remodelamento dos tecidos (LEONARD; SIEGRIST-KAISER; ZUCKERMAN, 1990; LUEGMAYR et al., 1996; GOULART-SILVA et al., 2006).

Com relação à translocação de GLUT4 induzida pelo HT, embora ela tenha sido evidenciada no nosso laboratório, os mecanismos envolvidos ainda não foram esclarecidos. Conforme descrito anteriormente, as vias da PI3-K e da Cap-Cbl, ativadas pela insulina, e a da AMPK, ativada pela contração muscular, são peças chaves nesse processo. Assim, é possível que o HT promova ativação de ao menos uma dessas vias.

Nesse sentido, há evidências de que o T3 ativa a via de transdução de sinais da PI3K/AKT/PKB. Cao et al. (2005) demonstraram que o hormônio tireoidiano participa da ativação da mTOR (mammalian target of rapamycin) e que esta ativação ocorre minutos após a adição de T3. Além disso, essa ativação não é inibida pela cycloheximide (CHX), um inibidor da síntese proteica, demonstrando ser essa uma ação não genômica do T3 e independente de síntese de novas proteínas. Eles evidenciaram também que a ativação da mTOR promovida pelo T3 é 
mediada pela PI3-K, e que a PI3-K é capaz de se ligar ao TR independentemente do T3. No entanto, a ligação do T3 ao seu receptor é necessária para a ativação da PI3-K. Cao et al., também demonstraram que o T3 induz a translocação nuclear da AKT/PKB de maneira dependente da PI3-K (CAO et al., 2005).

Estudos têm demonstrado que o T3 também pode aumentar a expressão da AMPK (PARK et al., 2002; WINDER et al., 2003), mas não há estudos relatando se a AMPK é capaz de se ligar ao receptor de hormônio tireoidiano, como foi demonstrado para a PI3-K.

Os resultados obtidos no nosso laboratório evidenciando que a translocação do GLUT4 pode ser induzida pelo HT são de grande importância, pelo que foi relatado e também porque se trata de uma ação não genômica do T3 até então desconhecida, sendo fundamental o esclarecimento dos mecanismos envolvidos nesse efeito. Torna-se interessante avaliar também o efeito do T4 nesse mesmo processo, já que ele tem sido identificado como o principal efetor de algumas das ações não genômicas dos hormônios tireoidianos. 


\section{OBJETIVO}

O presente trabalho tem o objetivo de avaliar, por meio de estudos in vivo e in vitro, o efeito da administração aguda (30 minutos) de T3 e T4 sobre a expressão e translocação do GLUT4, bem como as diferentes vias envolvidas nesse evento. 


\section{MATERIAL E MÉTODOS}

\subsection{Protocolo Experimental}

\subsubsection{Estudo in vivo}

Foram utilizados ratos da cepa Wistar, jovens, com peso em torno de 200-250 g, provenientes do biotério do Instituto de Ciências Biomédicas da USP, onde foram mantidos sob condições padronizadas de temperatura ambiental $\left(23 \pm 2{ }^{\circ} \mathrm{C}\right)$ e ciclo claro/escuro $(12 / 12 \mathrm{~h}$ diárias). A água e a alimentação foram fornecidas ad libitum.

Parte dos animais foi submetida à tiroidectomia cirúrgica (TX), sendo adicionados à água de beber metimazol $(0.03 \%)$ e $\mathrm{CaCl} 2(0,05 \%)$, por um período aproximado de 21 dias (grupo hipotiroideo). Os animais TX foram, ainda, divididos em grupos aos quais se administrou de 200$250 \mu 1$ de solução contendo T4 ou T3, através da punção venosa da jugular, conforme especificado abaixo.

1. grupo eutireoideo $(\mathrm{C}=$ controle $)$

2. grupo hipotiroideo (TX)

3. grupo hipotiroideo + T4: animais TX tratados com doses fisiológicas de T4 $(0,8$ $\mu \mathrm{g} / 100 \mathrm{~g}$ de peso corporal); 5 vezes a fisiológica (4 $\mu \mathrm{g} / 100 \mathrm{~g}$ de peso corporal); e 50 vezes a fisiológica (40 $\mu \mathrm{g} / 100 \mathrm{~g}$ de peso corporal) e sacrificados após 30 minutos.

4. grupo hipotiroideo + T3: animais TX tratados com doses fisiológicas de T3 (0,3 $\mu \mathrm{g} / 100 \mathrm{~g}$ de peso corporal); 5 vezes a fisiológica (1.5 $\mu \mathrm{g} / 100 \mathrm{~g}$ de peso corporal); 50 vezes a fisiológica $(15 \mu \mathrm{g} / 100 \mathrm{~g}$ de peso corporal); e 300 vezes a fisiológica (100 $\mu \mathrm{g} / 100 \mathrm{~g}$ de peso corporal) e sacrificados após 30 minutos.

Os animais foram anestesiados com Ketamina e Xylazina (100 e $10 \mathrm{mg} / \mathrm{Kg}$ de peso corporal, respectivamente) e os tratamentos especificados foram realizados.

Após a retirada dos tecidos de interesse (muscular esquelético: Soleus e extensor digital longo-EDL; e tecido adiposo periepididimal) os animais foram sacrificados por decapitação e o sangue foi colhido do tronco, centrifugado, e o soro estocado a $-20^{\circ} \mathrm{C}$ para dosagem dos níveis séricos de T4 e T3 por radioimunoensaio. 


\subsubsection{Estudo in vitro}

Para os estudos in vitro foi utilizada a linhagem celular 3T3-L1, que são células que apresentam uma morfologia semelhante a fibroblastos, mas que, sob condições apropriadas, se diferenciam em adipócitos. Essas células foram cedidas gentilmente pela Profa. Dra. Claudia Oller do Nascimento e foram cultivadas em meio DMEM suplementado com $10 \%$ de soro fetal bovino (SFB), $100 \mu \mathrm{l} / \mathrm{ml}$ de estreptomicina e $100 \mathrm{U} / \mathrm{ml}$ de penicilina, sob uma atmosfera de $5 \%$ de $\mathrm{CO} 2$ a uma temperatura de $37{ }^{\circ} \mathrm{C}$. Elas foram mantidas em cultura, nessas condições, até atingirem a confluência de cerca de 70\%; em seguida foram passadas para placas de 6 poços para realização de experimentos, nos quais avaliamos o conteúdo e a taxa de translocação do GLUT4. Assim, após terem atingido $100 \%$ de confluência, essas células foram submetidas a um processo de diferenciação, permanecendo por 3 dias em um meio contendo DMEM, 10\% de SFB, 100 mM de IBMX, $1 \mathrm{mM}$ de dexametasona e $5 \mathrm{mg} / \mathrm{ml}$ de insulina. Após esse período, as células ficaram por 7 dias em meio contendo DMEM, $10 \%$ de SFB e $5 \mathrm{mg} / \mathrm{ml}$ de insulina.

Foi utilizada ainda a linhagem celular L6, obtida do banco de células do Rio de Janeiro e L6-GLUT4myc e L6-GLUT1 myc, cedidas gentilmente pela Profa. Dra. Amira Klip.

Adicionalmente, foi utilizada uma linhagem de células L6 que superexpressa a proteína AS160. Essa proteína tem importante função na translocação das vesículas contendo o GLUT4, participando do processo de ancoragem/inserção do GLUT4 na membrana plasmática (KANE et al., 2002; RANDHAWA et al., 2008).

As células L6, L6-GLUT4myc e L6-GLUT1myc são mioblastos que, após atingirem $100 \%$ de confluência e submetidas à baixa concentração de soro fetal bovino, se diferenciam em miotubos. Elas foram cultivadas em meio DMEM suplementado com 10\% de SFB, $100 \mu 1 / \mathrm{ml}$ de estreptomicina e $100 \mathrm{U} / \mathrm{ml}$ de penicilina, sob uma atmosfera de 5\% de CO2 a uma temperatura de $37{ }^{\circ} \mathrm{C}$ até atingirem a confluência de cerca de $80 \%$. Após essa etapa, elas foram passadas para placas de 6 poços para realização de experimentos nos quais avaliamos o conteúdo e a taxa de translocação do GLUT4. Dessa forma, após atingirem a confluência de $100 \%$ elas foram mantidas por 6 dias em meio contendo apenas 2\% de SFB, condição necessária para sua diferenciação.

Posteriormente, após 80\% das células 3T3-L1, L6, L6-GLUT4myc e L6-GLUT1myc terem se diferenciado em adipócitos e miotubos respectivamente, parte das células foi submetida a depleção do HT por 24 horas. Para isso, as células foram mantidas em meio DMEM 
suplementado com SFB depletado de HT. A depleção do HT foi realizada por adsorção, com o uso da resina analítica por troca aniônica AG 2-X8, como descrito nos materiais e métodos (SAMUELS; STANLEY; CASANOVA, 1979). Após a depleção do HT as células foram submetidas aos tratamentos descritos a seguir.

1. Grupo eutiroideu $(\mathrm{C}=$ controle $)$

2. Grupo hipotireoideo (TX): células que foram incubadas em meio depletado de hormônio tireoidiano, por 24 horas.

3. Grupo hipotireoideo $(\mathrm{TX})+\mathrm{T} 3$ : células que foram incubadas em meio livre de hormônio tireoidiano por 24 horas e após esse período foram tratadas com concentrações crescentes de T3 $\left(10^{-9}\right.$ a $\left.10^{-6} \mathrm{M}\right)$, por 30 minutos, com o objetivo de se escolher a dose em que os efeitos que pretendemos estudar são mais acentuados.

4. Grupo hipotireoideo $(\mathrm{TX})+\mathrm{T} 3+$ ActD (Actinomicina $\mathrm{D}$ ): células que foram incubadas em meio livre de hormônio tireoidiano por 24 horas e após esse período acrescidas de $2 \mu \mathrm{g} / \mathrm{ml}$ de ActD (antibiótico que bloqueia a transcrição) por 1 hora antes da administração de T3 na dose $10^{-9} \mathrm{M}$ por 30 minutos.

5. Grupo hipotireoideo $(\mathrm{TX})+\mathrm{T} 3+\mathrm{CHX}$ (Cicloheximide): células que foram incubadas em meio depletado de hormônio tireoidiano por 24 horas, e após esse período acrescidas de $10 \mu \mathrm{g} / \mathrm{ml}$ de CHX (antibiótico que bloqueia a tradução) por 1 hora antes da administração de T3 na dose $10^{-9} \mathrm{M}$ por 30 minutos.

6. Grupo hipotireoideo $(\mathrm{TX})+\mathrm{T} 3+$ Indinavir: células que foram incubadas em meio livre de hormônio tireoidiano por 24 horas e após esse período foram administrados $100 \mu \mathrm{M}$ de indinavir (fármaco que bloqueia especificamente o GLUT4) após administração de T3 na dose de $10^{-8} \mathrm{M}$, por 30 minutos.

7. Grupo hipotireoideo $(\mathrm{TX})+\mathrm{GC} 1$ : células que foram incubadas em meio depletado de hormônio tireoidiano por 24 horas e após esse período foram tratadas com GC1 (agonista do TR $\beta$ ) na dose de $10^{-9} \mathrm{M}$, por 30 minutos.

Após os tratamentos especificados, o meio foi retirado e as células foram lavadas com PBS gelado para retirar o excesso de meio. Todos os passos seguintes foram realizados a $4{ }^{\circ} \mathrm{C}$. 


\subsection{Procedimentos}

\subsubsection{Avaliação do Grau de Diferenciação das Células 3T3L1 e L6}

Após 10 dias de diferenciação retiramos o meio de cultura das células 3T3-L1 e as lavamos com PBS1X duas vezes. Posteriormente, cobrimos as células com paraformaldeído a 4\% diluído em $2 \mathrm{ml}$ de PBS1X. Após 30 minutos de incubação à temperatura ambiente, lavamos as células com PBS 1X 3 vezes. Em seguida, incubamos as células por $2 \mathrm{~h}$ a $37^{\circ} \mathrm{C}$ com o corante oil red, que identifica triacilgliceróis. Após esse período lavamos as células com água destilada 3 vezes e observamos o grau de coloração dessas células.

A avaliação do grau de diferenciação das células L6 foi confirmada por microscopia óptica, pela qual avaliamos o conteúdo de células fusiformes e multinucleadas (miotubos).

\subsubsection{Preparo do soro fetal bovino (SFB) depletado de Hormônios Tireoidianos}

A depleção de T3/T4 do SBF foi realizada por adsorção, com o uso da resina analítica por troca aniônica AG 2-X8 (SAMUELS; STANLEY; CASANOVA, 1979). Assim, a resina foi lavada 3 vezes com água destilada e então $50 \mathrm{mg}$ de resina foi adicionado a cada $\mathrm{ml}$ de soro. A solução foi mantida em agitação a $4{ }^{\circ} \mathrm{C}$ por $24 \mathrm{~h}$. A seguir, o SFB foi centrifugado a $1000 \mathrm{~g}$ por 10 minutos. O soro foi coletado cuidadosamente e submetido a uma nova centrifugação (1000 g/10 min). O soro foi coletado novamente e, então, filtrado primeiramente em filtros de $0.45 \mu \mathrm{m}$ e, posteriormente, em filtros de $0.2 \mu \mathrm{m}$.

\subsubsection{Determinação sérica do TSH, T4 e T3}

Fez-se a dosagem dos hormônios T3, T4 e TSH a partir do soro obtido dos ratos dos experimentos in vivo. Para determinar as concentrações séricas de TSH, T4 e T3, as amostras foram enviadas para a empresa Gênese Produtos Diagnósticos, que efetuou a dosagem dos hormônios pelo ensaio LINCOplex ${ }^{\mathrm{TM}}$, conforme instruções e determinações do fabricante (ELSHAL e MCCOY, 2006).

\subsubsection{Extração das Proteínas Microssomais e de Membrana Plasmática (GLUT4)}

Os músculos esqueléticos Soleus, extensor digital longo (EDL) e o tecido adiposo periepididimal foram removidos, pesados e homogeneizados no equipamento Polytron PT 2100 
(Kinematica), em solução tampão contendo: Tris $10 \mathrm{mM}$, EDTA $1 \mathrm{mM}$ e sacarose $250 \mathrm{mM}$, numa relação de $1 \mathrm{~g}$ de tecido/6 $\mathrm{ml}$ de solução tampão, por aproximadamente 20 segundos à 30.000 rpm. O mesmo tampão de homogeneização foi utilizado para as células 3T3-L1 e L6.

Os homogeneizados do músculo Soleus, EDL e das células L6 foram, posteriormente, submetidos às centrifugações necessárias para o fracionamento subcelular, de acordo com o método de Yonemitsu et al. (1991), com modificações especificadas em Mitsumoto e Klip (1992). Assim, foram realizadas duas centrifugações a $760 \mathrm{~g}$, a $4{ }^{\circ} \mathrm{C}$, de 5 minutos cada, com o objetivo de descartar o material nuclear presente no precipitado. $\mathrm{O}$ sobrenadante obtido das duas centrifugações anteriores foi centrifugado a $31.000 \mathrm{~g}$, a $4{ }^{\circ} \mathrm{C}$ por 60 minutos. O precipitado resultante, rico em proteínas de membrana plasmática, foi ressuspenso em $200 \mu \mathrm{l}$ de tampão de homogeneização, constituindo a fração de membrana plasmática (MP). O sobrenadante resultante foi centrifugado a $190.000 \mathrm{~g}$, a $4{ }^{\circ} \mathrm{C}$ por 60 minutos. O precipitado resultante foi ressuspenso em $150 \mu \mathrm{l}$ de tampão de homogeneização, constituindo a fração microssomal (M).

Os homogeneizados do tecido adiposo e das células 3T3L1 foram também submetidos à centrifugações necessárias para o fracionamento subcelular, de acordo com Machado et al. (1993 e 1995). Assim, foi realizada uma centrifugação de $1000 \mathrm{~g}$, a $4{ }^{\circ} \mathrm{C}$ por 15 minutos, com o objetivo de descartar a gordura sobrenadante ("fat cake"). O intranadante contendo extrato livre de gordura (fat free extract - FFE) obtido na centrifugação anterior foi centrifugado a 12.000 g, a 4 ${ }^{\circ} \mathrm{C}$ por 15 minutos. O precipitado resultante, rico em proteínas de membrana plasmática, foi ressuspenso em $300 \mu \mathrm{l}$ de solução tampão de homogeneização, constituindo a fração de membrana plasmática (MP). O sobrenadante resultante foi centrifugado a $28.000 \mathrm{~g}$ a $4{ }^{\circ} \mathrm{C}$ por 15 minutos, e o precipitado rico em microssoma de alta densidade (HDM) foi descartado. O sobrenadante foi, então, centrifugado a $146.000 \mathrm{~g}$, a $4{ }^{\circ} \mathrm{C}$ por 75 minutos. O precipitado obtido foi ressuspenso em $300 \mu \mathrm{l}$ de tampão de homogeneização, constituindo a fração microssomal de baixa densidade (LDM).

\subsubsection{Extração das Proteínas Totais}

Para avaliação do grau de fosforilação das proteínas envolvidas na(s) via(s) relacionadas à translocação do GLUT4, utiliza-se um protocolo de extração de proteínas totais diferente do anteriormente descrito, conforme descrito abaixo. 
Os músculos Soleus e EDL direitos foram removidos. Em seguida, foram injetados na veia jugular 1,5 $\mu \mathrm{g} / 100 \mathrm{~g}$ de peso corporal de T3 e após 5, 10, 20 e 30 minutos, removeu-se o músculo Soleus e EDL esquerdos. Os músculos foram homogeneizados em tampão quente (96 ${ }^{\circ} \mathrm{C}$ ) (Trisma Base $100 \mathrm{mM}$, pH 7,5; EDTA 10 mM, SDS 1\%, Fluoreto de Sódio $100 \mathrm{mM}$; Pirofosfato de Sódio $10 \mathrm{mM}$; Ortovanadato de Sódio $10 \mathrm{mM}$ e água deionizada) e as amostras colocadas em banho quente $\left(96^{\circ} \mathrm{C}\right)$ por 10 minutos. Em seguida, foram transferidas para tubos eppendorf e colocadas no gelo. Posteriormente as amostras foram centrifugadas a $13.400 \mathrm{~g}$ por 40 minutos, a $4{ }^{\circ} \mathrm{C}$.

As células L6-GLUT4myc foram tratadas com $10^{-8} \mathrm{M}$ de T3 por 30 minutos e em seguida homogeneizadas em tampão contendo: PBS, $1 \%$ de Triton X-100, 0.2\% de PIC (Coquetel Inibidor de Protease - Sigma) e $1 \mathrm{mM}$ de Ortovanadato de Sódio. As células foram homogeneizadas e centrifugadas a 10.000 g por 10 minutos, a $4{ }^{\circ} \mathrm{C}$.

\subsubsection{Dosagem das Proteínas pelo Método de Bradford}

A concentração das proteínas das diferentes frações subcelulares (MP e M) e do extrato total foi avaliada pelo método de Bradford (Bio-Rad, Dye Reagent Concentrate).

Assim, foi preparada uma solução de albumina bovina para a confecção de uma curva (pontos: $0.2 ; 0.4 ; 0.6 ; 0.8$ e $1.0 \mu \mathrm{g} / \mu \mathrm{l}$ ) que juntamente com as amostras foram aplicadas em placas de Elisa [6 $\mu \mathrm{l}$ da amostra e $300 \mu \mathrm{l}$ do reagente de Bradford diluído em água deionizada (1:5)]. Após incubação por 10 minutos, na ausência de luz, realizou-se a leitura das amostras em espectrofotômetro a $595 \mathrm{~nm}$.

\subsubsection{Preparo das Amostras e Eletroforese em Gel de Poliacrilamida - SDS (SDS- PAGE)}

Após a dosagem proteica, $20 \mu \mathrm{g}$ de proteínas microssomais e de membrana plasmática foram previamente aquecidas por 5 minutos a $100^{\circ} \mathrm{C}$ em uma mistura contendo $0.05 \mathrm{M}$ Tris, $15 \%$ glicerol, $0.05 \%$ azul de bromofenol, $9 \%$ SDS e 6\% de mercapto-etanol (Lammeli).

Em relação ao extrato proteico total, $100 \mu \mathrm{g}$ de proteínas foram aquecidas por 10 minutos a $100{ }^{\circ} \mathrm{C}$ em uma mistura contendo $50 \%$ glicerol, 0,1\% azul de bromofenol; $10 \%$ SDS, fosfato de sódio pH 7,0; DTT e água deionizada (Lammeli). 
Em seguida, elas foram aplicadas em gel de poliacrilamida composto por: um gel de empacotamento (Stacking Gel) (4\%) contendo 30\% de acrilamida, $1.0 \mathrm{M}$ Tris (pH 6,8), 10\% de SDS, $10 \%$ de persulfato de amônia (APS), Temed e Água Milli-Q (qsp) e por um gel de separação (Resolving Gel) (10\%) constituído por 30\% de acrilamida, 1,5 M Tris (pH 8,8), 10\% de SDS, $10 \%$ de persulfato de amônia, Temed, e Água Milli-Q (qsp). Posteriormente foram submetidas à eletroforese em tampão de corrida [25 mM de Tris - Base, $192 \mathrm{mM}$ de Glicina (ácido aminoacético), 0,1\% de SDS e $2 \mu \mathrm{M}$ de EDTA, pH 8,3]. A voltagem foi mantida em $40 \mathrm{~V}$ até as amostras atravessarem o stacking gel e em aproximadamente $90 \mathrm{~V}$ assim que atingiram o gel de separação. Uma amostra apresentando proteínas de pesos moleculares conhecidos (padrão) foi aplicada em uma das colunas do gel para se estimar a localização da banda correspondente à proteína de interesse.

\subsubsection{Western Blotting}

Após a eletroforese, realizou-se a transferência das proteínas do gel para uma membrana de nitrocelulose. A transferência foi feita por electrobloting, em tampão $25 \mathrm{mM}$ de Tris - Base, 192 mM de Glicina e 20\% de Metanol, por 2 horas, a 70 V. Após a transferência, o sistema foi desmontado cuidadosamente e a membrana foi corada com Vermelho Ponceau por, aproximadamente, 3 minutos e imediatamente lavada com PBS 1X para retirar o excesso de corante, etapa esta realizada para avaliar a qualidade da transferência. Em seguida a membrana foi colocada em solução bloqueadora (34 g de leite em pó desnatado em $150 \mathrm{ml}$ de solução PBS 1X) onde permaneceu por 30 minutos sob agitação constante, à temperatura ambiente (essa solução tem por objetivo saturar a membrana para minimizar as ligações inespecíficas que possam ocorrer ao longo das etapas seguintes). O gel também foi corado com Staining Solution e descorado após 30 minutos, para a análise comparativa das quantidades de proteínas aplicadas no mesmo.

\subsubsection{Immunoblotting}

Após o bloqueio, a membrana foi rapidamente lavada por 2 vezes com solução de PBS 1X para retirar o excesso de solução bloqueadora. Em seguida, as membranas foram incubadas com os anticorpos específicos: anti-GLUT4 (1/4000; Chemicon) em PBS 1X/BSA 8\%, por $3 \mathrm{~h}$ a $37^{\circ} \mathrm{C}$ e anti-pTyr (1/400; Santa Cruz), anti-p85 (1 $\mu \mathrm{g} / \mathrm{ml}$; Millipore), anti-p110 (1/1000; Cell Signaling), anti-pAKT (1/1000; Cell Signaling), anti-pAMPK $\alpha$ (1/1000; Cell Signaling) e $\beta$ (1/1000; Cell 
Signaling), anti-pAS160 (1/1000; Biosource) e anti p-p38- MAPK (1/100; Cell Signaling) em solução basal/BSA 3\%, overnight, a $4{ }^{\circ} \mathrm{C}$, sob agitação constante.

Posteriormente, a membrana foi rapidamente lavada por 2 vezes em PBS-Tween (PBS 1X; Tween 20 1\%), seguindo-se uma lavagem de 15 minutos e mais 3 lavagens de 5 minutos cada com a mesma solução. Após as lavagens, a membrana foi submetida à incubação com anticorpo secundário diluído na proporção de 1/10000 em PBS 1X/BSA 1\%, por 1h em temperatura ambiente, sob agitação constante. Em seguida, a membrana foi lavada rapidamente por 2 vezes em PBS-Tween (PBS 1X; Tween 20 1\%), seguindo-se uma lavagem de 15 minutos e mais 3 lavagens de 5 minutos cada com a mesma solução.

A detecção das bandas foi obtida em auto-radiografias, por quimioluminescência, após exposição em filmes de raios $\mathrm{X}$, por tempo aproximado de 1 minuto. A abundância das proteínas foi estimada por meio da análise densitométrica das bandas (método semi-quantitativo).

Para se estimar o conteúdo de GLUT4/g de tecido foram realizados cálculos para a recuperação proteica nas porções de membrana plasmática e microssoma.

\subsubsection{Captação de 2-Deoxy-Glicose}

As células foram tratadas com $10^{-8} \mathrm{M}$ de $\mathrm{T} 3$ por 10, 20, 30 e 40 minutos. Após o tratamento, as células foram lavadas 2 vezes com HBS (140 mM NaCl, 20 mM Hepes [pH 7.4], 5 $\mathrm{mM} \mathrm{KCl}, 2.5 \mathrm{mM} \mathrm{MgSO}_{4}$ e $1.0 \mathrm{mM} \mathrm{CaCl}_{2}$ ) e então incubadas por 5 minutos com $250 \mu \mathrm{de}$ solução transporte (HBS, $10 \mu \mathrm{M}$ 2-Deoxy-Glicose, $0.5 \mu \mathrm{Ci} / \mathrm{ml}{ }^{3} \mathrm{H}$ 2-Deoxy-Glicose). Após a incubação, as células foram lavadas 3 vezes com $\mathrm{NaCl}(0.9 \%)$ e $0.5 \mathrm{ml}$ de $\mathrm{NaOH}(0.05 \mathrm{~N})$ foi adicionado. As células foram, então, removidas e a captação foi medida em contador beta. Como controle positivo nós medimos a captação de glicose em células que foram incubadas com 100 nM de insulina por 20 minutos. A captação inespecífica de glicose foi determinada na presença de $10 \mu \mathrm{M}$ de citocalasina $\mathrm{B}$, um inibidor não seletivo dos transportadores de glicose, e então subtraída dos valores totais.

\subsubsection{Deteç̧ão Óptica do Conteúdo de GLUT4myc na Superfície da Membrana Plasmática}

Após o tratamento, as células foram lavadas 2 vezes com PBS gelado e, então, fixadas com paraformaldeído (3\%) por 10 minutos a $4{ }^{\circ} \mathrm{C}$ e por 20 minutos a temperatura ambiente. 
Todos os passos seguintes foram realizados a temperatura ambiente. Assim, as células foram incubadas com $0.1 \mathrm{M}$ de glicina por 10 minutos e então bloqueadas com 5\% de soro de cabra durante pelo menos 15 minutos. Após o bloqueio, as células foram incubadas com anticorpo antic-Myc (Sigma) por 60 minutos. Em seguida, as células foram submetidas a uma nova incubação com anticorpo secundário (Jackson Immuno Research) por 60 minutos. Após a retirada do anticorpo secundário, as células foram lavadas com PBS e, então, incubadas por 20 minutos com $1 \mathrm{ml}$ de reagente OPD (O-Phenylenediamine Dihydrochloride - Sigma). A reação foi interrompida pela adição de $\mathrm{HCl}(0.6 \mathrm{M})$. A absorbância óptica do sobrenadante foi medida em $492 \mathrm{~nm}$.

\subsubsection{Extração do RNA}

Nos estudos in vitro o RNA total foi extraído a partir do reagente Trizol (Invitrogen). Desta maneira, após os respectivos tratamentos, o meio de cultura DMEM foi removido e as células foram lavadas com PBS 1X estéril e então, homogeneizadas com Trizol. Adicionou-se 0,2 $\mathrm{ml}$ de clorofórmio e as amostras foram centrifugadas a $12.000 \mathrm{~g}$, a $4{ }^{\circ} \mathrm{C}$ por 15 minutos. A fase aquosa foi coletada e precipitada com isopropanol, seguindo-se de incubação em temperatura ambiente e nova centrifugação a $12.000 \mathrm{~g}$, a $4{ }^{\circ} \mathrm{C}$ por 10 minutos. $\mathrm{O}$ sobrenadante foi removido e o precipitado, que corresponde ao RNA total, foi lavado com etanol 95\% e centrifugado a $6000 \mathrm{~g}$ a $4{ }^{\circ} \mathrm{C}$ por 5 minutos. O sobrenadante foi removido, o precipitado ressuspenso em $30 \mu$ de água DEPC autoclavada. As amostras de RNA total foram quantificadas em espectrofotometro e mantidas a $-80{ }^{\circ} \mathrm{C}$ até o momento de uso.

\subsubsection{Real Time-PCR}

Para determinar o grau de expressão do mRNA do GLUT4 nas células 3T3-L1, realizouse a técnica de Real Time PCR. Primeiramente, foi feita a reação de transcrição reversa, para obtenção dos cDNAs, a partir de $3 \mu \mathrm{g}$ do RNA total de cada amostra, com volume total de reação de $20 \mu \mathrm{l}$. Foram adicionados: oligo dT (100 $\mu \mathrm{g} / \mathrm{ml}), 10 \mathrm{mM}$ de dNTP, 5X First-Strand buffer e 2

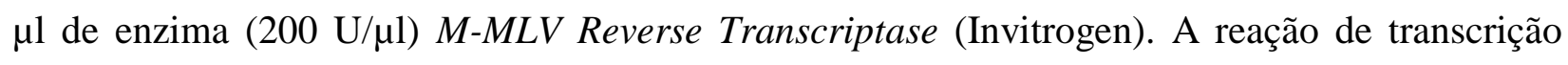
reversa foi realizada num ciclo de $65^{\circ} \mathrm{C}$ por 10 minutos, seguido de $42{ }^{\circ} \mathrm{C}$ por 60 minutos e $95^{\circ} \mathrm{C}$ por 10 minutos. $\mathrm{O}$ produto da reação foi estocado a $-20{ }^{\circ} \mathrm{C}$ até o momento de sua utilização na reação de Real Time PCR. 
A detecção em tempo real do produto do PCR foi feita pela quantificação de fluorescência emitida pelo reagente SYBR ${ }^{\circledR}$ Green PCR, avaliada pelo detector de sequência ABI Prism 7300 (Applied Biosystems, Foster City, CA, USA), baseado na metodologia corrente.

Foram utilizados $50 \mathrm{ng}$ do produto do RT em $10 \mu \mathrm{l}$ de reação de Real Time PCR contendo $200 \mathrm{nM}$ de cada par de primers designados para o gene do GLUT4 e da ciclofilina, que foi utilizado como controle endógeno, e amplificado para normalizar os níveis de expressão do mRNA do GLUT4 (Tabela 1).

Tabela 1 - Primers construídos para análise da expressão gênica por PCR em tempo real.

\begin{aligned} & \hline Gene \multicolumn{1}{c}{ Primers (5'-3') } \\ & \hline \multirow{2}{*}{ GLUT4 } Sense: GGGCTGTGAGTGAGTGCTTTC \\ & Antisense: CAGCGAGGCAAGGCTAGA \\ & \multirow{2}{*}{ Ciclofilina } Sense: GGATTCATGTGCCAGGGTGG \\ & Antisense: CACATGCTTGCCATCCAGCC \\ & \hline\end{aligned}

A reação de PCR foi realizada em aparelho ABI PRISM 7300 (Applied Biosystems) nas seguintes condições: $50{ }^{\circ} \mathrm{C}$ por 2 minutos, $95^{\circ} \mathrm{C}$ por 2 minutos, e 40 repetições de um ciclo de 62 ${ }^{\circ} \mathrm{C}$ por 1 minuto e $72{ }^{\circ} \mathrm{C}$ por 15 segundos. Os resultados das reações de PCR foram analisados pelo programa ABI PRISM 7300 Sequence Detection System. Neste programa, a expressão gênica é calculada a partir do número de ciclos $(\mathrm{Ct})$ necessários para que a fluorescência emitida por uma amostra, para cada gene, ultrapasse um limiar (treshold) determinado. A reação de cada amostra foi realizada em duplicata. Para as análises quantitativas, foi utilizado o método de curva padrão relativa. Os resultados foram calculados usando o método $2^{-\Delta \Delta \mathrm{Ct}}$ (LIVAK $\mathrm{e}$ SCHMITTGEN, 2001) e estão apresentados como variação da expressão do GLUT4 dos grupos tratados em relação aos respectivos grupos controle.

\subsubsection{Dosagem da Insulina: Radioimunoiensaio (RIE)}

Para avaliação da secreção de insulina foi utilizada a técnica de radioimunoensaio conforme descrito por Pupo et al. (1970). Foram adicionados a $50 \mu \mathrm{l}$ da amostra: albumina (BSA 0,25\%) $(50 \mu \mathrm{l}), 50 \mu \mathrm{l}(1: 50)$ de anticorpo anti-insulina e de insulina marcada (I - $\left.{ }^{125} \mathrm{I}\right)$ (1:300 $50 \mu$ l). Agitou-se em vórtex e incubou-se a $4{ }^{\circ} \mathrm{C}$ por 48 horas. 
Após este período de incubação, foram acrescentados às amostras $100 \mu \mathrm{l}$ de soro carreador (soro de rato) e $1 \mathrm{ml}$ de PEG 15\% (polietilenoglicol em tampão borato, $\mathrm{pH}$ 8.0). Os tubos foram agitados e centrifugados a $2000 \mathrm{~g}$ por 30 minutos, a $4{ }^{\circ} \mathrm{C}$. Posteriormente, o sobrenadante foi aspirado e a atividade foi contada em contador gama $(\gamma)$. 


\section{ANÁLISE ESTATÍSTICA}

Todos os dados estão expressos por média \pm SEM, e as diferenças foram consideradas significativas quando $\mathrm{p} \leq 0.05$. Para comparações entre dois grupos independentes, foi utilizado o teste $t$ de Student não pareado e entre grupos dependentes, o teste $t$ de Student pareado. Na comparação entre três ou mais grupos independentes utilizou-se a análise de Variância one-way ANOVA. Quando houve diferença significativa na análise de variância, testes para comparações múltiplas foram utilizados. O teste de Student-Newman-Keuls foi utilizado quando os grupos foram comparados entre si e o teste de Dunnett quando as comparações foram feitas em relação ao grupo controle, conforme especificado nos resultados abaixo (Package: Prism Graph Pad Version: 4.0). 


\section{RESULTADOS}

\subsection{Estudo in vivo}

\subsubsection{Avaliação da eficiência dos procedimentos experimentais realizados}

As concentrações séricas de TSH, T4 e T3 foram mensuradas como parâmetros de avaliação da eficiência da tireoidectomia e da administração aguda de T3 nos ratos.

Na figura 1 estão representados os dados correspondentes a dosagem sérica de TSH e T4 dos animais eutireoideos (C) e hipotireoideos (TX). Já a figura 2 apresenta os dados correspondentes à concentração sérica de T3 nos animais TX antes e após administração de T3 nas doses de $0.3,1.5,15$ e $100 \mu \mathrm{g} / 100 \mathrm{~g}$ de PC.

Conforme esperado, houve elevação do TSH e decréscimo do T4 sérico nos animais TX, bem como elevação da concentração sérica de T3 após os animais TX serem submetidos à doses crescentes de T3, o que confirma a eficiência dos procedimentos efetuados. 
A)

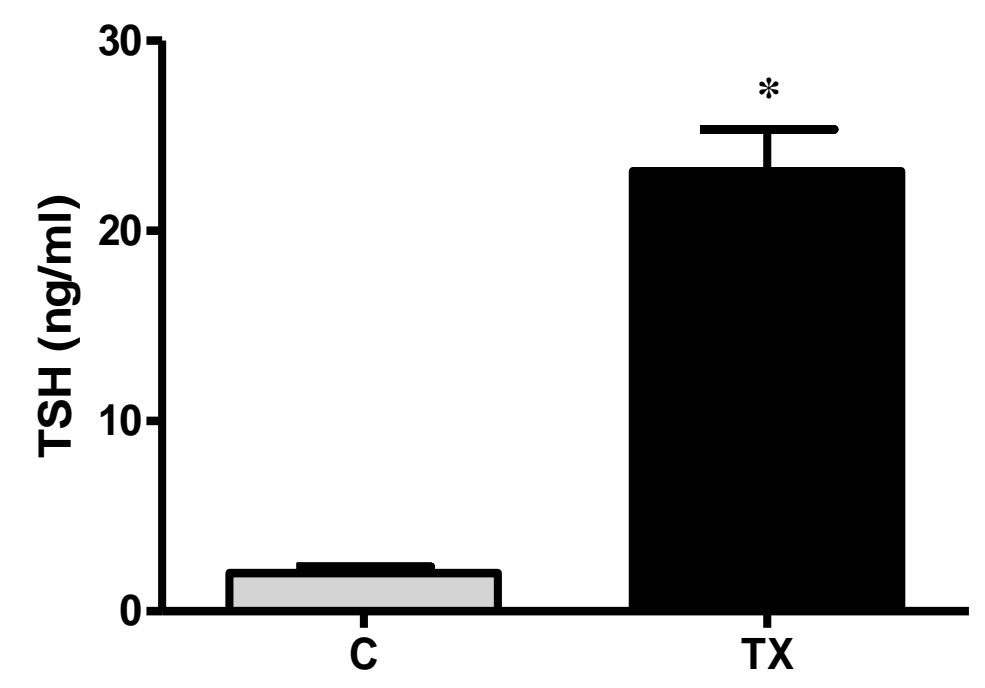

B)

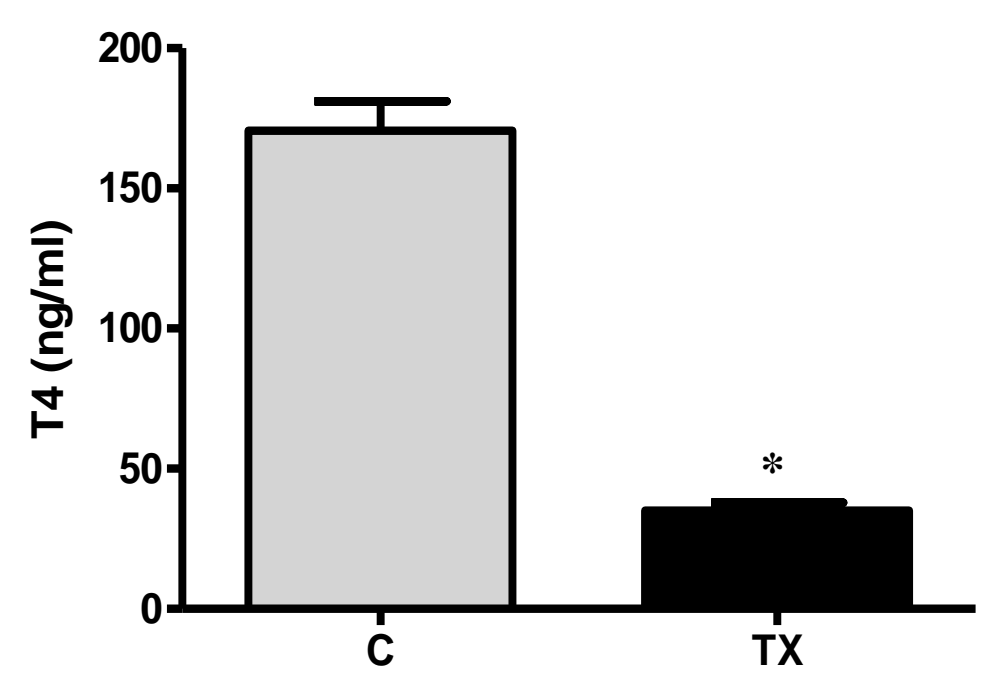

Figura 1 - Representação gráfica da dosagem sérica de TSH (A) e de T4 (B) dos ratos eutireoideos (C) e hipotireoideos (TX). Os dados estão expressos pela média \pm SEM. O nível de significância entre os grupos foi obtido utilizando-se o Teste T de Student (não pareado), * $\mathrm{p}<0,001$ vs controle $(\mathrm{n}=6)$. 


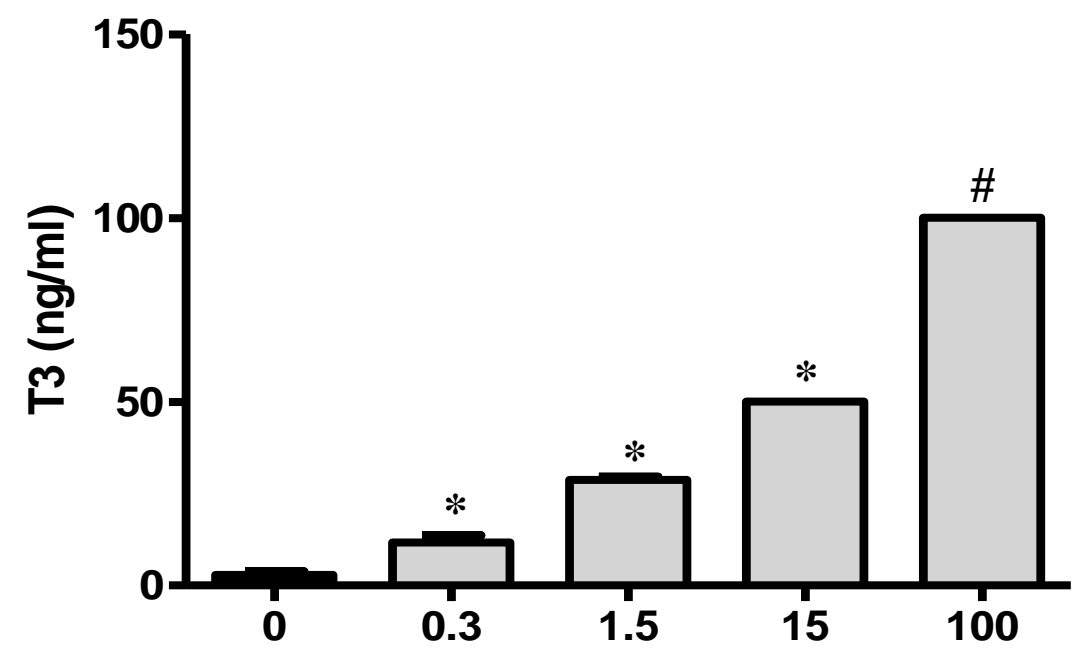

Figura 2 - Representação gráfica da dosagem sérica de T3 dos ratos hipotireoideos (TX) antes (0) e após administração de T3 nas doses 0.3, 1.5, 15 e $100 \mu \mathrm{g} / 100 \mathrm{~g}$ de PC. Os dados estão expressos pela média \pm SEM e foram obtidos utilizando-se a análise de variância one-way ANOVA, seguida pelo teste de comparações múltiplas Dunnet, * p <0,001 vs TX, \# esse grupo não foi considerado na análise estatística pois a concentração sérica de T3 superou o limite de detecção do ensaio utilizado, $(n=6)$.

\subsubsection{Efeito da tireoidectomia sobre o conteúdo de GLUT4 no tecido muscular esquelético e adiposo}

A figura 3 apresenta os dados referentes à análise densitométrica do conteúdo da proteína GLUT4 nas frações Microssomal (M) e de Membrana Plasmática (MP), correspondentes ao conteúdo total de GLUT4 (M+MP) por grama de tecido. Os dados apresentados se referem ao múculo esquelético (Soleus e EDL) e tecido adiposo dos animais eutiroideos e hipotireoideos. $\mathrm{Na}$ figura 4 é mostrada a porcentagem de GLUT4 presente na membrana plasmática dos grupos citados, nos respectivos tecidos.

Podemos observar que a tireoidectomia provoca redução tanto do conteúdo total de GLUT4/g de tecido, quanto do GLUT4 presente na membrana plasmática. 
1)

A)

C TX

2)
B)

C TX

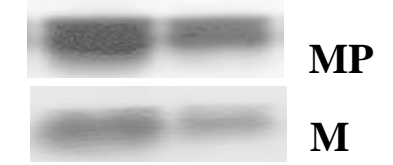

E)
C)

C TX

MP

M

F)
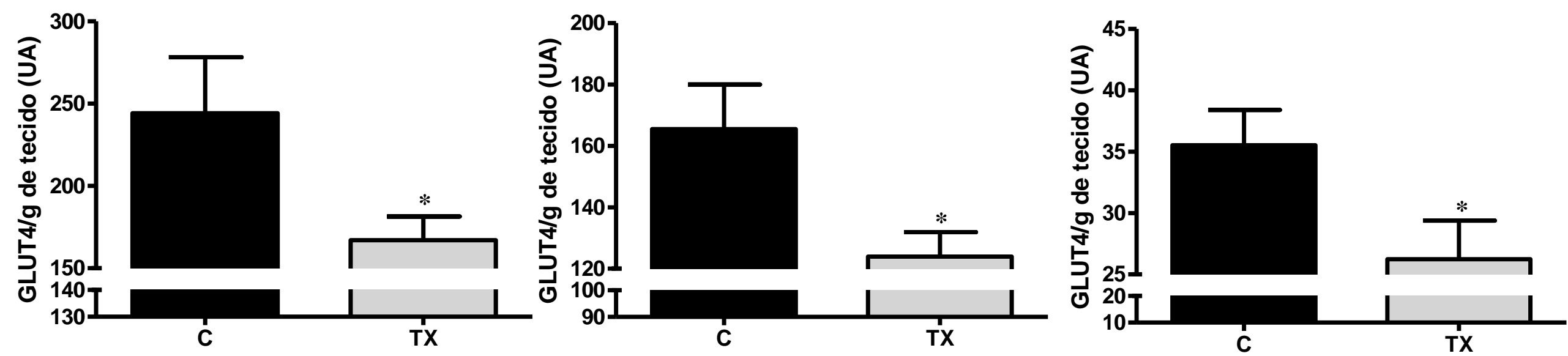

Figura 3 - 1) Imagem representativa da auto-radiografia das bandas referentes ao conteúdo da proteína GLUT4 nas frações Microssomal (M) e de Membrana Plasmática (MP) no músculo EDL (A), Soleus (B) e tecido adiposo (C) dos ratos eutireoideos (C) e hipotireoideos (TX). 2) Representação gráfica do conteúdo total de GLUT4 no músculo EDL (D), Soleus (E) e tecido adiposo (F) dos ratos eutireoideos (C) e hipotireoideos (TX). Os dados estão expressos pela média \pm SEM e foram analisados utilizando-se o Teste $T$ de Student (não pareado), * $\mathrm{p}<0,05$ vs $\mathrm{C}(\mathrm{n}=14)$. 
A)

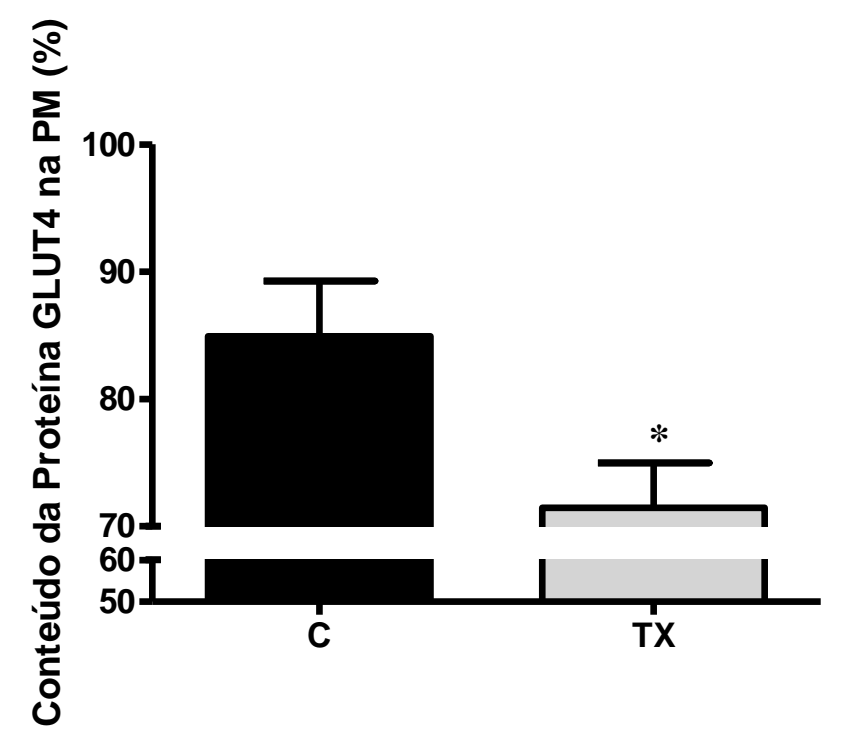

B)

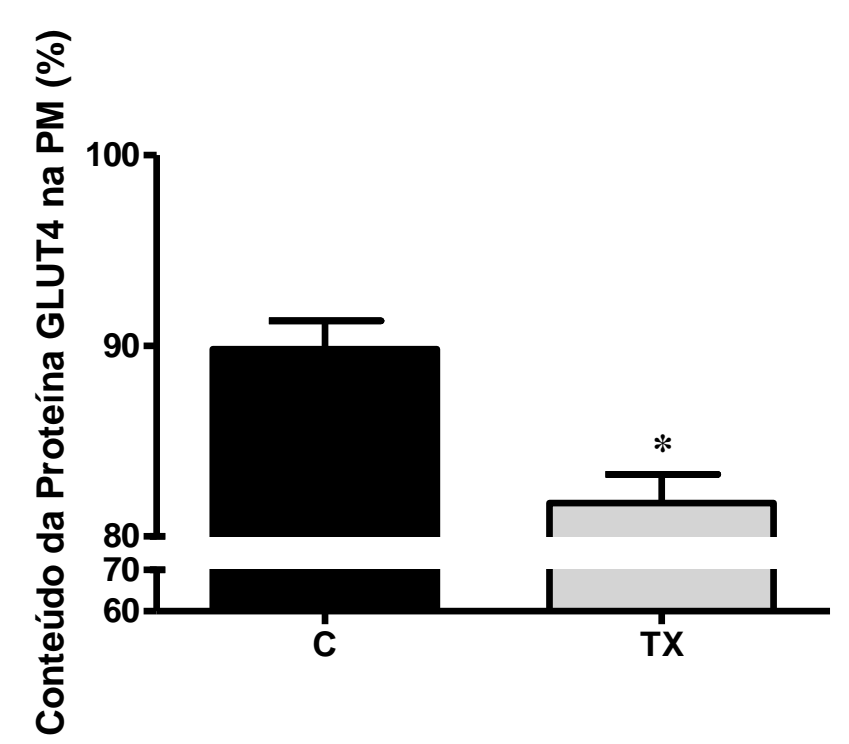

C)

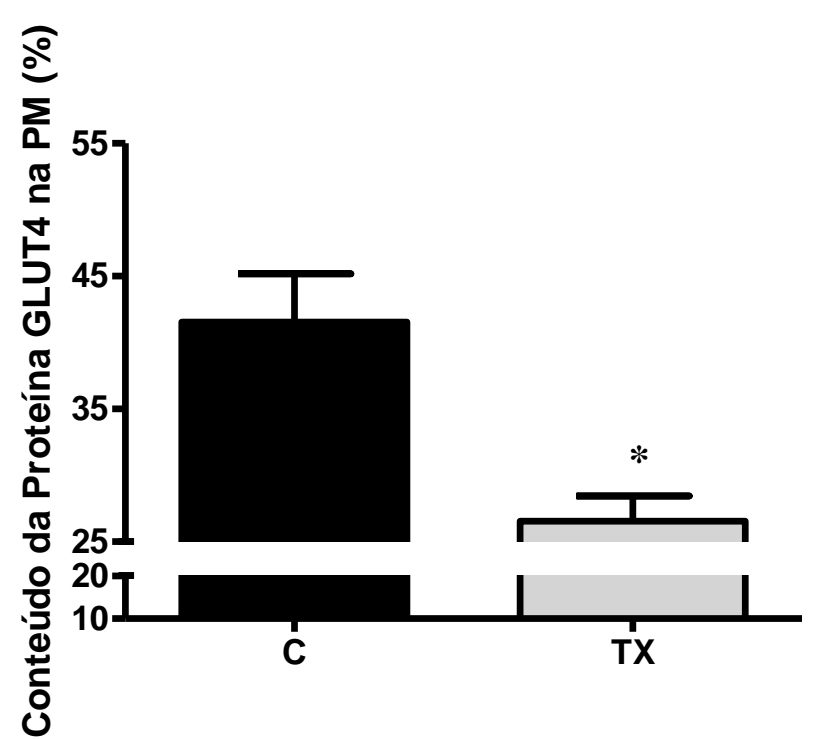

Figura 4 - Representação gráfica do conteúdo da proteína GLUT4 na membrana plasmática do músculo EDL (A), Soleus (B) e tecido adiposo (C) de ratos eutireoideos (C) e hipotireoideos (TX). Os dados estão expressos pela média \pm SEM e foram analizados utilizando-se o Teste $T$ de Student (não pareado), * $\mathrm{p}<0,05(\mathrm{n}=14)$. 


\subsubsection{Efeito da administração aguda (30 minutos) de T4 sobre o conteúdo de GLUT4 no tecido muscular esquelético e adiposo}

Neste estudo, nós avaliamos o conteúdo total de GLUT4 (MP + M) por grama de tecido e a porcentagem de GLUT4 presente na Membrana Plasmática (MP) do músculo esquelético e do tecido adiposo após o tratamento agudo (30 minutos) com T4. O objetivo principal deste estudo foi investigar se o T4, apontado como protagonista da grande maioria das ações não genômicas dos hormônios tireoidianos, poderia induzir alterações, a curto prazo, na expressão do GLUT4.

As figuras 5 e 6 apresentam, respectivamente, o conteúdo total de GLUT4 (MP + M) por grama de tecido; e a porcentagem de GLUT4 presente na Membrana Plasmática (MP) do músculo esquelético (Soleus e EDL) e do tecido adiposo dos animais hipotiroideos (TX) submetidos ou não ao tratamento agudo com T4.

Podemos observar que ocorreu um aumento no conteúdo total de GLUT4 por grama de tecido no tecido adiposo e no músculo Soleus com a administração de T4 na dose fisiológica ( 0.8

$\mu \mathrm{g} / 100 \mathrm{~g}$ de PC) e na dose 50 vezes a fisiológica ( $40 \mu \mathrm{g} / 100 \mathrm{~g}$ de PC) respectivamente (figura 5). No entanto, nenhuma alteração foi observada na porcentagem de GLUT4 presente na membrana plasmática (figura 6). 
1)

A)

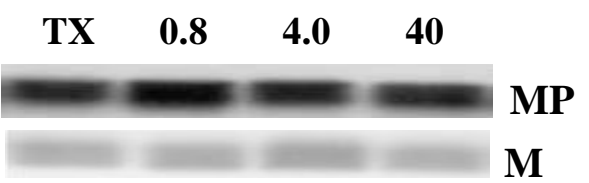

2)

D)

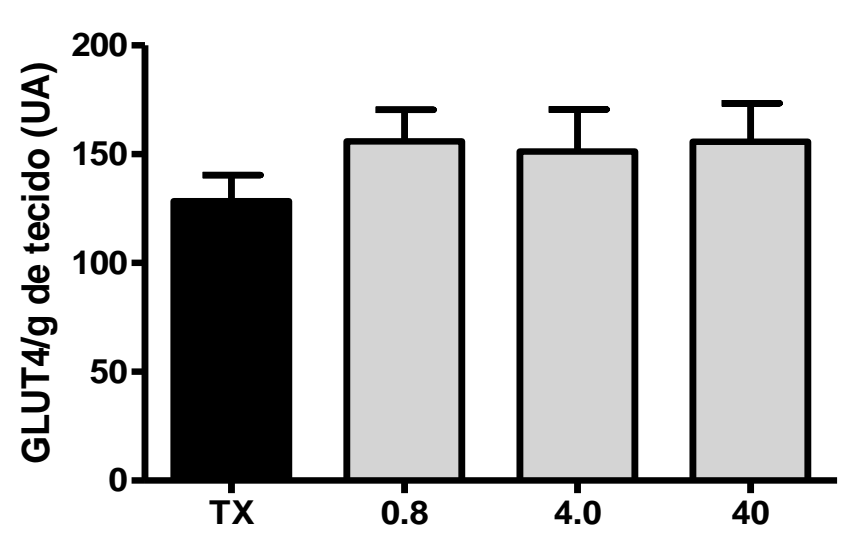

B)

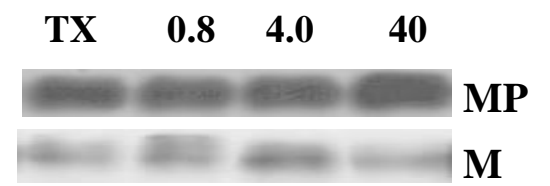

E)

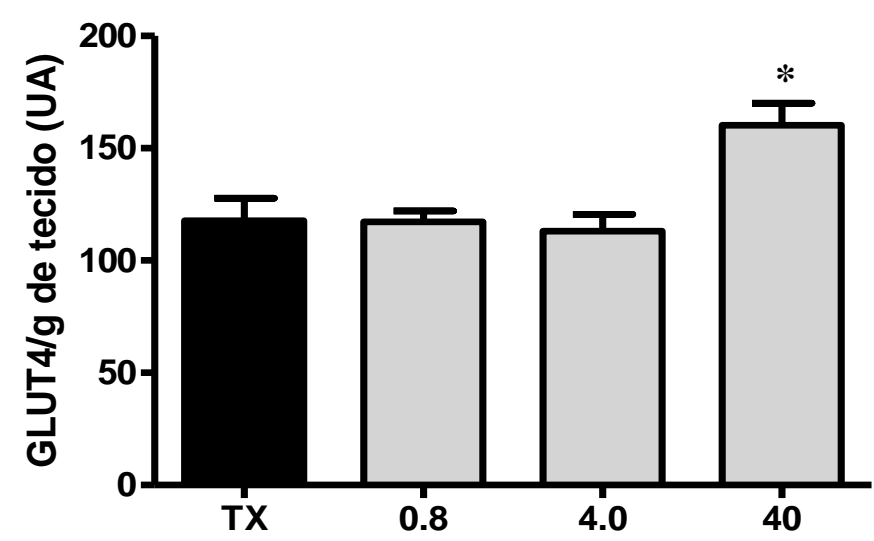

C)

$$
\begin{array}{llll}
\text { TX } & 0.8 & 4.0 & 40
\end{array}
$$

MP

M

F)

Figura 5 - 1) Imagem representativa da auto-radiografia das bandas referentes ao conteúdo da proteína GLUT4 nas frações Microssomal (M) e de Membrana Plasmática (MP) no músculo EDL (A), Soleus (B) e tecido adiposo (C) dos ratos hipotireoideos (TX) e hipotireoideos que receberam T4 nas doses $0.8,4.0$ e $40 \mu \mathrm{g} / 100 \mathrm{~g}$ de peso corporal, e.v. e foram sacrificados após 30 minutos. 2) Representação gráfica do conteúdo total de GLUT4 no músculo EDL (D), Soleus (E) e tecido adiposo (F) de ratos hipotireoideos (TX) e hipotireoideos que receberam T4 nas doses $0.8,4.0$ e $40 \mu \mathrm{g} / 100 \mathrm{~g}$ de peso corporal, e.v. e foram sacrificados após 30 minutos. Os dados estão expressos pela média \pm SEM e foram avaliados utilizando-se a análise de variância one-way ANOVA, seguida pelo teste de comparações múltiplas Dunnet, * $\mathrm{p}<0.05$ vs TX $(\mathrm{n}=14)$. 
A)

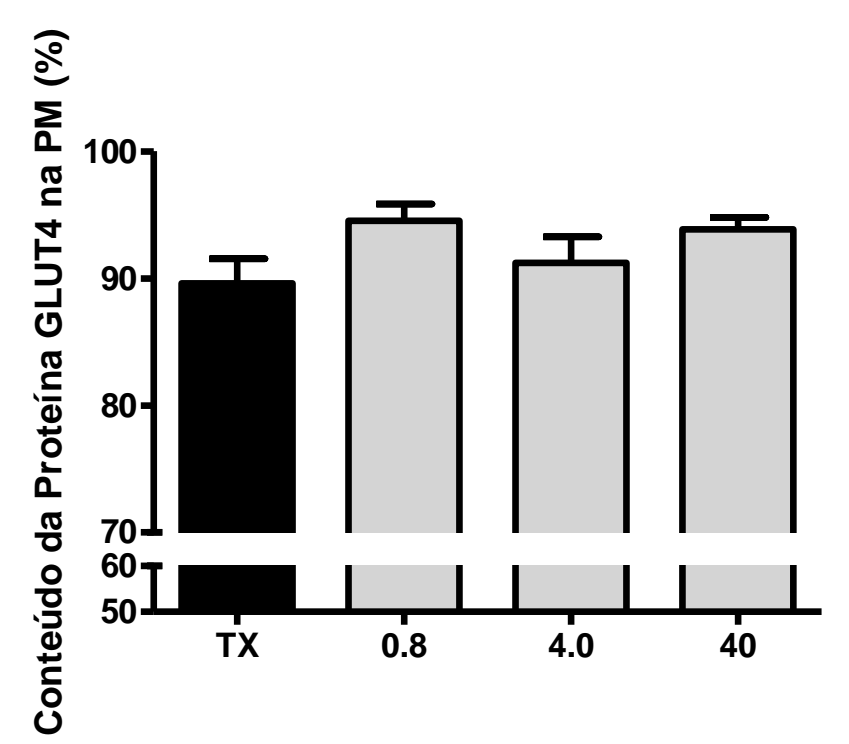

B)

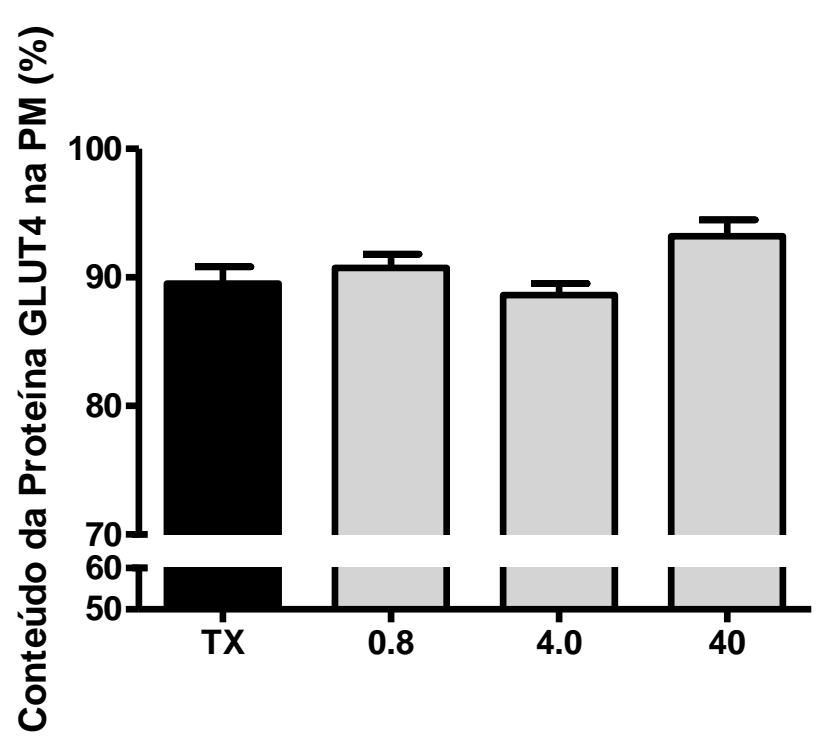

C)

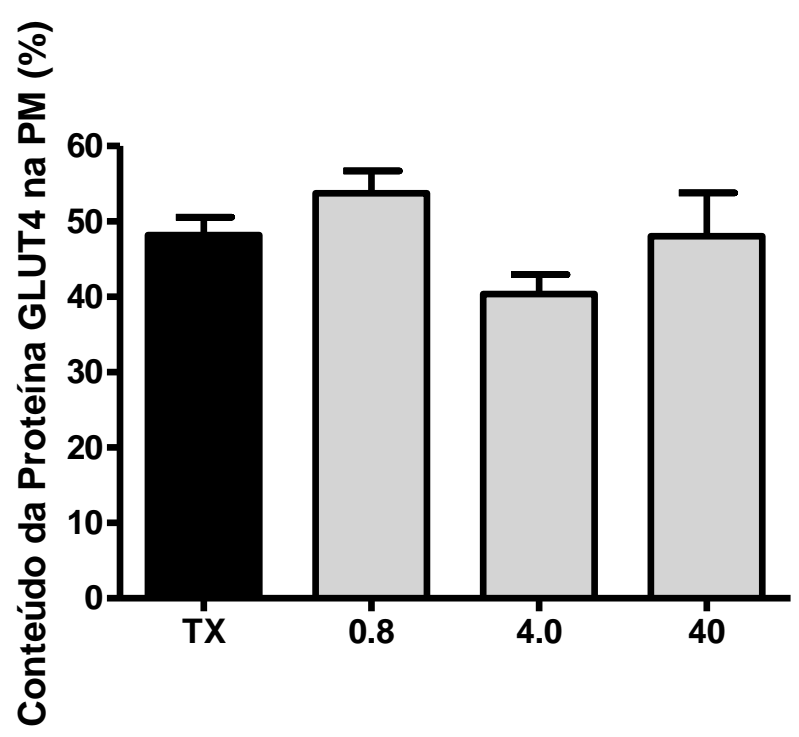

Figura 6 - Representação gráfica do conteúdo da proteína GLUT4 na membrana plasmática no músculo EDL (A), Soleus (B) e tecido adiposo (C) de ratos hipotireoideos (TX) e hipotireoideos que receberam T4 nas doses $0.8,4.0$ e $40 \mu \mathrm{g} / 100 \mathrm{~g}$ de peso corporal, e.v. e foram sacrificados após 30 minutos. Os dados estão expressos pela média \pm SEM e foram avaliados utilizando-se a análise de variância oneway ANOVA, seguida pelo teste de comparações múltiplas Dunnet $(\mathrm{n}=14)$. 


\subsubsection{Efeito da administração aguda (30 minutos) de T3 sobre o conteúdo de GLUT4 no tecido muscular esquelético e adiposo}

Neste estudo, nós avaliamos os mesmos parâmetros investigados no item anterior, ou seja, o conteúdo total de GLUT4 $(\mathrm{MP}+\mathrm{M})$ por grama de tecido e a porcentagem de GLUT4 presente na Membrana Plasmática (MP) do músculo esquelético e do tecido adiposo, após o tratamento agudo (30 minutos) com T3.

As figuras 7 e 8 apresentam, respectivamente, os dados correspondentes ao conteúdo total de GLUT4 por grama de tecido e a porcentagem de GLUT4 presente na membrana plasmática dos animais hipotiroideos (TX) submetidos ou não ao tratamento agudo (30 minutos) com T3.

Podemos observar que no músculo esquelético e no tecido adiposo o tratamento agudo com T3 (30 minutos) não foi capaz de aumentar significativamente o conteúdo total de GLUT4 por grama de tecido (figura 7).

No entanto, quando nós avaliamos a porcentagem de GLUT4 presente na membrana plasmática, nossos resultados mostram que doses fisiológicas $(0.3 \mu \mathrm{g} / 100 \mathrm{~g}$ de PC) e doses 5 vezes a fisiológica $(1.5 \mu \mathrm{g} / 100 \mathrm{~g}$ de PC) foram capazes de aumentar significativamente esse parâmetro nos músculos EDL e Soleus respectivamente (figura 8). Nossos resultados mostram ainda que apenas doses fisiológicas de T3 $(0.3 \mu \mathrm{g} / 100 \mathrm{~g}$ de PC) foram capazes de provocar esse aumento no tecido adiposo (figura 8). Dessa forma, nossos resultados chamam a atenção para ações do HT que são tecido-específicas. 
1)

A)

$\begin{array}{lllll}\text { TX } & 0.3 & 1.5 & 15 & 100\end{array}$

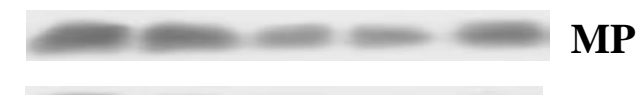

M
B)

$\begin{array}{lllll}\mathrm{TX} & 0.3 & 1.5 & 15 & 100 \\ \end{array}$

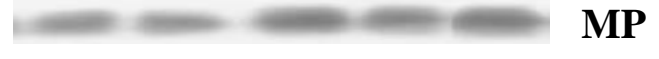

M
C)

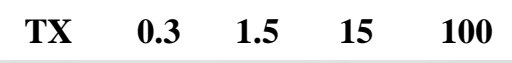

MP

M

2)

D)

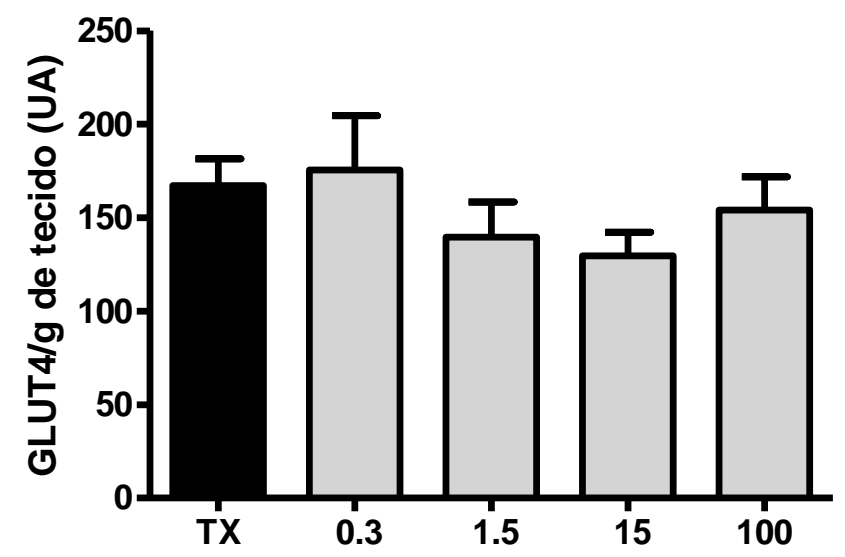

E)

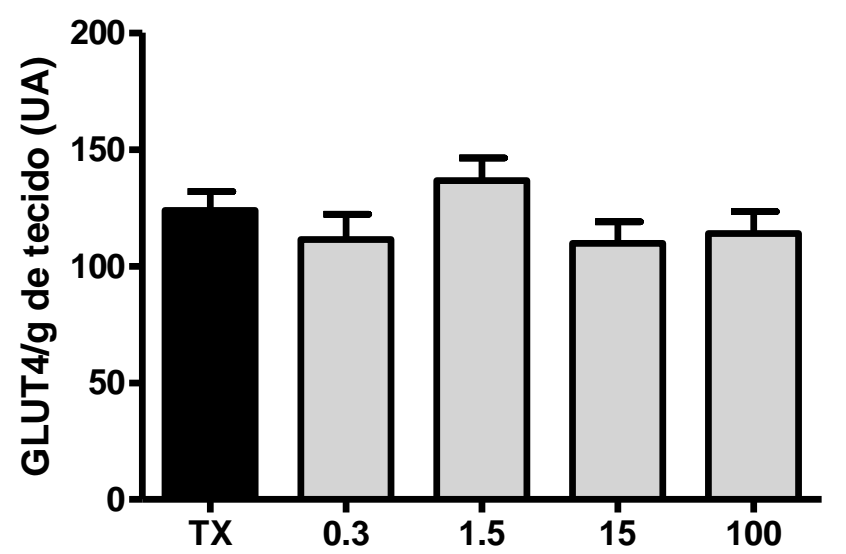

F)

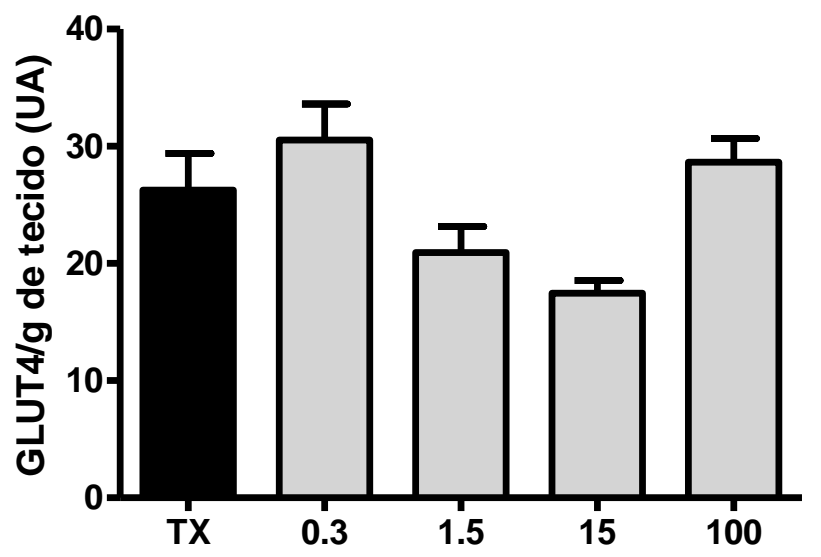

Figura 7 - 1) Imagem representativa da auto-radiografia das bandas referentes ao conteúdo da proteína GLUT4 nas frações Microssomal (M) e de Membrana Plasmática (MP) no músculo EDL (A), Soleus (B) e tecido adiposo (C) dos ratos hipotireoideos (TX) e hipotireoideos que receberam T3 nas doses 0,3; 1,5; 15 e $100 \mu \mathrm{g} / 100 \mathrm{~g}$ de peso corporal, e.v. e foram sacrificados após 30 minutos. 2) Representação gráfica do conteúdo total de GLUT4 no músculo EDL (D), Soleus (E) e tecido adiposo (F) de ratos hipotireoideos (TX) e hipotireoideos que receberam T3 nas doses 0,3; 1,5; 15 e $100 \mu \mathrm{g} / 100 \mathrm{~g}$ de peso corporal, e.v. e foram sacrificados após 30 minutos. Os dados estão expressos pela média \pm SEM e foram avaliados utilizando-se a análise de variância one-way ANOVA, seguida pelo teste de comparações múltiplas Dunnet $(\mathrm{n}=10)$. 
A)

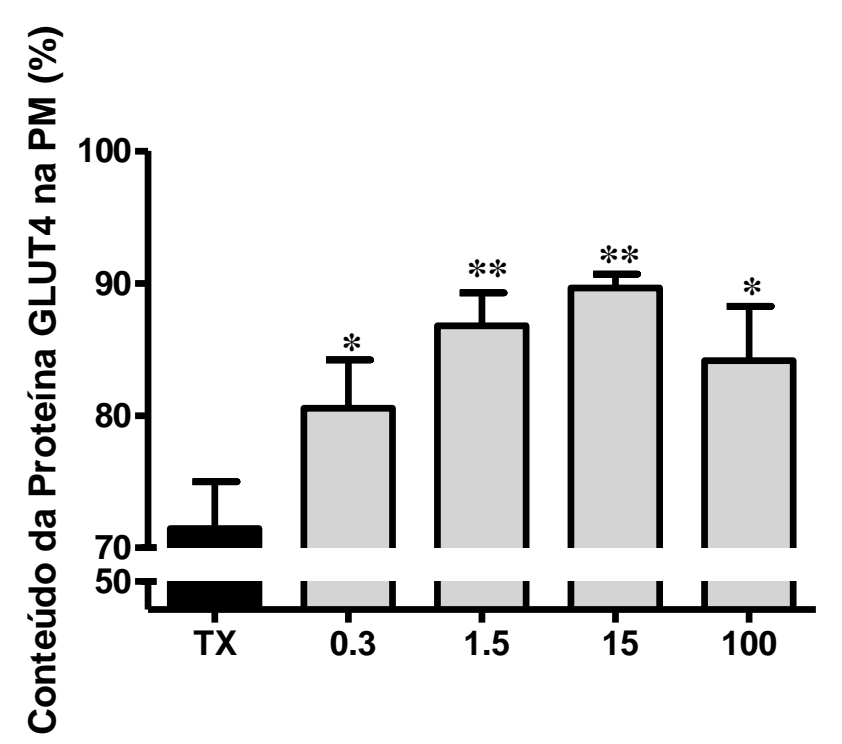

B)

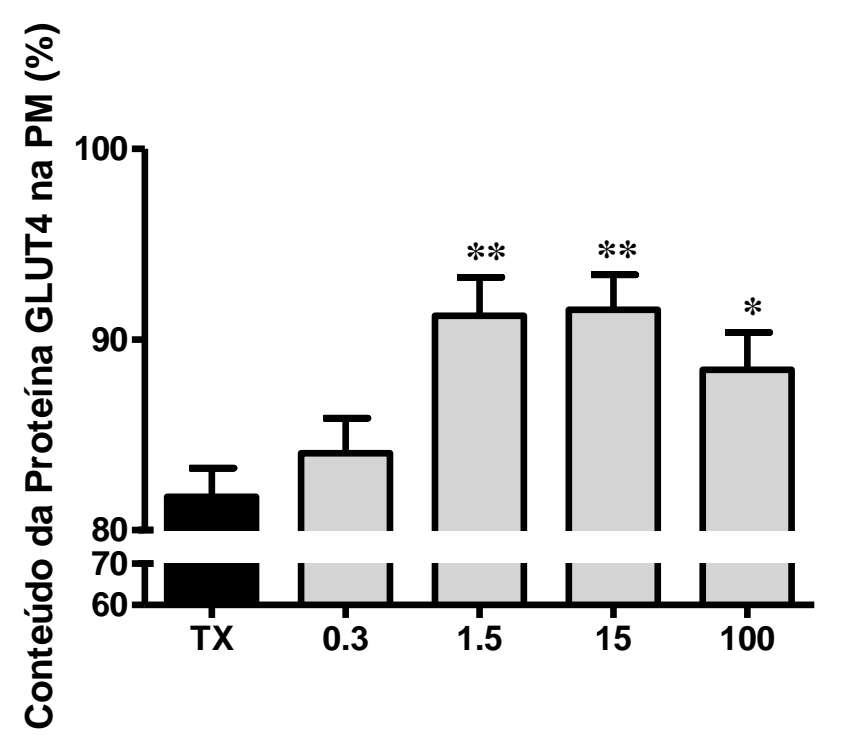

C)

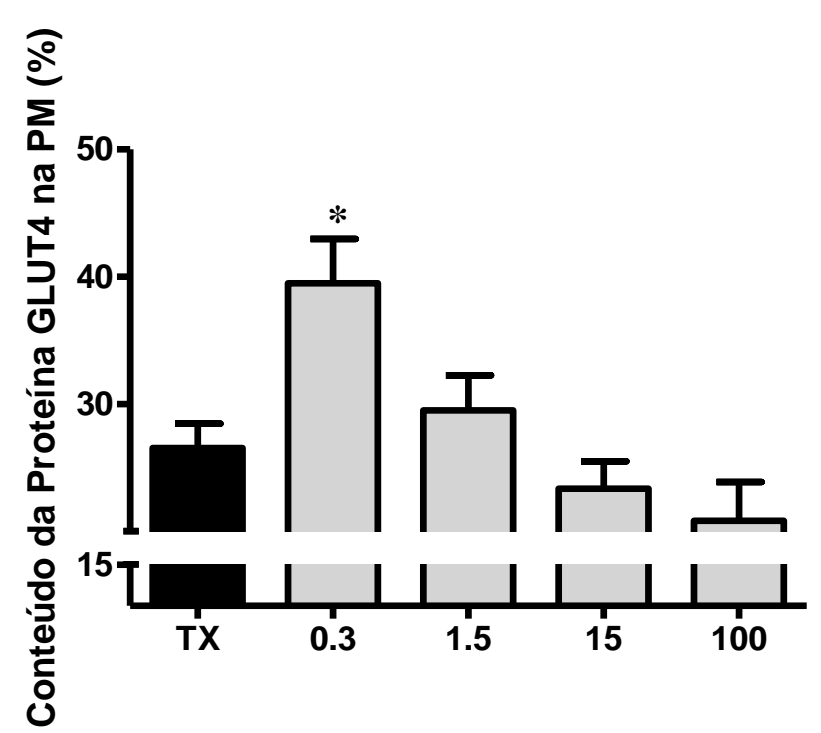

Figura 8 - Representação gráfica do conteúdo da proteína GLUT4 na membrana plasmática no músculo EDL (A), Soleus (B) e tecido adiposo (C) de ratos hipotireoideos (TX) e hipotireoideos que receberam T3 nas doses $0.3,1.5,15$ e $100 \mu \mathrm{g} / 100 \mathrm{~g}$ de peso corporal, e.v. e foram sacrificados após 30 minutos. Os dados estão expressos pela média \pm SEM e foram avaliados utilizando-se a análise de variância one-way ANOVA, seguida pelo teste de comparações múltiplas Dunnet, ** p <0,01 vs TX; * p < 0,05 vs TX (n=10). 


\subsubsection{Efeito da administração aguda de T3 sobre o grau de fosforilação de proteínas classicamente envolvidas na translocação do GLUT4 para a membrana plasmática}

Nossos resultados demonstram que o T3 promove, rapidamente (30 minutos), um aumento da porcentagem de GLUT4 presente na membrana plasmática dos músculos Soleus e EDL e do tecido adiposo. Nossos resultados mostram ainda uma resposta tecido específica à ação do T3, já que no EDL o aumento do GLUT4 na MP ocorreu em todas as doses estudadas, enquanto que no Soleus esse aumento só foi verificado a partir de dose $5 \mathrm{X}$ a fisiológica $(1,5$ $\mu \mathrm{g} / 100 \mathrm{~g}$ de peso corporal) e no tecido adiposo apenas após a administração de doses fisiológicas de T3 $(0,3 \mu \mathrm{g} / 100 \mathrm{~g}$ de peso corporal). Conforme sabido, a translocação de GLUT4 envolve a fosforilação de várias proteínas, sendo essa a razão pela qual esse experimento foi realizado.

Os resultados apresentados aqui se referem aos estudos desenvolvidos no músculo esquelético (Soleus e EDL), nos quais avaliamos o grau de fosforilação de algumas proteínas sabidamente envolvidas com a translocação do GLUT4. O estudo foi realizado após 5, 10, 20 e 30 minutos da administração de doses 5 vezes a fisiológica de T3.

Para avaliar a eficiência dos procedimentos empregados, nós utilizamos como controle interno o grau de fosforilação de algumas das proteínas abaixo especificadas, após a administração da insulina. Dessa forma, nós iniciamos nossos estudos avaliando a participação da via de sinalização ativada pela insulina, a saber: o receptor de insulina (IR); os substratos do receptor de insulina (IRS1/2) e a proteína AKT, bem como o conteúdo da proteína p85 (subunidade regulatória da PI3-K) e da p110 (subunidade catalítica da PI3-K). Além disso, nós avaliamos o grau de fosforilação da AMPK $\alpha$ e $\beta$, proteínas sabidamente envolvidas com a translocação do GLUT4 que ocorre após a contração muscular.

Podemos observar na figura 9 que 30 minutos após a administração de T3 ocorreu um aumento na fosforilação do receptor de insulina (IR) no EDL e no Soleus, embora esse aumento não tenha sido significativo no Soleus. Nenhuma alteração foi detectada no substrato do receptor de insulina (IRS1/2) (figura 10), bem como no conteúdo da proteína p85 e p110 (figura 11 e 12) em ambos os tecidos nos diferentes tempos estudados. Surpreendentemente a fosforilação da AKT, após a administração de T3, apresentou-se reduzida em ambos os músculos estudados 
(figura 13). Também não observamos alteração no grau de fosforilação das proteínas AMPK $\alpha$ e $\beta$ nos músculos esqueléticos, conforme ilustram as figuras 14 e 15. 
1) A)

\begin{tabular}{|c|c|c|c|c|c|c|c|c|c|c|}
\hline \multirow[t]{2}{*}{ A } & \multicolumn{2}{|c|}{$5 \mathrm{~min}$} & \multicolumn{2}{|c|}{$10 \mathrm{~min}$} & \multicolumn{2}{|c|}{$20 \mathrm{~min}$} & \multicolumn{2}{|c|}{$30 \mathrm{~min}$} & \multicolumn{2}{|c|}{$1.5 \mathrm{~min}$} \\
\hline & $=$ & - & - & - & 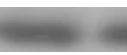 & $=$ & - & $=$ & & 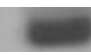 \\
\hline T3 & - & + & - & + & - & + & - & + & . & + \\
\hline sulina & - & - & - & - & - & - & - & - & & + \\
\hline
\end{tabular}

2)

C)

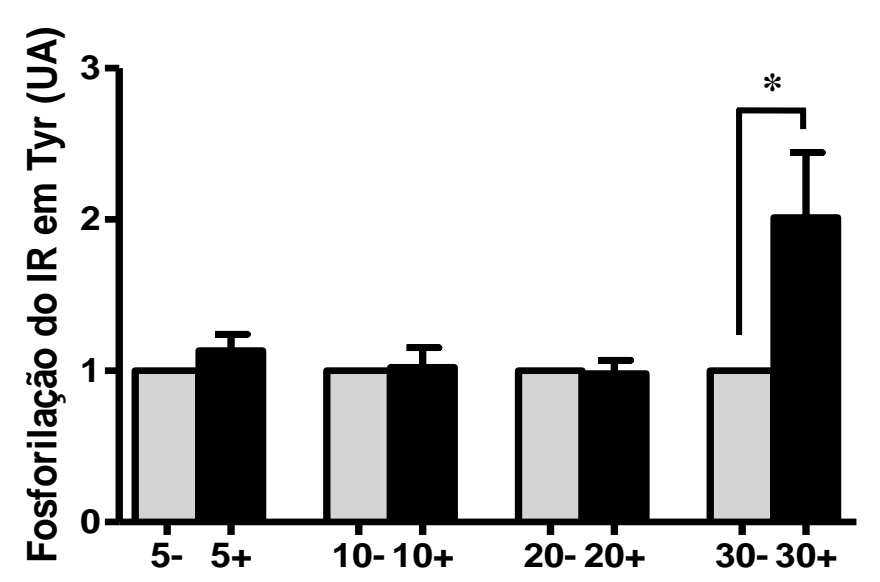

B)

$$
5 \text { min } \quad 10 \min \quad 20 \min \quad 30 \text { min }
$$

$1.5 \mathrm{~min}$

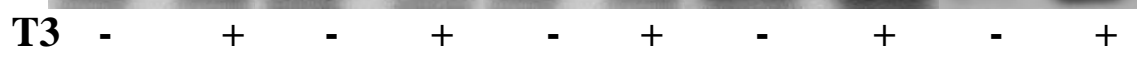

Insulina -

D)

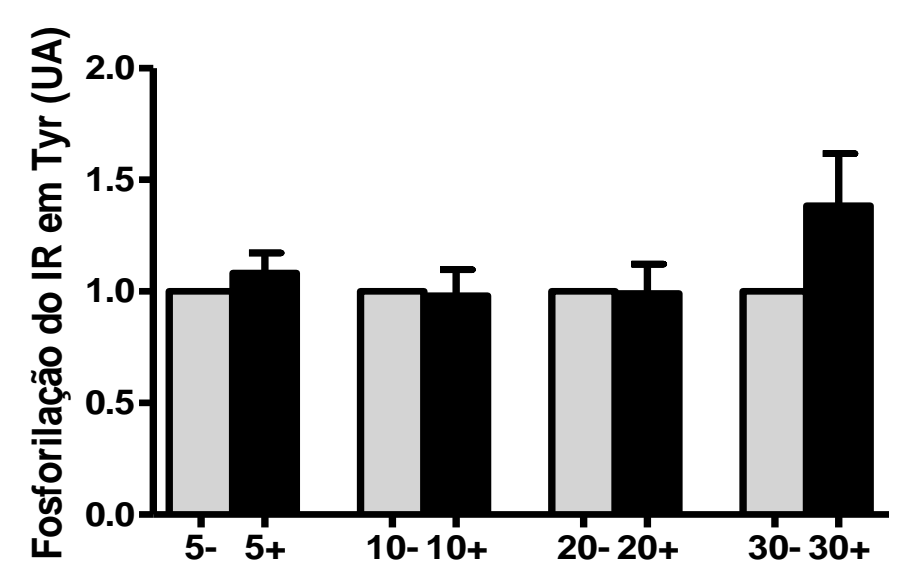

Figura 9 - 1) Imagem representativa da auto-radiografia das bandas referentes à fosforilação do receptor de insulina (IR) no músculo EDL (A) e Soleus (B) de ratos hipotiroideos antes (-) e após (+) 5, 10, 20, 30 e 1,5 minutos da administração de T3 na dose de 1,5 $\mu \mathrm{g} / 100 \mathrm{~g}$ de peso corporal e de insulina (1U) respectivamente. 2) Representação gráfica da fosforilação do receptor de insulina (IR) no músculo EDL (C) e Soleus (D) de ratos hipotiroideos antes (-) e após (+) 5, 10, 20 e 30 minutos da administração de T3 na dose de 1,5 $\mu \mathrm{g} / 100 \mathrm{~g}$ de peso corporal, e.v. Os dados estão expressos pela média \pm SEM e foram avaliados utilizando-se o Teste $T$ de Student (pareado). $\mathrm{O}$ valor de 1 foi atribuído à condição basal, * $\mathrm{p}<0,05(\mathrm{n}=8)$. 
1)

\begin{tabular}{|c|c|c|c|c|c|}
\hline A) & $5 \mathrm{~min}$ & $10 \mathrm{~min}$ & $20 \mathrm{~min}$ & $30 \mathrm{~min}$ & $1.5 \mathrm{~min}$ \\
\hline $\mathbf{T 3}$ & + & + & + & + & + \\
\hline Insulina & - & - & - & - & + \\
\hline
\end{tabular}

B)

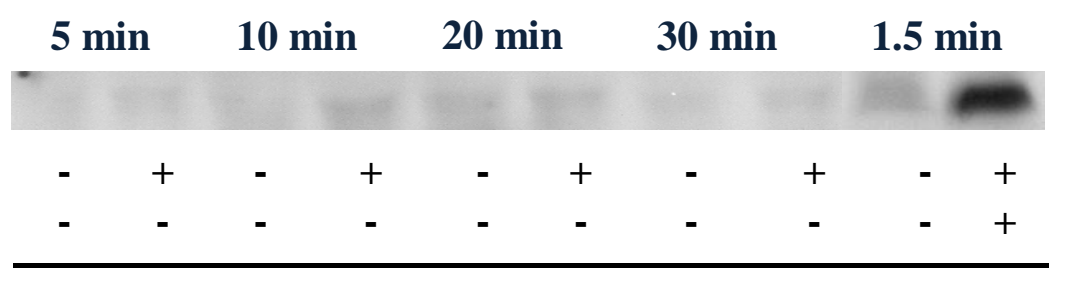

2)

C)

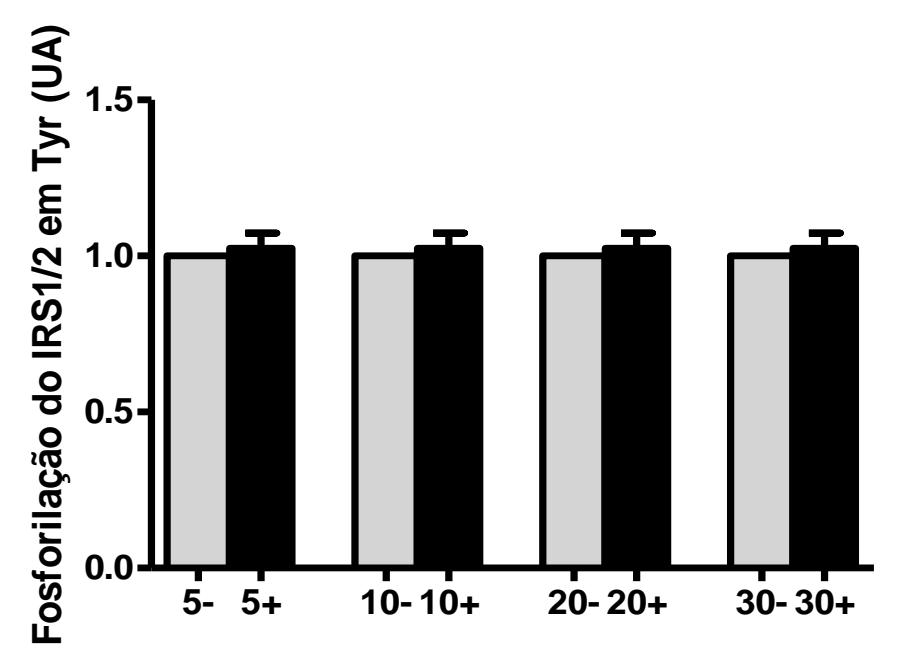

D)

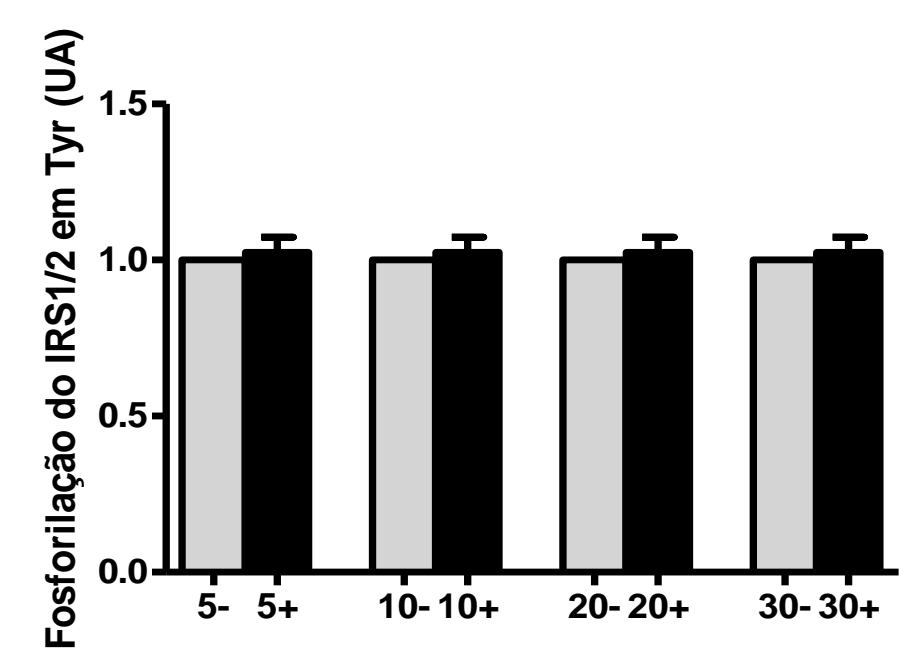

Figura 10 - 1) Imagem representativa da auto-radiografia das bandas referentes à fosforilação do substrato do receptor de insulina (IRS1/2) no músculo EDL (A) e Soleus (B) de ratos hipotiroideos antes (-) e após (+) 5, 10, 20, 30 e 1,5 minutos da administração de T3 na dose de $1,5 \mu \mathrm{g} / 100 \mathrm{~g}$ de peso corporal e de insulina (1U) respectivamente. 2) Representação gráfica da fosforilação do substrato do receptor de insulina (IRS1/2) no músculo EDL (C) e Soleus (D) de ratos hipotiroideos antes (-) e após (+) 5, 10, 20 e 30 minutos da administração de T3 na dose de 1,5 $\mu \mathrm{g} / 100 \mathrm{~g}$ de peso corporal, e.v. Os dados estão expressos pela média \pm SEM e foram avaliados utilizando-se o Teste $T$ de Student (pareado). $\mathrm{O}$ valor de 1 foi atribuído à condição basal $(\mathrm{n}=8)$. 
1)

A)

\begin{tabular}{|c|c|c|c|c|c|c|}
\hline \multirow[t]{2}{*}{$5 \mathrm{~min}$} & \multicolumn{2}{|c|}{$10 \mathrm{~min}$} & \multicolumn{2}{|c|}{$20 \mathrm{~min}$} & \multicolumn{2}{|c|}{$30 \mathrm{~min}$} \\
\hline & $=$ & $=$ & $=$ & $=$ & $=$ & $=$ \\
\hline+ & - & + & - & + & - & + \\
\hline
\end{tabular}

2)

C)

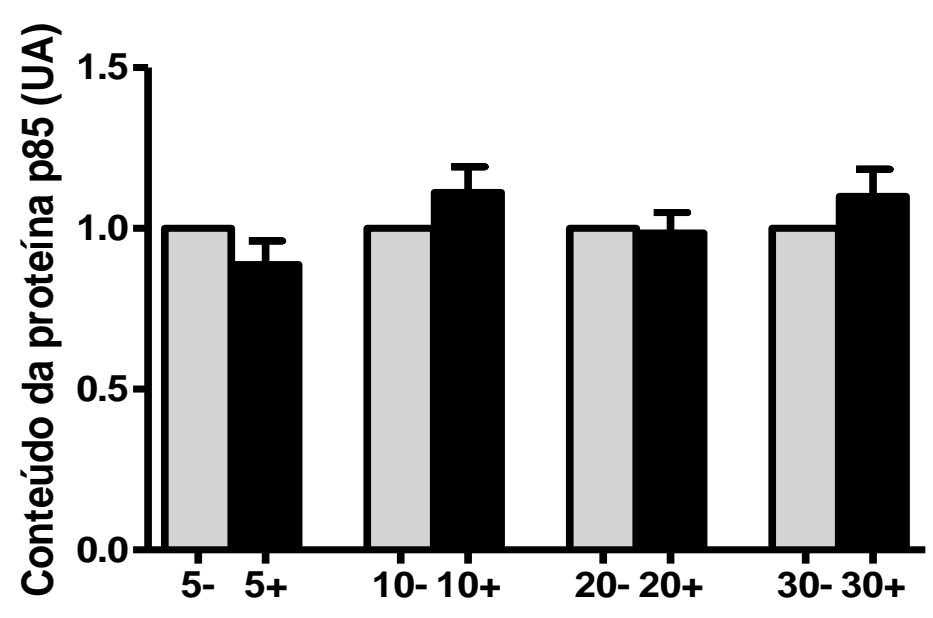

B)

\begin{tabular}{|c|c|c|c|c|c|c|}
\hline 5 min & & 10 min & & & 30 I & \\
\hline - & -1 & - & - & $=$ & - & - \\
\hline - & - & + & - & + & - & + \\
\hline
\end{tabular}

D)

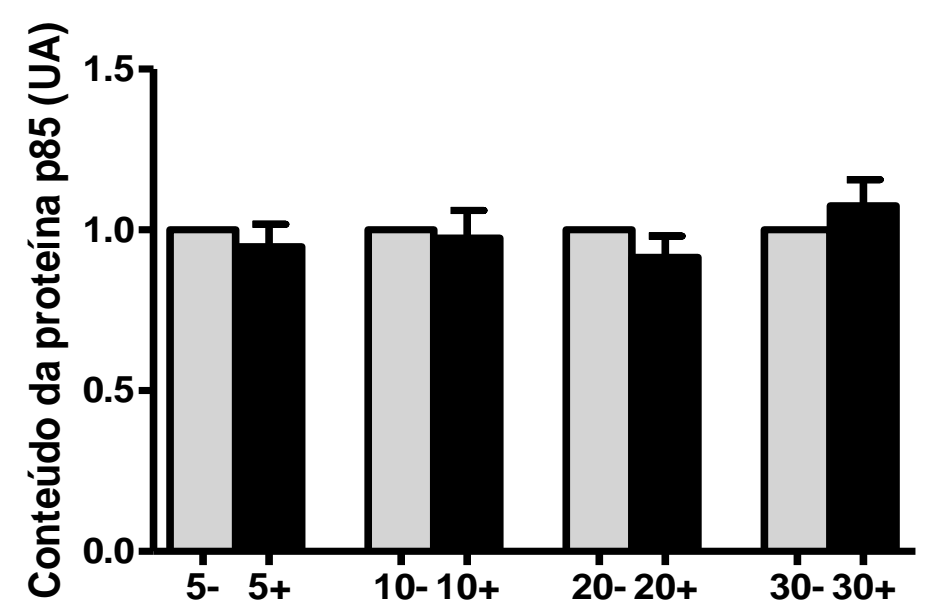

Figura 11 - 1) Imagem representativa da auto-radiografia das bandas referentes ao conteúdo da proteína p85 no músculo EDL (A) e Soleus (B) de ratos hipotiroideos antes (-) e após (+) 5, 10, 20, 30 minutos da administração de T3 na dose de 1,5 $\mu \mathrm{g} / 100 \mathrm{~g}$ de peso corporal. 2) Representação gráfica do conteúdo da proteína p85 no músculo EDL (C) e Soleus (D) de ratos hipotiroideos antes (-) e após (+) 5, 10, 20 e 30 minutos da administração de T3 na dose de $1,5 \mu \mathrm{g} / 100 \mathrm{~g}$ de peso corporal, e.v. Os dados estão expressos pela média \pm SEM e foram avaliados utilizando-se o Teste $T$ de Student (pareado). $\mathrm{O}$ valor de 1 foi atribuído à condição basal $(\mathrm{n}=8)$. 
1)

A)

$$
5 \text { min }
$$

$10 \min$

20 min

30 min

T3 $+$
$+$

$-$

$+$

B)

\begin{tabular}{|c|c|c|c|c|c|c|c|}
\hline & $5 \mathrm{~min}$ & \multicolumn{2}{|c|}{$10 \mathrm{~min}$} & \multicolumn{2}{|c|}{$20 \mathrm{~min}$} & \multicolumn{2}{|c|}{$30 \mathrm{~min}$} \\
\hline & 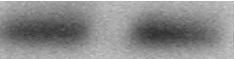 & shos: & $x+2=8$ & sen & 6hes: & wemes: & ans: \\
\hline & + & - & + & - & + & - & + \\
\hline
\end{tabular}

D)

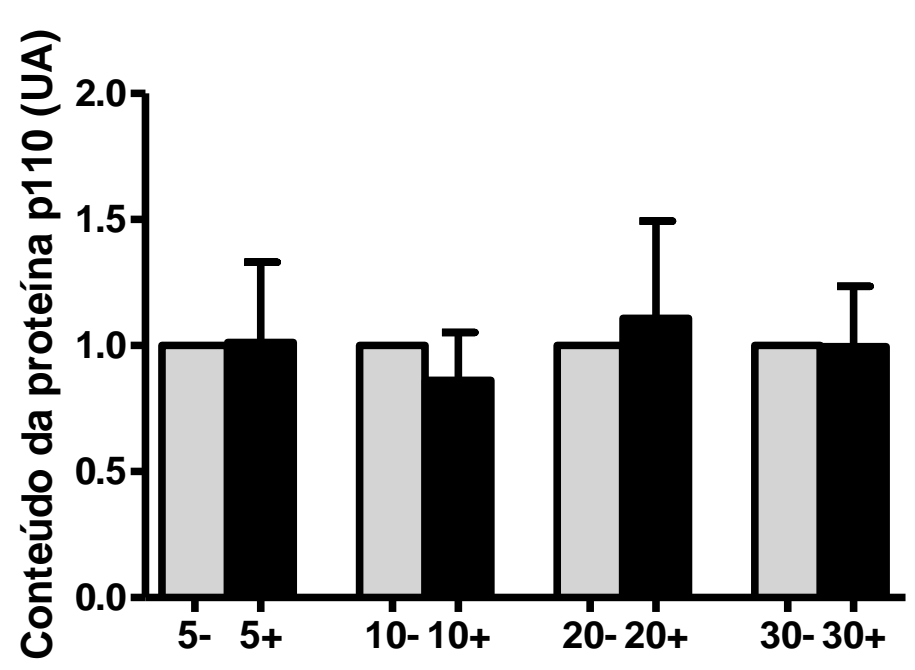

Figura 12 - 1) Imagem representativa da auto-radiografia das bandas referentes ao conteúdo da proteína p110 no músculo EDL (A) e Soleus (B) de ratos hipotiroideos antes (-) e após (+) 5, 10, 20, 30 minutos da administração de T3 na dose de 1,5 $\mu \mathrm{g} / 100 \mathrm{~g}$ de peso corporal. 2) Representação gráfica do conteúdo da proteína p110 no músculo EDL (C) e Soleus (D) de ratos hipotiroideos antes (-) e após (+) 5, 10, 20 e 30 minutos da administração de T3 na dose de $1,5 \mu \mathrm{g} / 100 \mathrm{~g}$ de peso corporal, e.v. Os dados estão expressos pela média \pm SEM e foram avaliados utilizando-se o Teste T de Student (pareado). O valor de 1 foi atribuído à condição basal $(\mathrm{n}=8)$. 
1)

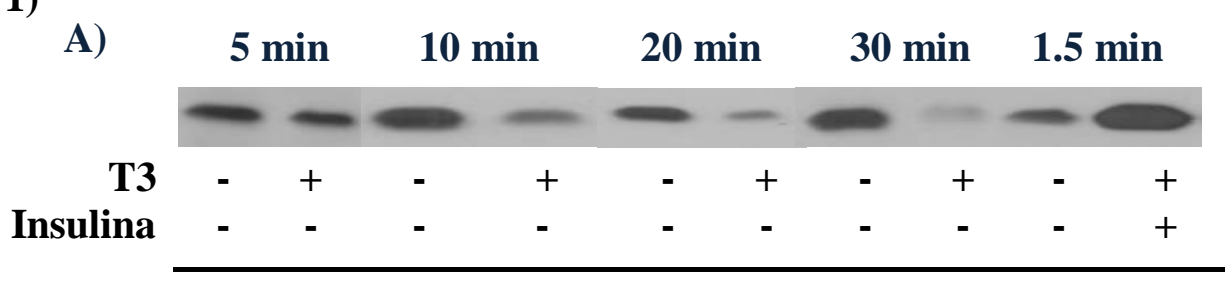

2)

C)

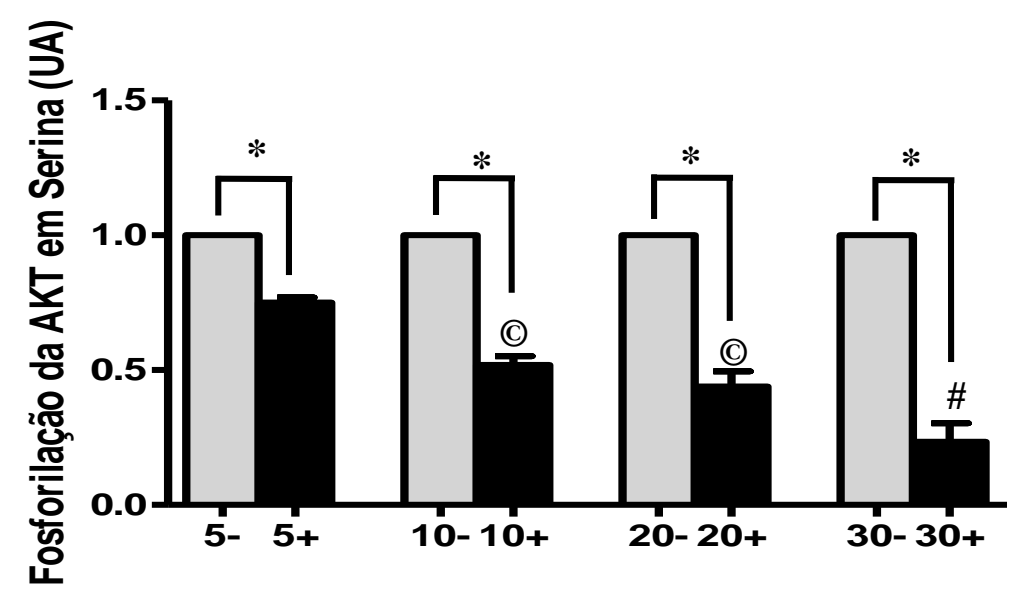

D)

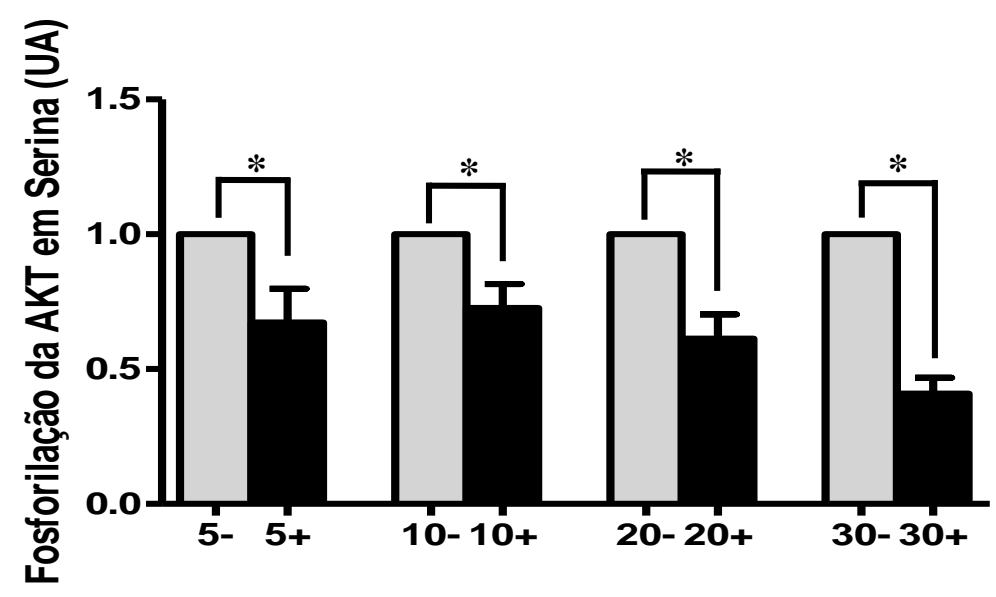

Figura 13 - 1) Imagem representativa da auto-radiografia das bandas referentes à fosforilação da AKT em serina no músculo EDL (A) e Soleus (B) de ratos hipotiroideos antes (-) e após (+) 5, 10, 20, 30 e 1,5 minutos da administração de T3 na dose de 1,5 $\mu \mathrm{g} / 100 \mathrm{~g}$ de peso corporal e de insulina (1U) respectivamente. 2) Representação gráfica da fosforilação da AKT em serina no músculo EDL (C) e Soleus (D) de ratos hipotiroideos antes (-) e após (+) 5, 10, 20 e 30 minutos da administração de T3 na dose de $1,5 \mu \mathrm{g} / 100 \mathrm{~g}$ de peso corporal, e.v. Os dados estão expressos pela média \pm SEM e foram avaliados utilizando-se o Teste T de Student (pareado), para comparações entre a condição basal (-) e tratada (+); e a análise de variância one-way ANOVA, seguida pelo teste de comparações múltiplas Newman-Keuls, para as comparações entre os grupos tratado (+). O valor de 1 foi atribuído à condição basal, * p $<0.05$, \# p $<0.05$ vs todos, $(9 \mathrm{p}<0.05$ vs $5+,(\mathrm{n}=8)$. 
1)

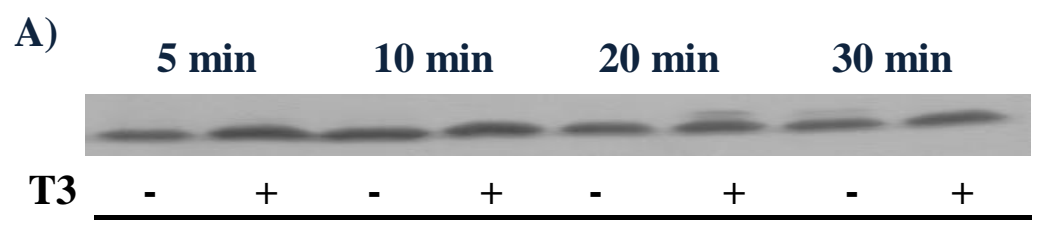

B)

\begin{tabular}{|c|c|c|c|c|c|c|c|}
\hline \multicolumn{2}{|c|}{$5 \mathrm{~min}$} & \multicolumn{2}{|c|}{$10 \mathrm{~min}$} & \multicolumn{2}{|c|}{$20 \mathrm{~min}$} & \multicolumn{2}{|c|}{$30 \mathrm{~min}$} \\
\hline- & - & $=$ & $=$ & $=$ & - & $=$ & $=$ \\
\hline- & + & - & + & - & + & - & + \\
\hline
\end{tabular}

2)

C)

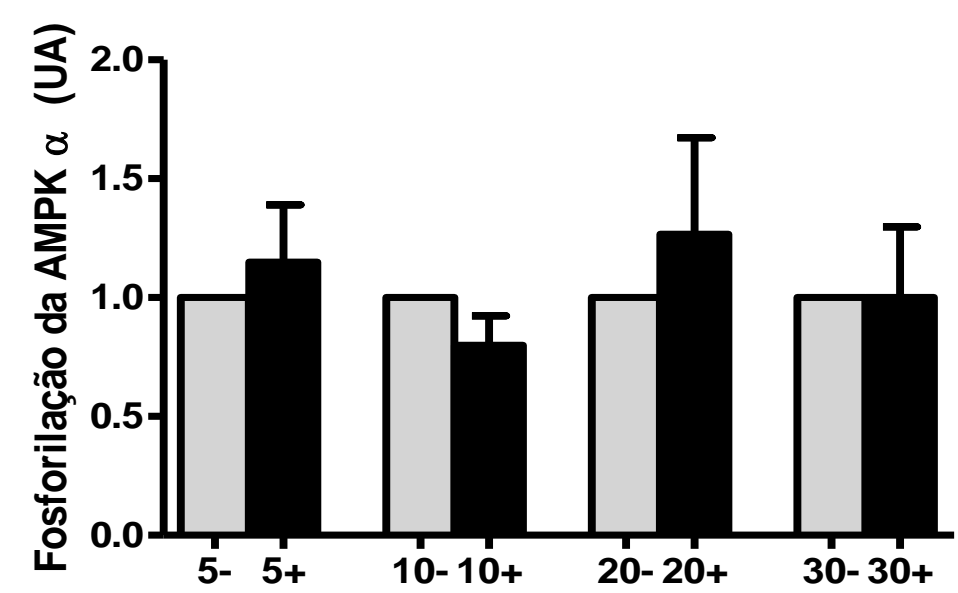

D)

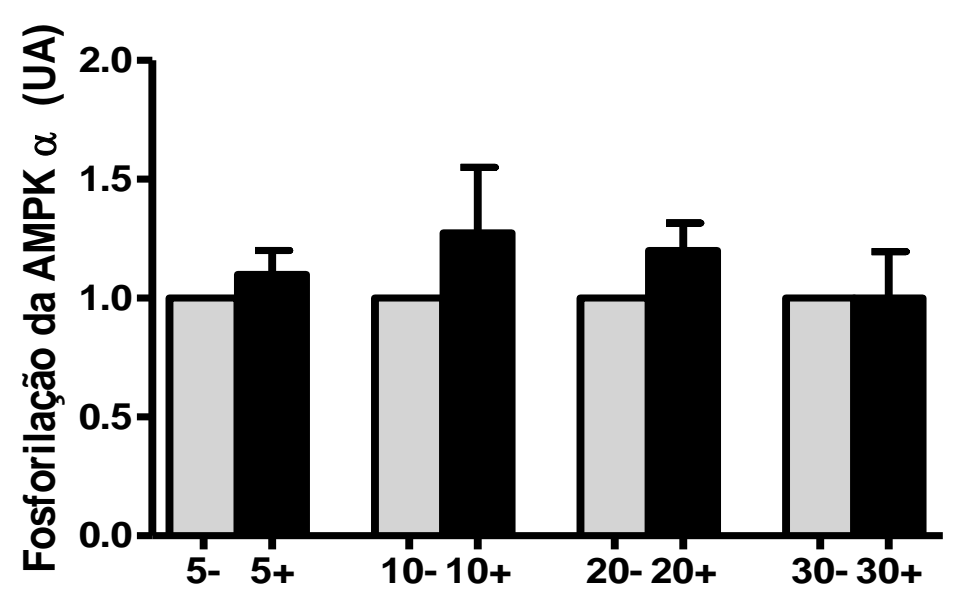

Figura 14 - 1) Imagem representativa da auto-radiografia das bandas referentes à fosforilação da AMPK $\alpha$ em Thr no músculo EDL (A) e Soleus (B) de ratos hipotiroideos antes (-) e após (+) 5, 10, 20, 30 minutos da administração de T3 na dose de 1,5 $\mu \mathrm{g} / 100 \mathrm{~g}$ de peso corporal. 2) Representação gráfica da fosforilação da AMPK $\alpha$ em Thr no músculo EDL (C) e Soleus (D) de ratos hipotiroideos antes (-) e após (+) 5, 10, 20 e 30 minutos da administração de T3 na dose de 1,5 $\mu \mathrm{g} / 100 \mathrm{~g}$ de peso corporal, e.v. Os dados estão expressos pela média \pm SEM e foram avaliados utilizando-se o Teste T de Student (pareado). O valor de 1 foi atribuído à condição basal $(\mathrm{n}=8)$. 
1)

A)

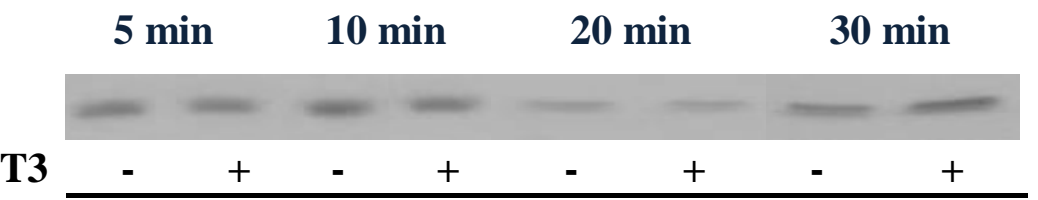

2)

C)

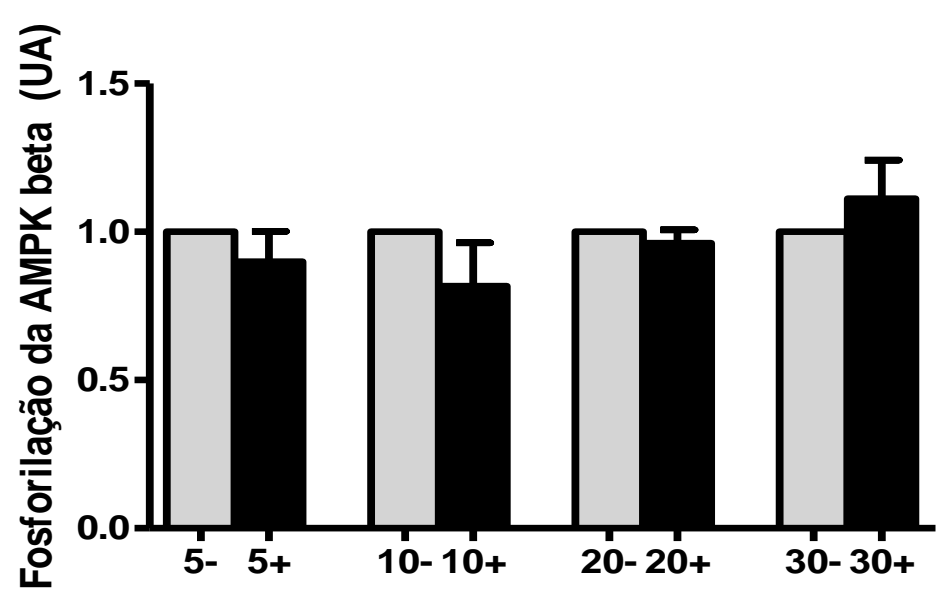

B)

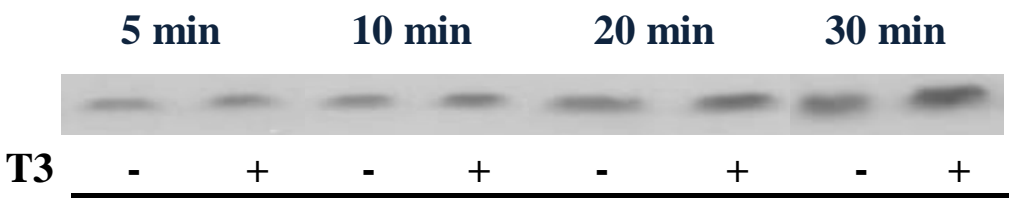

D)

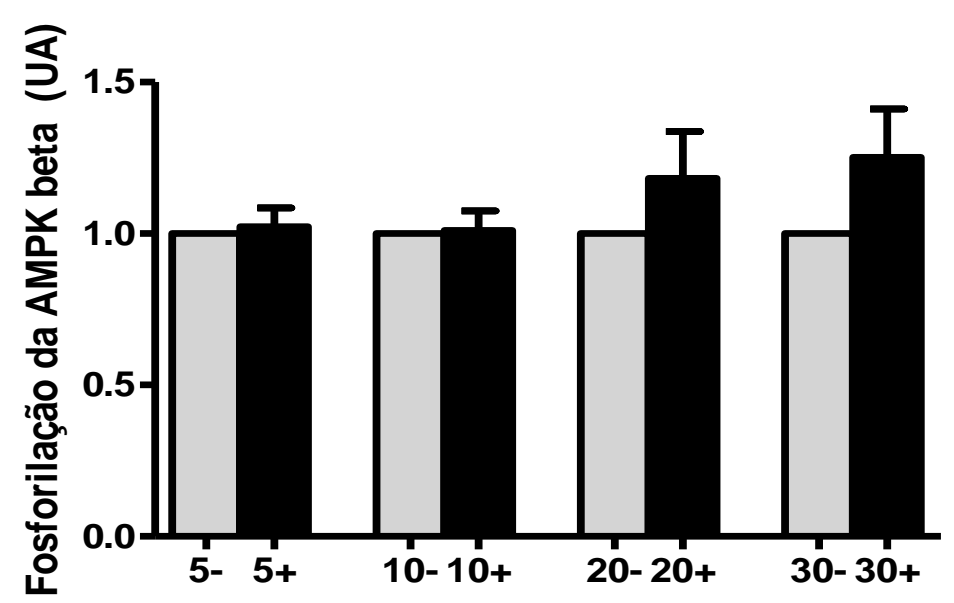

Figura 15 - 1) Imagem representativa da auto-radiografia das bandas referentes à fosforilação da AMPK $\beta$ em serina no músculo EDL (A) e Soleus (B) de ratos hipotiroideos antes (-) e após (+) 5, 10, 20, 30 minutos da administração de T3 na dose de 1,5 $\mu \mathrm{g} / 100 \mathrm{~g}$ de peso corporal. 2) Representação gráfica da fosforilação da AMPK $\beta$ em serina no músculo EDL (C) e Soleus (D) de ratos hipotiroideos antes (-) e após (+) 5, 10, 20 e 30 minutos da administração de T3 na dose de 1,5 $\mu \mathrm{g} / 100 \mathrm{~g}$ de peso corporal, e.v. Os dados estão expressos pela média \pm SEM e foram avaliados utilizando-se o Teste $T$ de Student (pareado). O valor de 1 foi atribuído à condição basal $(n=8)$. 


\subsubsection{Efeito da administração aguda de T3 sobre a concentração sérica de insulina}

Após avaliarmos a participação da via de sinalização ativada pela insulina no aumento do GLUT4 presente na membrana plasmática, nós avaliamos também se o T3 poderia aumentar rapidamente a concentração da insulina e assim, indiretamente, promover essa ação. Dessa forma, nós dosamos a concentração sérica de insulina nos animais eutiroideos, hipotiroideos (TX) e nos TX que receberam doses 5 vezes a dose fisiológica de T3 $(1.5 \mu \mathrm{g} / 100 \mathrm{~g}$ de PC) e os animais foram sacrificados 30 minutos depois. Conforme ilustrado na figura 16, a secreção de insulina encontra-se reduzida nos animais TX, quadro que não se altera com a administração de T3.

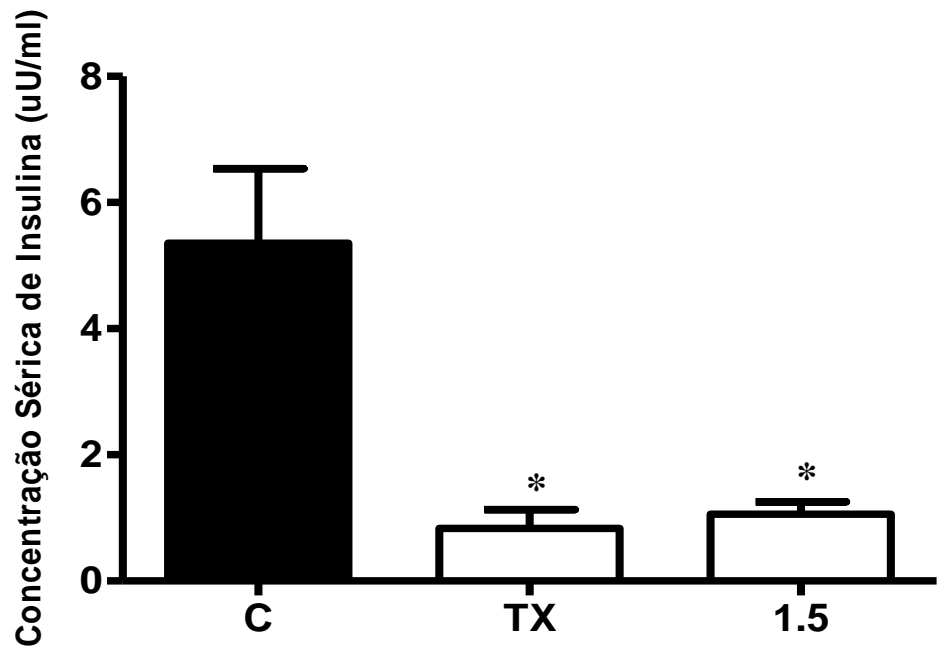

Figura 16 - Representação gráfica da concentração sérica de insulina nos animais eutiroideos (C), hipotiroideos (TX) e nos TX 30 minutos após a administração de T3 na dose de 1,5 $\mu \mathrm{g} / 100 \mathrm{~g}$ de peso corporal, e.v. Os dados estão expressos pela média \pm SEM e foram avaliados por meio da análise de variância one-way ANOVA, seguida pelo teste de comparações múltiplas Newman-Keuls, * $\mathrm{p}<0.05$ vs $\mathrm{C}(\mathrm{n}=6)$. 


\subsection{Estudo in vitro nas células L6}

\subsubsection{Aspectos morfológicos do cultivo das células L6}

Na figura 17 apresentamos as imagens obtidas (aumento de 40X) das células L6, antes (A) e após (B) 8 dias de diferenciação. Podemos observar em B a presença de células fusiformes e multinucleadas, o que as caracteriza como miotubos.

A)

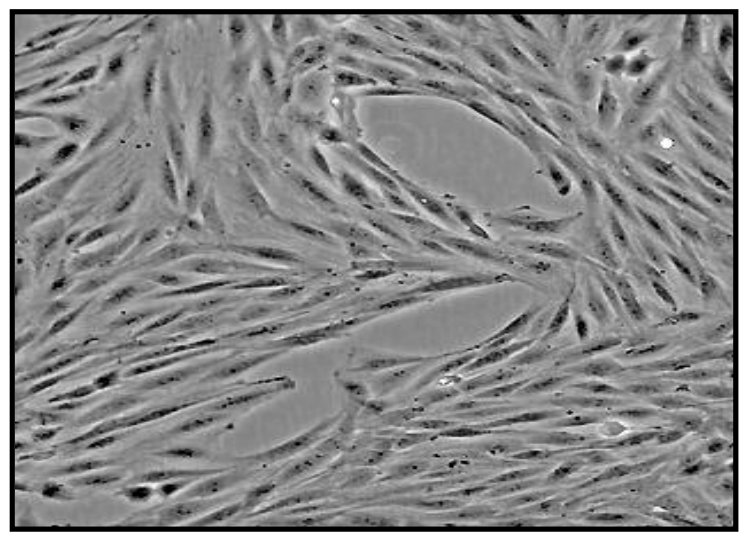

B)

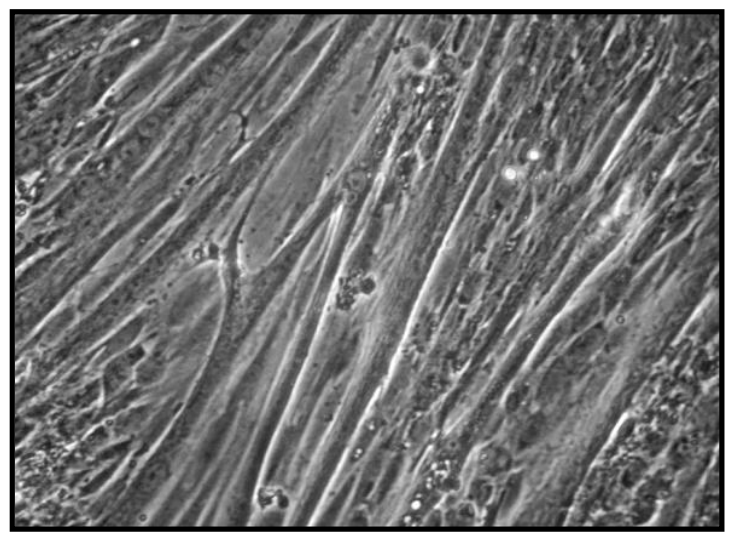

Figura 17 - Imagem das células L6. A) Células indiferenciadas (mioblastos) com $80 \%$ de confluência. B) Células L6 após 8 dias de diferenciação (miotubos).

\subsubsection{Efeito do T3 sobre o conteúdo da proteína GLUT4 nas células L6}

Assim como nos estudos in vivo, nos estudos in vitro, nós avaliamos o conteúdo total de GLUT4 (MP + M) e sua porcentagem na Membrana Plasmática (MP) após o tratamento agudo (30 minutos) com T3.

As figuras 18 e 19 apresentam, respectivamente, os dados da análise do conteúdo total de GLUT4 e da porcentagem de GLUT4 presente na membrana plasmática das células L6 submetidas à meio de cultura depletado (TX) ou não (controle) de T3. Já as figuras 20 e 21 apresentam, respectivamente, a análise do conteúdo total de GLUT4 e da porcentagem de GLUT4 presente na membrana plasmática das células L6 antes e após o tratamento com T3.

Podemos observar que a ausência de T3 provocou redução signifícativa tanto do conteúdo total de GLUT4 (figura 19), quanto da porcentagem de GLUT4 presente na membrana plasmática (figura 20). Além disso, nossos resultados demonstraram que a 
administração de T3 aumentou significativamente o conteúdo de GLUT4 presente na membrana plasmática (figura 21), embora não tenha sido capaz de aumentar o conteúdo total dessa proteína (figura 20).

A)

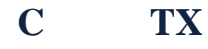

MP

M

B)

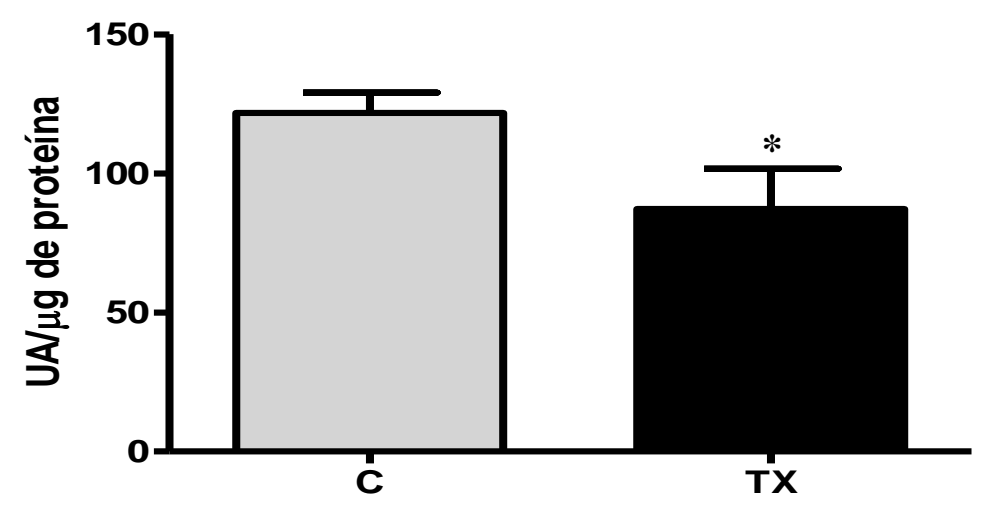

Figura 18 - A) Imagem representativa da auto-radiografia das bandas referentes ao conteúdo da proteína GLUT4 nas frações Microssomal (M) e de Membrana Plasmática (MP) nas células L6 controle $(\mathrm{C})$ e submetidas à depleção de T3 (TX). B) Representação gráfica do conteúdo total de GLUT4 nas células L6 controle (C) e submetidas à depleção de T3 (TX). Os dados estão expressos pela média \pm SEM e foram avaliados utilizando-se o Teste $T$ de Student (não pareado), * $\mathrm{p}<0.05$ vs $\mathrm{C}(\mathrm{n}=8)$. 
A)

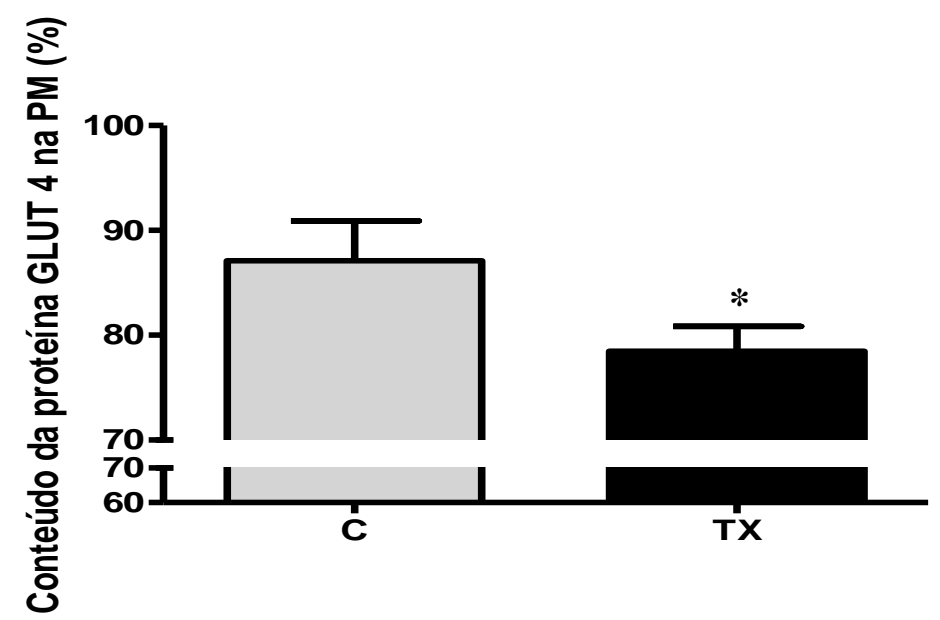

Figura 19 - Representação gráfica do conteúdo de GLUT4 na membrana plasmática das células L6 controle $(\mathrm{C})$ e submetidas à depleção de T3 (TX). Os dados estão expressos pela média \pm SEM e foram avaliados utilizando-se o Teste T de Student (não pareado), * $\mathrm{p}<0.05$ vs C $(n=8)$.

A)

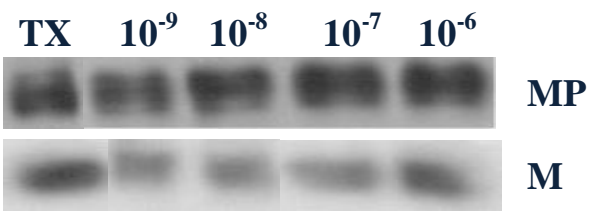

B)

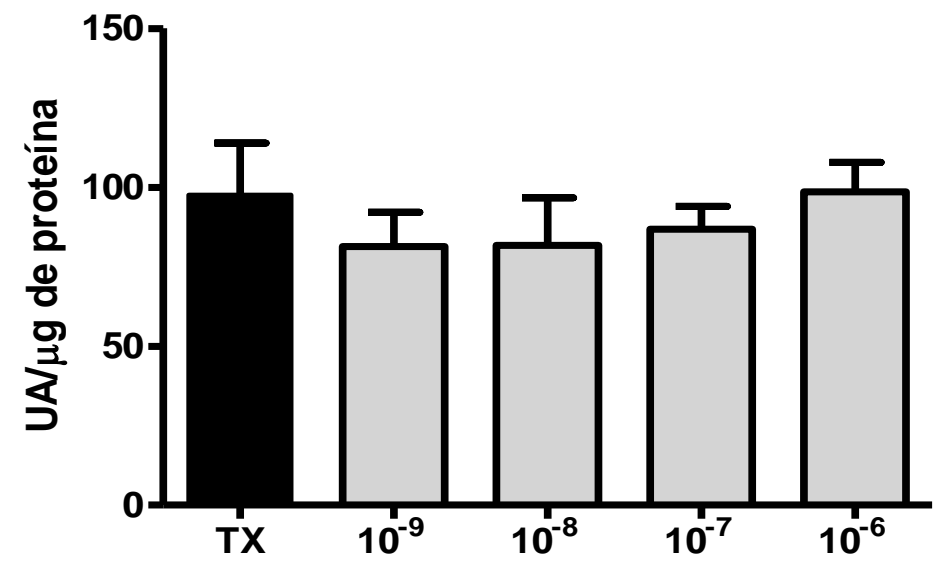

Figura 20: A) Imagem representativa da auto-radiografia das bandas referentes ao conteúdo da proteína GLUT4 nas frações Microssomal (M) e de Membrana Plasmática (MP) nas células L6 submetidas à depleção de T3 (TX) e no grupo TX que recebeu T3 nas doses $10^{-9}, 10^{-8}, 10^{-7}$ e $10^{-6} \mathrm{M}$ de T3 por 30 minutos. B) Representação gráfica do conteúdo total de GLUT4 nas células L6 submetidas à depleção de T3 (TX) e no grupo TX que recebeu T3 nas doses $10^{-9}, 10^{-8}, 10^{-7}$ e $10^{-6} \mathrm{M}$ de T3 por 30 minutos. Os dados estão expressos pela média \pm SEM e foram avaliados utilizando-se a análise de variância oneway ANOVA, seguida pelo teste de comparações múltiplas Dunnet $(\mathrm{n}=8)$. 


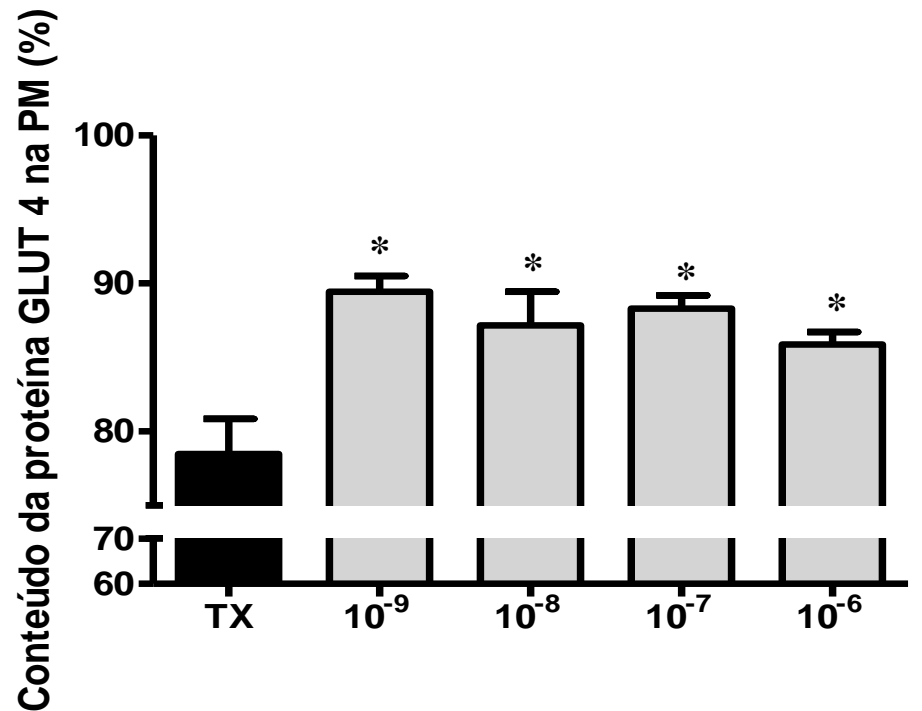

Figura 21 - Representação gráfica do conteúdo de GLUT4 na membrana plasmática das células L6 submetidas à depleção de T3 (TX) e no grupo TX que recebeu T3 nas doses $10^{-9}, 10^{-8}$, $10^{-7}$ e $10^{-6} \mathrm{M}$ de T3 por 30 minutos. Os dados estão expressos pela média \pm SEM e foram avaliados utilizando-se a análise de variância one-way ANOVA, seguida pelo teste de comparações múltiplas Dunnet, * $\mathrm{p}<0.01$ vs TX $(\mathrm{n}=8)$.

\subsubsection{Efeito do T3 sobre o conteúdo de GLUT4myc presente na MP das células L6- GLUT4myc}

Os estudos anteriores indicaram que o T3 aumentou o conteúdo de GLUT4 na membrana plasmática, e que o reduziu na fração microssomal; ou seja, demonstrou-se que houve translocação de GLUT4 em direção à membrana. No entanto para que se tenha certeza de que esse GLUT4 foi inserido na membrana, realizamos estudos nas células L6GLUT4myc, que foram construídas com esse objetivo conforme explicitado a seguir.

As células L6-GLUT4myc são células L6 transfectadas com o objetivo de superexpressar o GLUT4, em cuja primeira alça extracelular foi inserido um epítopo humano (c-myc). Essas células se diferenciam normalmente de mioblastos para miotubos, fase em que respondem à insulina com um estímulo duas vezes maior para a captação de glicose e translocação do GLUT4myc. O conteúdo de GLUT4myc nas células L6-GLUT4myc é cerca de 100 vezes superior ao do GLUT4 ou GLUT1 endógeno. Essas células respondem à insulina por fosforilação do IRS-1, ativação da PI3-K e proteína quinase B (Akt / PKB), eventos necessários para a captação de glicose estimulada pela insulina, como discutido anteriormente.

As células L6-GLUT4myc são o único modelo disponível para o estudo in vitro da captação de glicose e translocação/inserção do GLUT4 na membrana, sem que haja a 
necessidade de permeabilizar ou fracionar as células; dessa forma, essa linhagem celular nos permite realizar um ensaio colorimétrico quantitativo e altamente reprodutível.

Assim, nós utilizamos as células L6-GLUT4myc para avaliarmos a quantidade de GLUT4myc presente na membrana plasmática, por meio de um ensaio colorimétrico que detecta apenas o GLUT4 realmente inserido na membrana. Essa metodologia difere da utilizada por nós anteriormente, uma vez que o fracionamento celular não é capaz de separar o GLUT4 ancorado daquele fundido, já que, após a translocação, o GLUT4 precisa ser inserido na MP, processo que envolve alguns passos, entre eles a ancoragem e a fusão do GLUT4 na MP.

A figura 22 mostra a análise do conteúdo de GLUT4 presente na membrana plasmática das células L6-GLUT4myc submetidas à meio de cultura depletado (TX) ou não (controle) de T3, e na figura 23, a análise do conteúdo de GLUT4 presente na membrana plasmática das células L6-GLUT4myc antes e após o tratamento com T3.

Podemos observar que a ausência de T3 provocou redução no conteúdo de GLUT4 na membrana plasmática (figura 22). No entanto, nossos resultados demonstram que a administração de T3 não alterou o conteúdo de GLUT4 presente na membrana plasmática (figura 23).

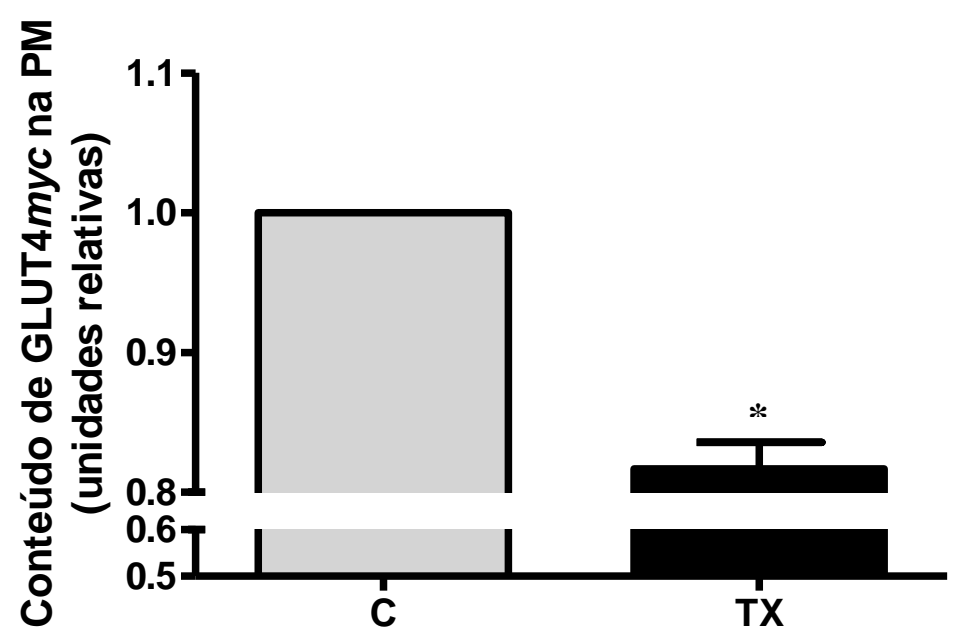

Figura 22 - Representação gráfica do conteúdo de GLUT4myc presente na membrana plasmática das células L6-GLUT4myc controle (C) e nas células submetidas à depleção de T3 (TX). Os dados estão expressos pela média \pm SEM e foram avaliados utilizando-se o Teste $T$ de Student (não pareado). O valor de 1 foi atribuído à condição basal, ${ }^{*} \mathrm{p}<0.01$ vs $\mathrm{TX}(\mathrm{n}=$ $6)$. 


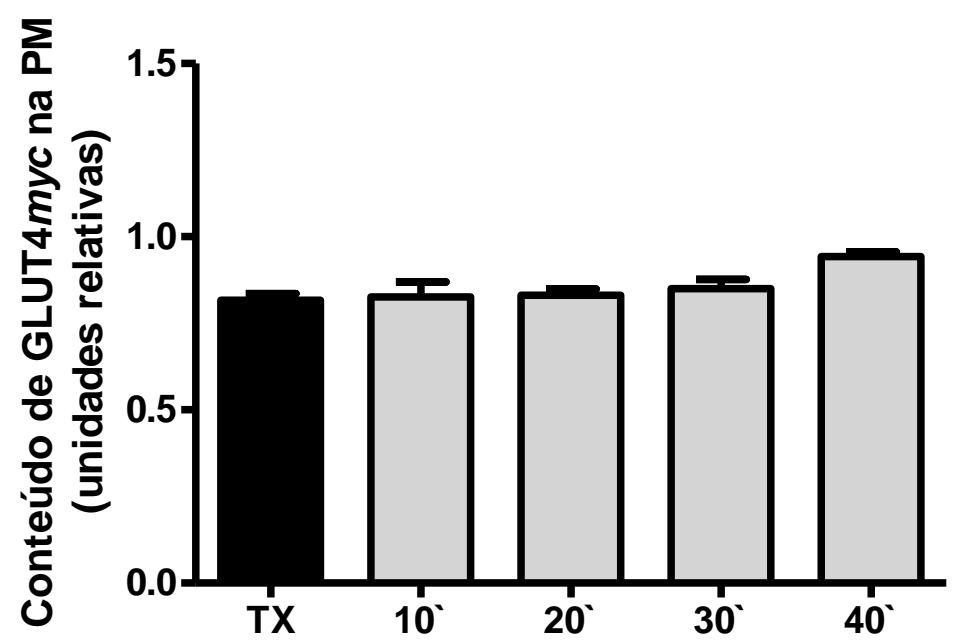

Figura 23 - Representação gráfica do conteúdo de GLUT4myc presente na membrana plasmática das células L6-GLUT4myc submetidas à depleção de T3 (TX) e no grupo TX que recebeu T3 na dose $10^{-8} \mathrm{M}$ por 10, 20, 30 e 40 minutos. Os dados estão expressos pela média \pm SEM e foram avaliados utilizando-se a análise de variância one-way ANOVA, seguida pelo teste de comparações múltiplas Dunnet, $(\mathrm{n}=7)$.

\subsubsection{Efeito do T3 sobre a captação de glicose nas células L6-GLUT4myc}

Neste estudo nós avaliamos o efeito da depleção e da administração aguda de T3 sobre a captação de glicose pelas células L6-GLUT4myc. Observou-se que na ausência do hormônio tireoidiano houve uma significativa redução na captação de glicose (figura 24), enquanto a administração de T3, já a partir de doses nanomolares, aumentou rapidamente esse parâmetro (figura 25). Utilizamos, então, a dose de $10^{-8} \mathrm{M}$ de T3 para avaliarmos, temporalmente, o efeito do hormônio sobre a captação de glicose. A figura 26 mostra que esse aumento é significativo a partir dos 30 minutos da administração de T3 $\left(10^{-8} \mathrm{M}\right)$. 


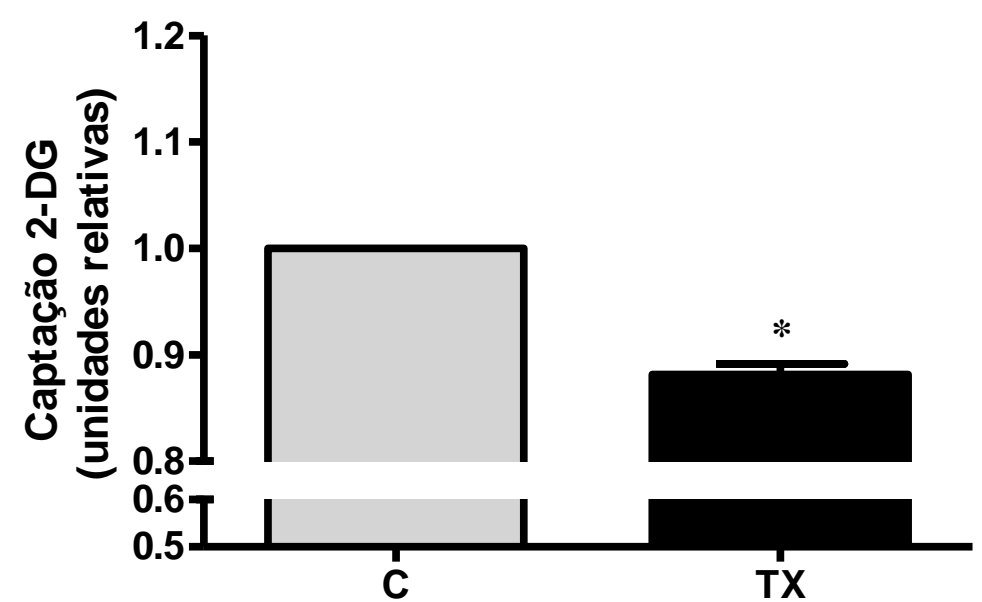

Figura 24 - Representação gráfica da captação de glicose nas células L6-GLUT4myc controle (C) e nas células submetidas à depleção de T3 (TX). Os dados estão expressos pela média \pm SEM e foram avaliados utilizando-se o Teste $T$ de Student (não pareado). O valor de 1 foi atribuído à condição basal, $* \mathrm{p}<0.05$ vs TX $(\mathrm{n}=8)$.

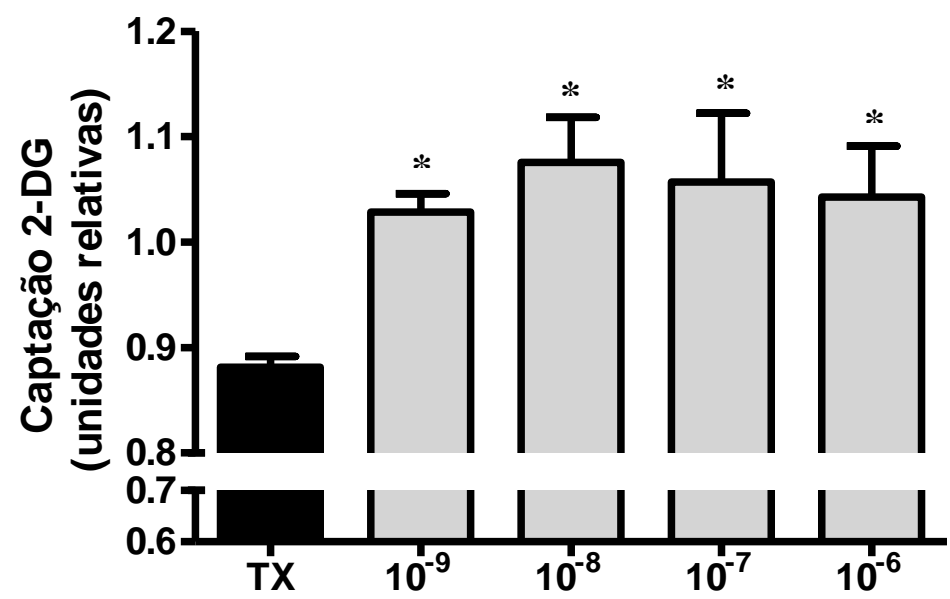

Figura 25 - Representação gráfica da captação de glicose no grupo de células L6-GLUT4myc submetidas à depleção de T3 (TX) e no grupo TX que recebeu T3 nas doses $10^{-9}, 10^{-8}$, $10^{-7}$ e $10^{-6} \mathrm{M}$ por 30 minutos. Os dados estão expressos pela média \pm SEM e foram avaliados utilizando-se a análise de variância one-way ANOVA, seguida pelo teste de comparações múltiplas Dunnet, * $\mathrm{p}<0.05$ vs TX $(\mathrm{n}=7)$. 


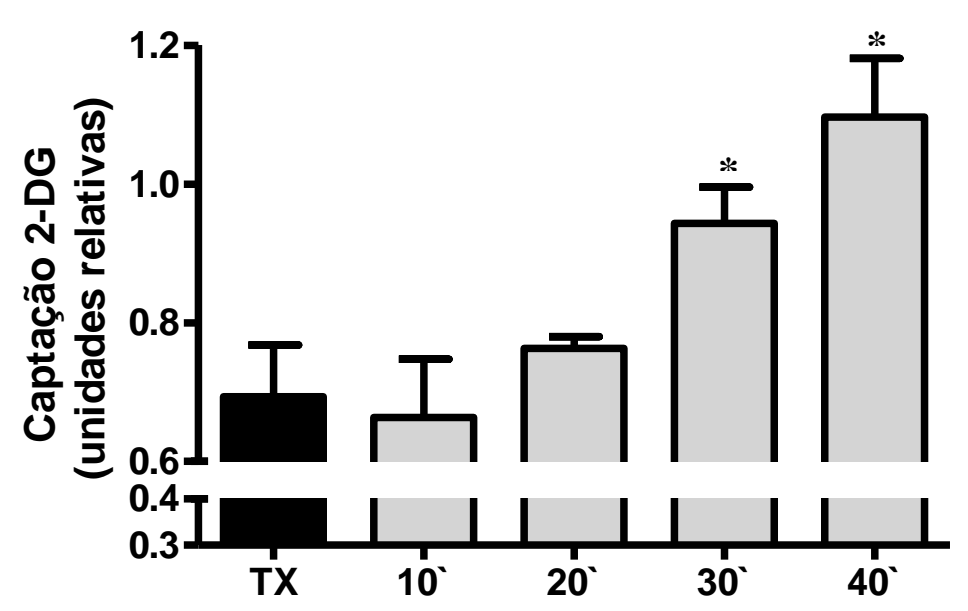

Figura 26 - Representação gráfica da captação de glicose no grupo de células L6-GLUT4myc submetidas à depleção de T3 (TX) e no grupo TX que recebeu T3 na dose $10^{-8} \mathrm{M}$ por 10 , 20, 30 e 40 minutos. Os dados estão expressos pela média \pm SEM e foram avaliados utilizando-se a análise de variância one-way ANOVA, seguida pelo teste de comparações múltiplas Dunnet * $\mathrm{p}<0.05$ vs $\mathrm{TX}(\mathrm{n}=7)$.

\subsubsection{Efeito do T3 sobre a resposta insulínica nas células L6-GLUT4myc}

Nesses experimentos, as células L6-GLUT4myc foram utilizadas para avaliação do efeito da administração conjunta de T3 e insulina sobre o conteúdo de GLUT4 presente na MP, bem como sobre a captação de glicose.

Nossos resultados demonstraram que, quando administrado juntamente com a insulina, o T3 aumenta significativamente a captação de glicose (figura 27), embora provoque uma redução no conteúdo de GLUT4 presente na MP (figura 28). Esses resultados sugerem que é possivel que outros fatores estejam envolvidos na captação de glicose estimulada pelo T3. 


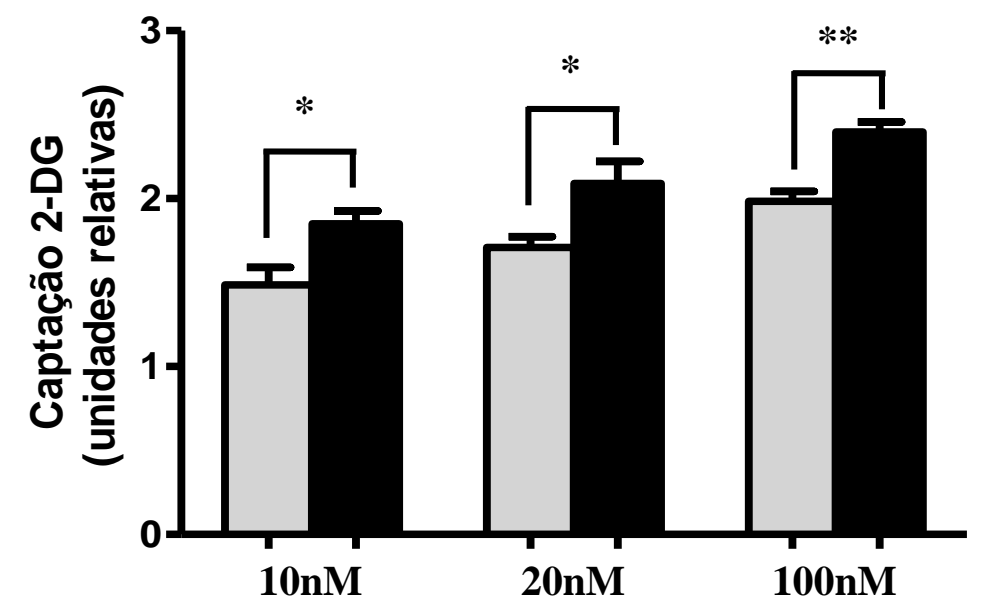

Figura 27 - Representação gráfica da captação de glicose nas células L6-GLUT4myc que foram submetidas à depleção de T3 (TX) e receberam insulina nas doses de 10, 20 e $100 \mathrm{nM}$ na ausência (cinza) ou presença (preto) de T3 na dose $10^{-8} \mathrm{M}$. Os dados estão expressos pela média \pm SEM e foram avaliados utilizando-se o Teste T de Student (não pareado), ** $\mathrm{p}<$ $0.01 \mathrm{e}^{*} \mathrm{p}<0.05(\mathrm{n}=6)$.

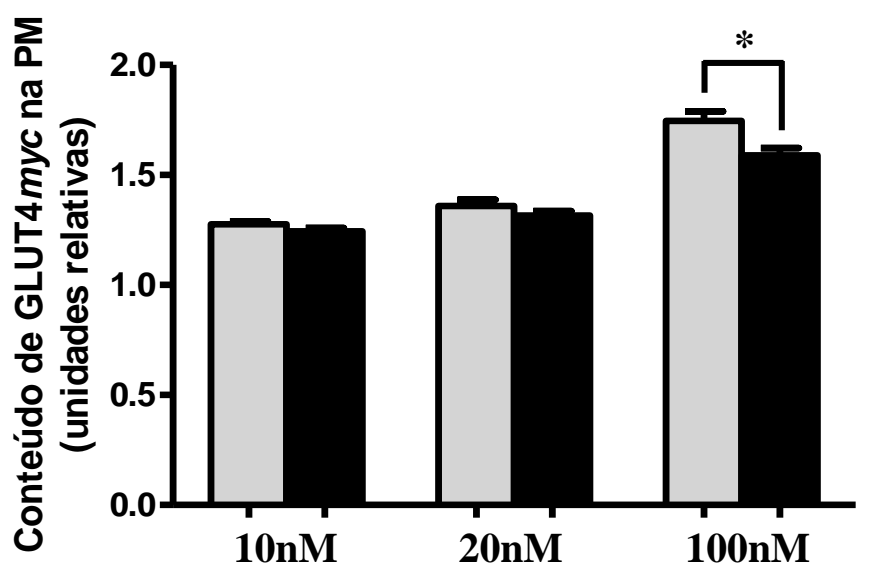

Figura 28 - Representação gráfica do conteúdo de GLUT4myc presente na membrana plasmática das células L6-GLUT4myc que foram submetidas à depleção de T3 (TX) e receberam insulina nas doses de 10, 20 e $100 \mathrm{nM}$ na ausência (cinza) ou presença (preto) de T3 na dose $10^{-8} \mathrm{M}$. Os dados estão expressos pela média \pm SEM e foram avaliados utilizandose o Teste T de Student (não pareado), ${ }^{*} \mathrm{p}<0.001(\mathrm{n}=6)$. 


\subsubsection{Efeito do tratamento com indinavir sobre a ação aguda de T3 nas células L6- GLUT4myc}

Nos experimentos mostrados, a seguir, as células L6-GLUT4myc foram tratadas com $10^{-8} \mathrm{M}$ de T3 por 30 minutos, na presença ou ausência de $100 \mu \mathrm{M}$ de indinavir, uma droga que bloqueia especificamente o GLUT4 por mecanismos ainda pouco conhecidos.

Nossos resultados demonstraram que, mesmo na presença de indinavir, o T3 aumentou significativamente a captação de glicose (figura 29). Além disso, quando avaliamos a porcentagem de inibição pelo indinavir, nossos resultados mostram que enquanto nas células controles e nas células submetidas a depleção de $\mathrm{T} 3$ a inibição foi de aproximadamente $25 \%$, nas células tratadas com T3, essa inibição foi de apenas 15\% (figura 30).

Esses resultados sugerem que a captação de glicose observada por nós 30minutos após a administração de T3 ocorre por um mecanismo independente do GLUT4. Por outro lado, estudos paralelos em que a captação de glicose após estímulo insulínico foi avaliada na presença de indinavir, mostram que a resposta à insulina foi inibida em aproximadamente 40\%. Isso faz com que a hipótese de que o GLUT4 esteja envolvido não possa ser totalmente descartada. Contudo, é possível que outro transportador de glicose, que não o GLUT4, participe nesse efeito do T3.

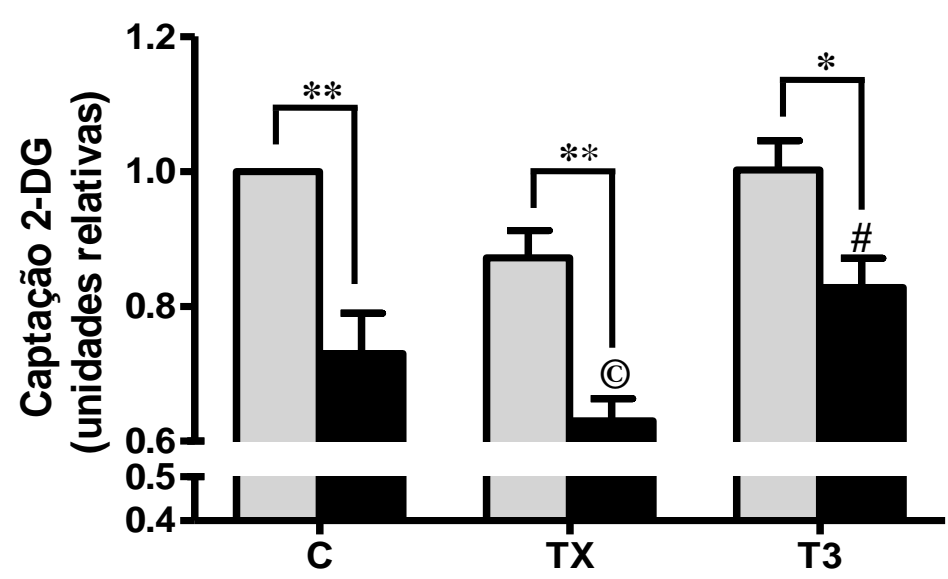

Figura 29 - Representação gráfica da captação de glicose na ausência (cinza) ou presença (preto) de $100 \mu \mathrm{M}$ de indinavir nos seguintes grupos: células L6-GLUT4myc controle (C); células submetidas à depleção de T3 (TX); células TX que receberam $10^{-8} \mathrm{M}$ de T3 por 30 minutos (T3). Os dados estão expressos pela média \pm SEM e foram avaliados utilizandose o Teste T de Student (não pareado), para comparações entre os grupos com ou sem indinavir e a análise de variância one-way ANOVA, seguida pelo teste de comparações múltiplas Newman-Keuls, para as comparações entre os grupos C, TX e T3. ** p $<0.01$, $* \mathrm{p}<0.05$, , $\mathrm{p}<0.05$ vs $\mathrm{C}, \# \mathrm{p}<0.05$ vs TX e $(\mathrm{n}=6)$. 


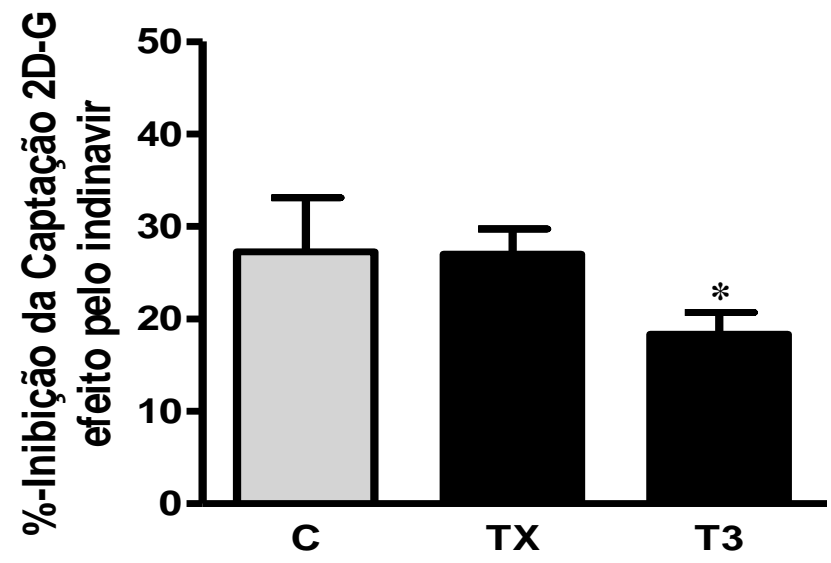

Figura 30 - Representação gráfica da porcentagem de inibição da captação de glicose pelo indinavir nos seguintes grupos: células L6-GLUT4myc controle (C); células submetidas à depleção de T3 (TX) e células TX que receberam $10^{-8} \mathrm{M}$ de T3 por 30 minutos (T3). Os dados estão expressos pela média \pm SEM, e foram avaliados utilizando-se a análise de variância one-way ANOVA, seguida pelo teste de comparações múltiplas Newman-Keuls, * p < 0.05 vs todos $(\mathrm{n}=6)$.

\subsubsection{Efeito do T3 sobre o conteúdo de GLUT1myc presente na MP das células L6- GLUT1myc}

O próximo passo foi avaliar o envolvimento do GLUT1 nesse efeito. Nesse sentido, estudos foram realizados em células L6-GLUT1myc. Essas células, assim como as células L6GLUT4myc, foram transfectadas de modo a superexpressar o GLUT1, em cuja primeira alça extracelular foi inserido um epítomo humano (c-myc). Essas células apresentam expressão de GLUT1myc superiores aos do GLUT4myc. Nós utilizamos essas células para avaliar tanto o conteúdo de GLUT1myc presente na membrana plasmática nas células controle, nas células submetidas a depleção de T3 (TX), e nas células TX tratadas com $10^{-8} \mathrm{M}$ de T3, por 30 minutos; quanto a captação de glicose nos mesmo grupos.

Observamos nas células depletadas de T3 uma significativa redução na captação de glicose e no conteúdo de GLUT1myc presente na MP (figura 31 e 32), e que a administração de T3 não restabeleceu esses parâmetros (figura 33 e 34), o que demonstra que o aumento na captação de glicose, observado 30 minutos após a administração de T3, não ocorre via GLUT1. 


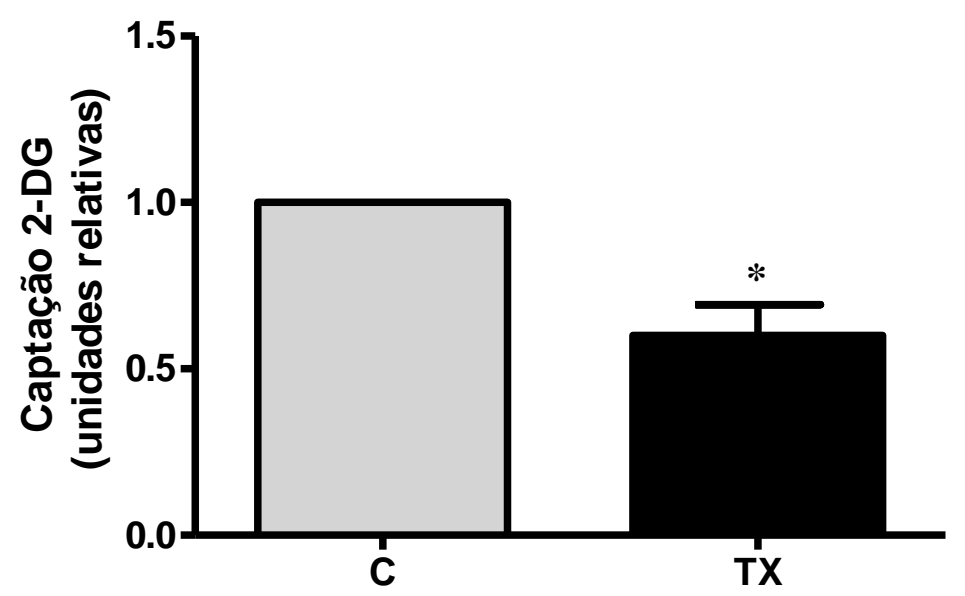

Figura 31 - Representação gráfica da captação de glicose nas células L6-GLUT1 myc controle (C) e nas células submetidas à depleção de T3 (TX). Os dados estão expressos pela média \pm SEM e foram avaliados utilizando-se o Teste T de Student (não pareado). O valor de 1 foi atribuído à condição basal, $* \mathrm{p}<0.05 v s \mathrm{TX}(\mathrm{n}=6)$.

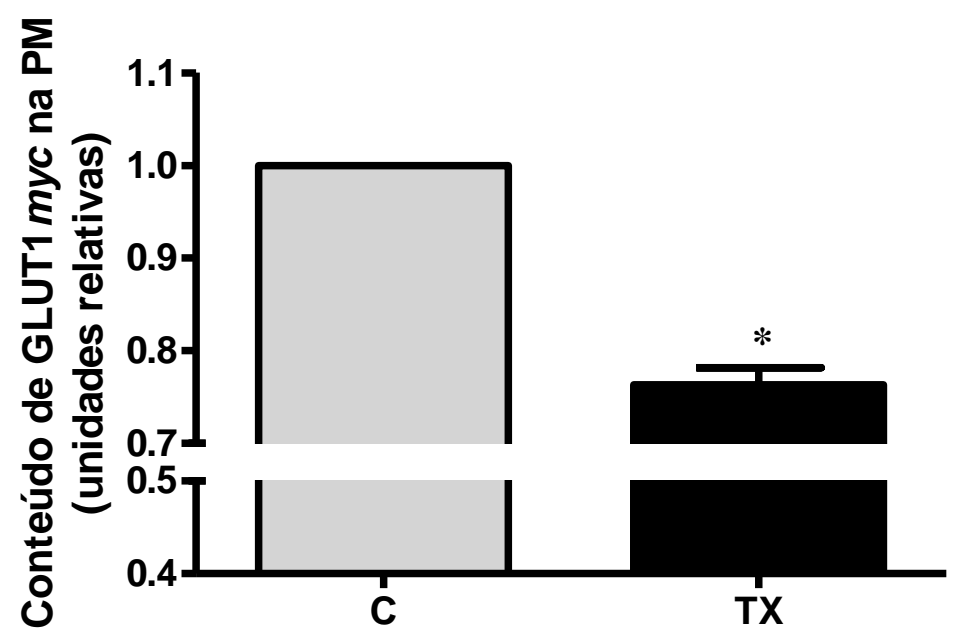

Figura 32 - Representação gráfica do conteúdo de GLUT1 myc presente na membrana plasmática das células L6-GLUT1 myc controle (C) e nas células submetidas à depleção de T3 (TX). Os dados estão expressos pela média \pm SEM e foram avaliados utilizando-se o Teste $T$ de Student (não pareado). O valor de 1 foi atribuído à condição basal, $* \mathrm{p}<0.05$ vs $\mathrm{TX}(\mathrm{n}=$ $6)$. 


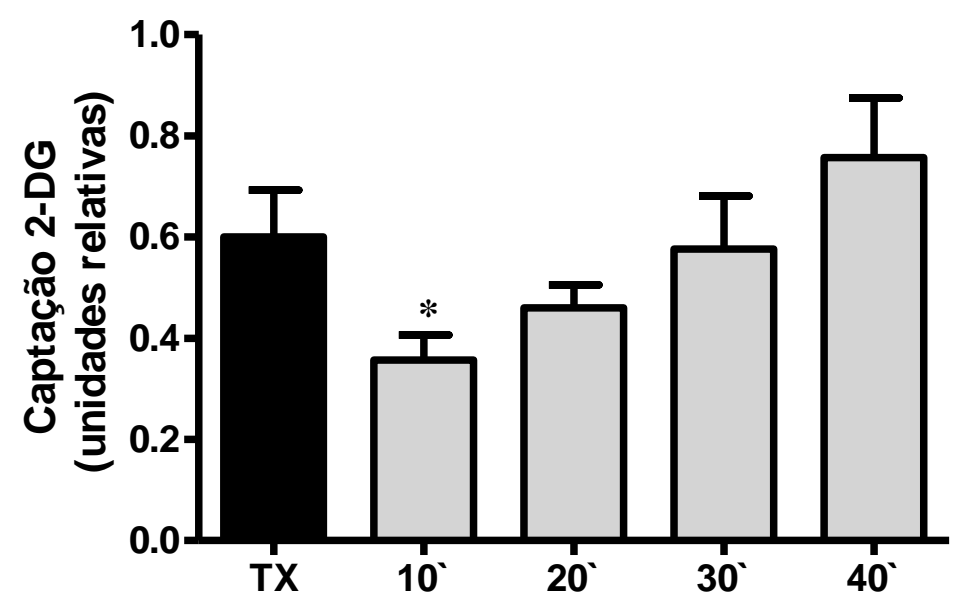

Figura 33 - Representação gráfica da captação de glicose no grupo de células L6-GLUT1myc submetidas à depleção de T3 (TX) e no grupo TX que recebeu T3 na dose $10^{-8} \mathrm{M}$ por 10 , 20,30 e 40 minutos. Os dados estão expressos pela média \pm SEM e foram avaliados utilizando-se a análise de variância one-way ANOVA, seguida pelo teste de comparações múltiplas Dunnet, * $\mathrm{p}<0.05$ vs TX $(\mathrm{n}=6)$.

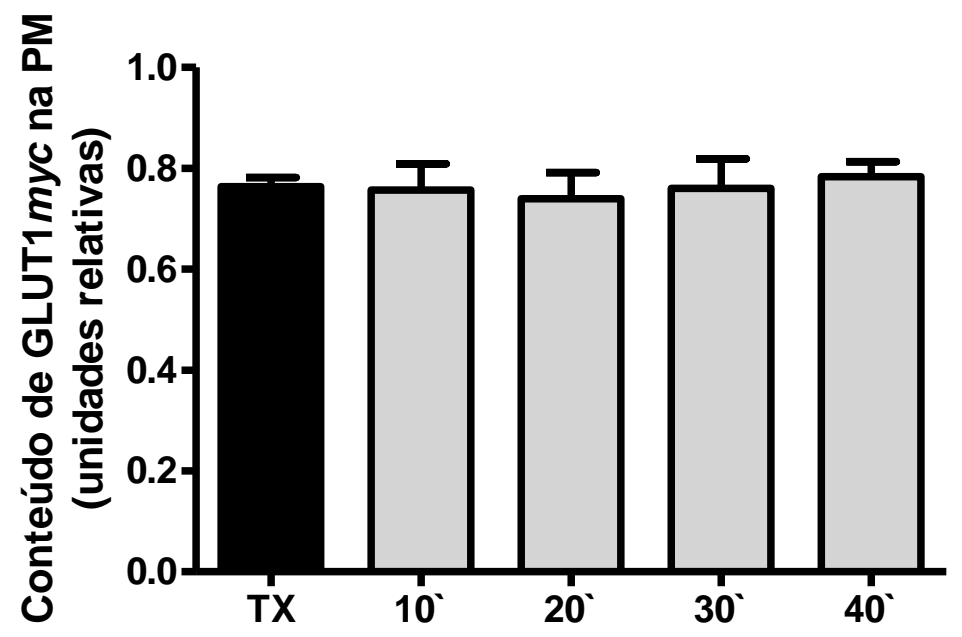

Figura 34 - Representação gráfica do conteúdo de GLUT1 myc presente na membrana plasmática das células L6-GLUT1myc submetidas à depleção de T3 (TX) e no grupo TX que recebeu T3 na dose $10^{-8} \mathrm{M}$ por 10, 20, 30 e 40 minutos. Os dados estão expressos pela média \pm SEM e foram avaliados utilizando-se a análise de variância one-way ANOVA, seguida pelo teste de comparações múltiplas Dunnet $(\mathrm{n}=3)$. 


\subsubsection{Efeito do tratamento agudo com T3 sobre o conteúdo total e a fosforilação de proteínas classicamente envolvidas na translocação do GLUT4 para a membrana plasmática em células L6-GLUT4myc}

Nossos estudos demonstraram que o T3 promove, rapidamente (30 minutos), um aumento da captação de glicose nas células L6-GLUT4myc, sem, contudo, alterar o conteúdo de GLUT4myc presente na MP.

Para tentarmos entender esse resultado aparentemente paradoxal, analisamos o grau de fosforilação de algumas proteínas sabidamente envolvidas com a translocação do GLUT4, avaliando a participação da via de sinalização ativada pela insulina, por meio da proteína AKT e da proteína AS160. Avaliamos também, o grau de fosforilação da AMPK $\alpha$, proteína envolvida com a translocação do GLUT4 em resposta à contração muscular. Além disso, avaliamos a fosforilação da proteína p38-MAPK, uma vez que alguns estudos demonstram que essa proteína teria um papel importante na ativação do GLUT4 inserido na membrana.

Embora nenhum aumento tenha sido observado na fosforilação da AKT (figura 36), podemos observar na figura 38 que, 30 minutos após a administração de T3, ocorreu um aumento na fosforilação da AS160. Nossos resultados mostram também, que a administração de T3 não foi capaz de aumentar significativamente a fosforilação da AMPK a (figura 40). Além disso, nossos resultados demonstram que o T3 aumentou rapidamente (10 minutos) a fosforilação da p38-MAPK (figura 42).

Esses resultados, juntamente com os apresentados anteriormente, sugerem que o aumento da captação de glicose observado 30 minutos após a administração de T3 possa decorrer da (a) ativação do GLUT4, processo atribuído a ativação da p38-MAPK; (b) ativação de vias diferentes das já conhecidas ou (c) por algum processo independente dessa proteína. 
1)

A)

C

TX

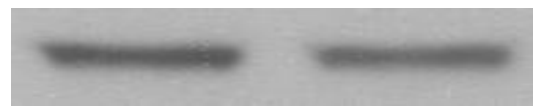

2)

C)

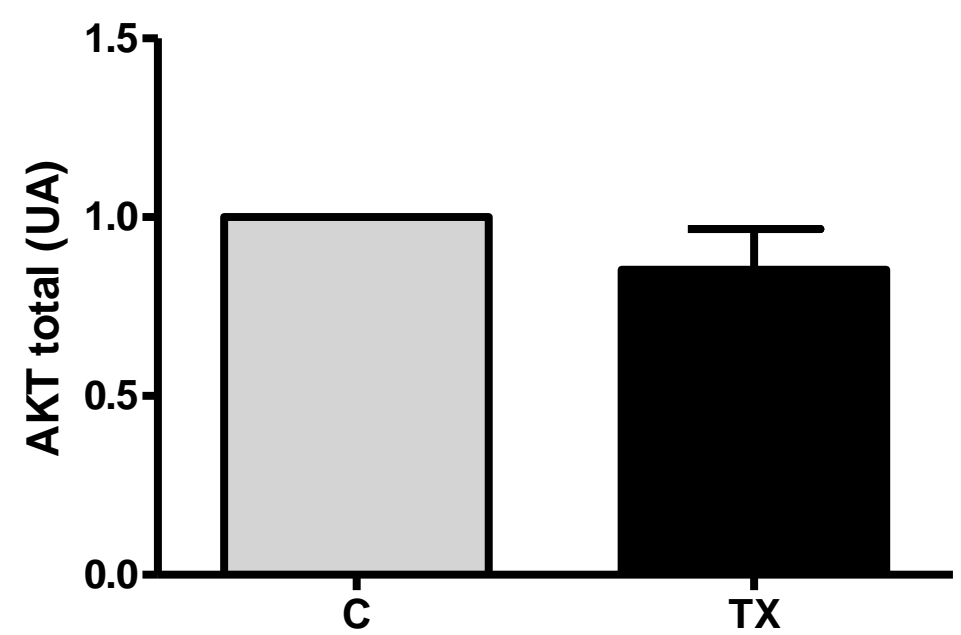

B)

C TX

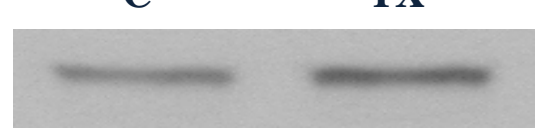

D)

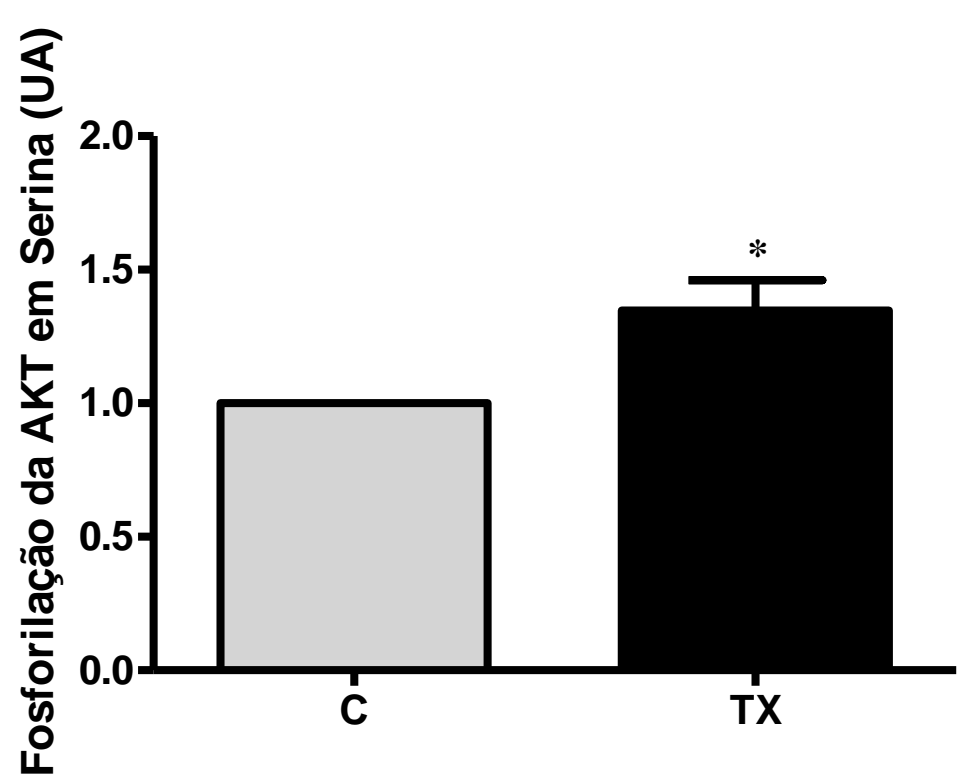

Figura 35 - 1) Imagem representativa da auto-radiografia das bandas referentes ao conteúdo da AKT total (A) e do conteúdo da AKT fosforilada em serina (B) nas células L6-GLUT4myc controle (C) e nas células submetidas à depleção de T3 (TX). 2) Representação gráfica do conteúdo da AKT total (C) e do conteúdo da AKT fosforilada em serina (D) nas células L6-GLUT4myc controle (C) e nas células submetidas à depleção de T3 (TX). Os dados estão expressos pela média \pm SEM e foram avaliados utilizando-se o Teste T de Student (não pareado). O valor de 1 foi atribuído à condição basal, * $\mathrm{p}<0.05 v s(\mathrm{n}=4)$. 
1)

A)

$$
\text { TX }
$$

$10 \mathrm{~min}$

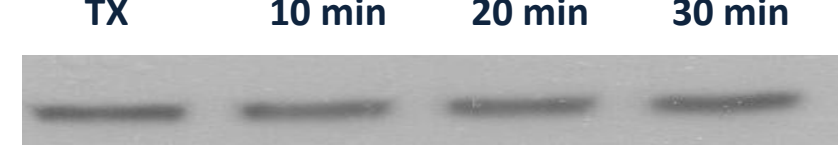

2)

C)

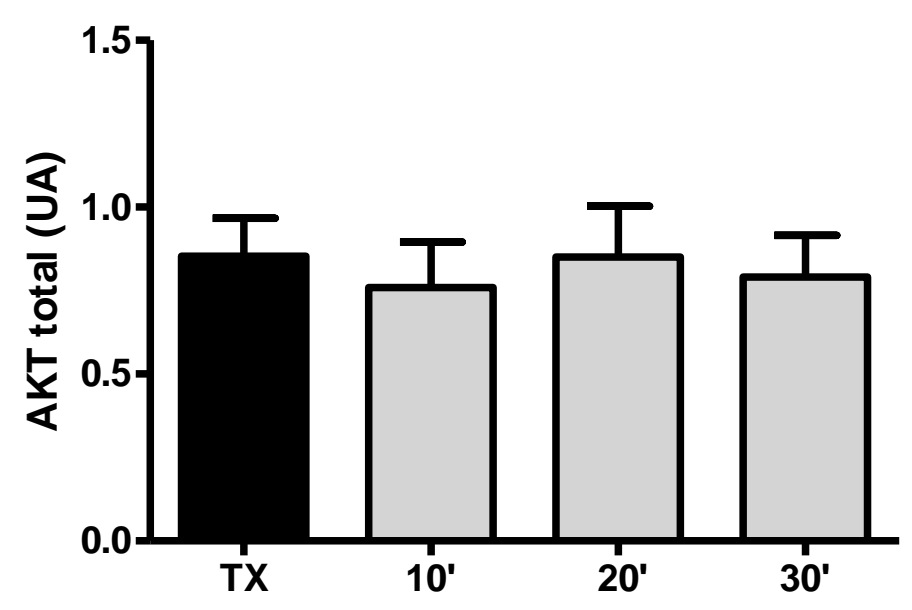

B)

TX $\quad 10 \mathrm{~min} \quad 20 \mathrm{~min} \quad 30 \mathrm{~min}$

D)

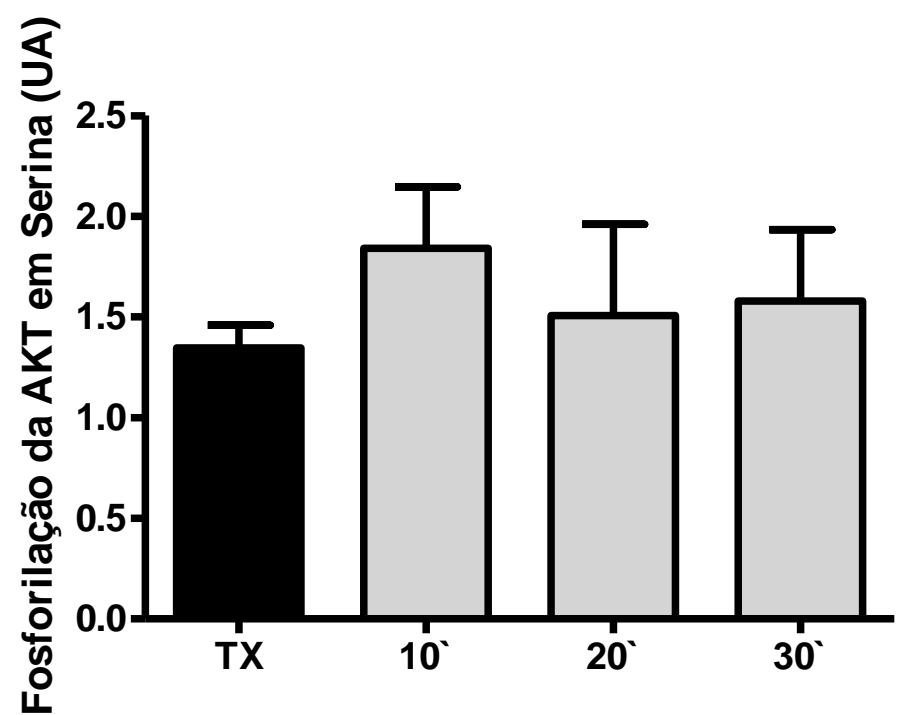

Figura 36: - 1) Imagem representativa da auto-radiografia das bandas referentes ao conteúdo da AKT total (A) e do conteúdo da AKT fosforilada em serina (B) no grupo de células L6-GLUT4myc submetidas à depleção de T3 (TX) e no grupo TX que recebeu T3 na dose $10^{-8} \mathrm{M}$ por 10, 20 e 30 minutos . 2) Representação gráfica do conteúdo da AKT total (C) e do conteúdo da AKT fosforilada em serina (D) no grupo de células L6-GLUT4myc submetidas à depleção de T3 (TX) e no grupo TX que recebeu T3 na dose $10^{-8}$ M por 10, 20 e 30 minutos. Os dados estão expressos pela média \pm SEM e foram avaliados o utilizando-se a análise de variância one-way ANOVA, seguida pelo teste de comparações múltiplas Dunnet $(\mathrm{n}=4)$. 
A)
C
TX

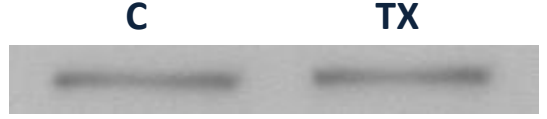

B)

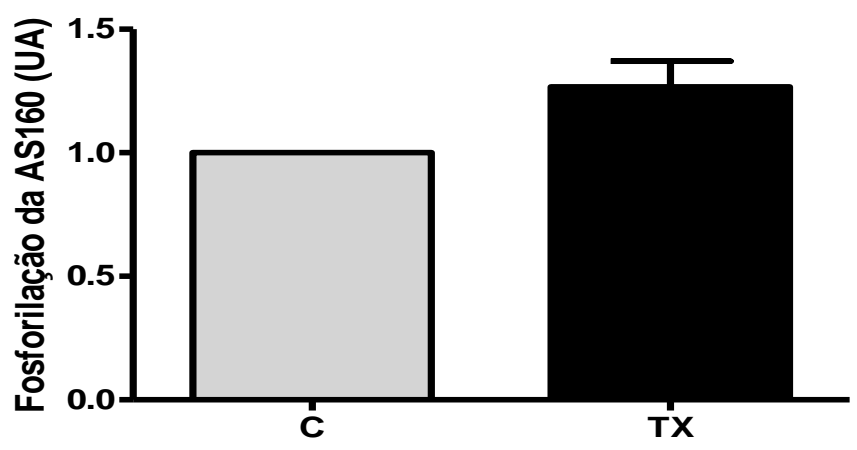

Figura 37 - A) Imagem representativa da auto-radiografia das bandas referentes ao conteúdo da proteína AS160 fosforilada nas células L6-GLUT4myc controle (C) e nas células submetidas à depleção de T3 (TX). B) Representação gráfica do conteúdo da proteína AS160 fosforilada nas células L6-GLUT4myc controle (C) e nas células submetidas à depleção de T3 (TX). Os dados estão expressos pela média \pm SEM e foram avaliados utilizando-se o Teste $T$ de Student (não pareado). O valor de 1 foi atribuído à condição basal, $(\mathrm{n}=4)$.

A)

B)
TX
$10 \mathrm{~min}$
$20 \mathrm{~min}$
$30 \mathrm{~min}$

$\longrightarrow+\frac{10 \mathrm{~min}}{-}=$

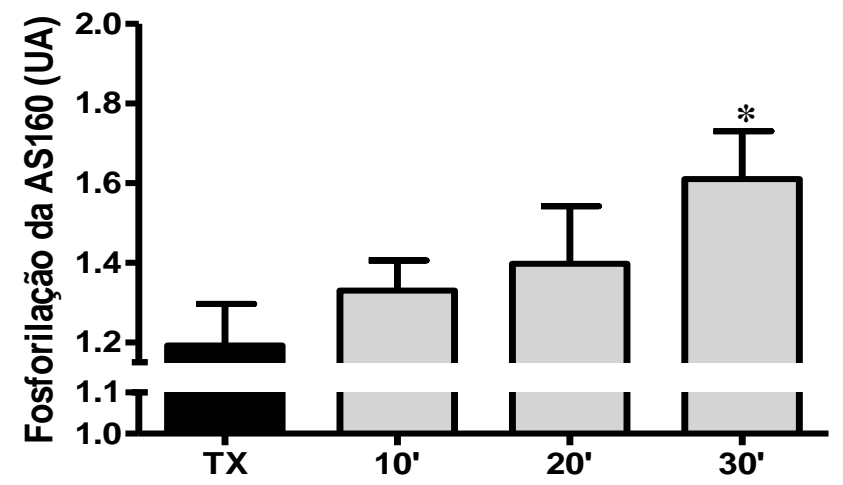

Figura 38 - A) Imagem representativa da auto-radiografia das bandas referentes ao conteúdo da proteina AS160 fosforilada no grupo de células L6-GLUT4myc submetidas à depleção de T3 (TX) e no grupo TX que recebeu T3 na dose $10^{-8} \mathrm{M}$ por 10,20 e 30 minutos . B) Representação gráfica do conteúdo da proteina AS160 fosforilada no grupo de células L6-GLUT4myc submetidas à depleção de T3 (TX) e no grupo TX que recebeu T3 na dose $10^{-8} \mathrm{M}$ por 10, 20 e 30 minutos. Os dados estão expressos pela média \pm SEM e foram avaliados utilizando-se a análise de variância one-way ANOVA, seguida pelo teste de comparações múltiplas Dunnet, ${ }^{*} \mathrm{p}<0.05$ vs TX $(\mathrm{n}=4)$. 
A)

C TX

B)

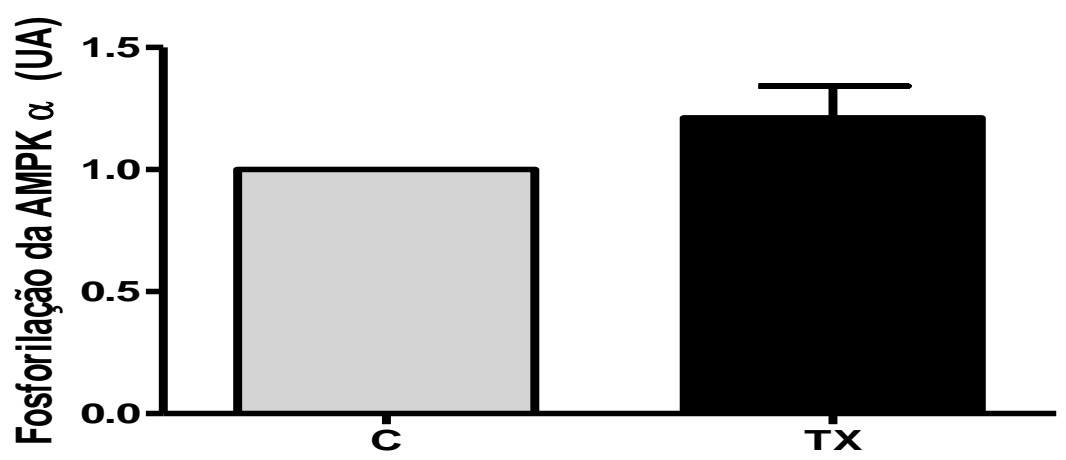

Figura 39 - A) Imagem representativa da auto-radiografia das bandas referentes ao conteúdo da AMPK $\alpha$ fosforilada nas células L6-GLUT4myc controle (C) e nas células submetidas à depleção de T3 (TX). B) Representação gráfica do conteúdo da AMPKa fosforilada nas células L6GLUT4myc controle (C) e nas células submetidas à depleção de T3 (TX). Os dados estão expressos pela média \pm SEM e foram avaliados utilizando-se o Teste $T$ de Student (não pareado). $\mathrm{O}$ valor de 1 foi atribuído à condição basal $(\mathrm{n}=4)$.

A)

TX $\quad 10 \mathrm{~min} \quad 20 \mathrm{~min} \quad 30 \mathrm{~min}$

B)

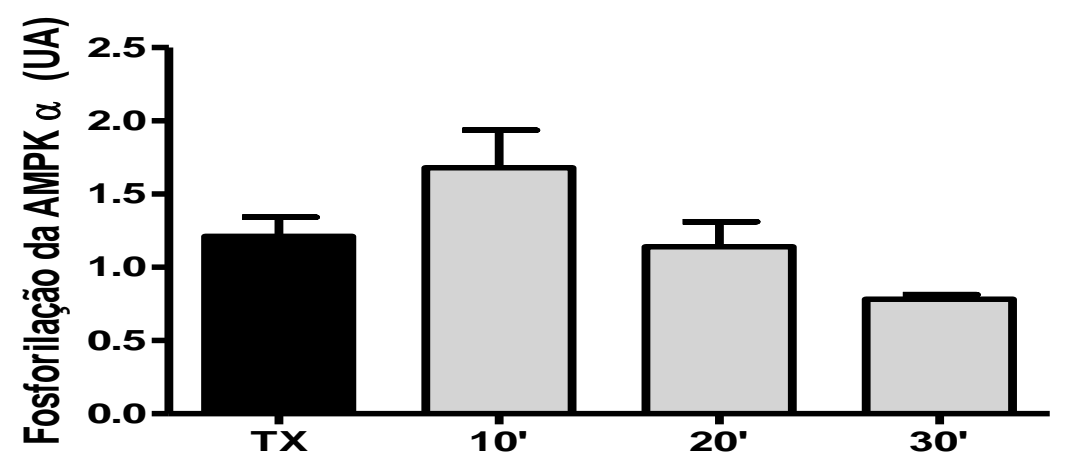

Figura 40 - A) Imagem representativa da auto-radiografia das bandas referentes ao conteúdo da AMPK $\alpha$ fosforilada no grupo de células L6-GLUT4myc submetidas à depleção de T3 (TX) e no grupo TX que recebeu T3 na dose $10^{-8} \mathrm{M}$ por 10, 20 e 30 minutos . B) Representação gráfica do conteúdo da AMPKa fosforilada no grupo de células L6-GLUT4myc submetidas à depleção de T3 (TX) e no grupo TX que recebeu T3 na dose $10^{-8} \mathrm{M}$ por 10,20 e 30 minutos Os dados estão expressos pela média \pm SEM e foram avaliados utilizando-se a análise de variância one-way ANOVA, seguida pelo teste de comparações múltiplas Dunnet, ( $(n=4)$. 
1)

A) C

TX

B)

D)

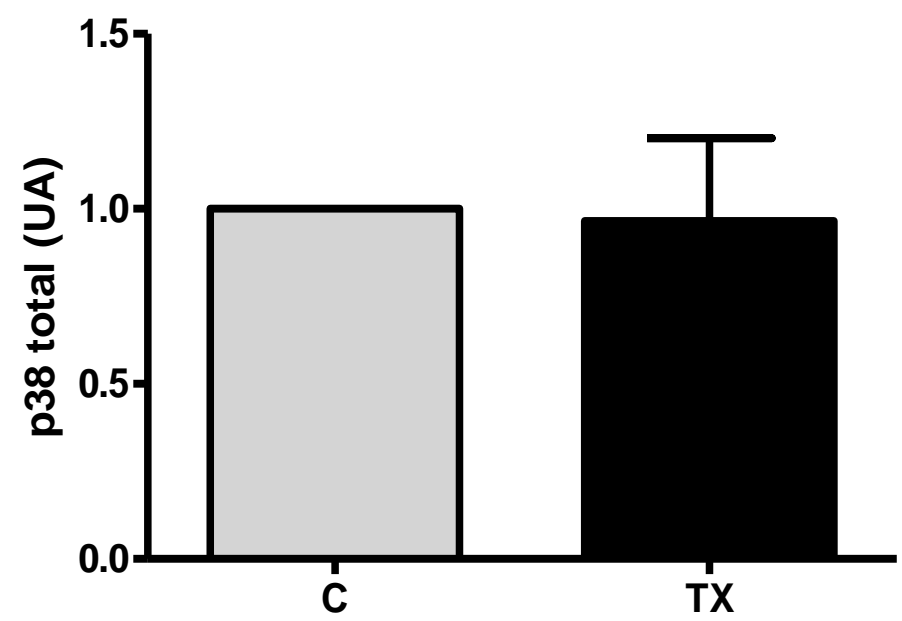

C)
C

TX

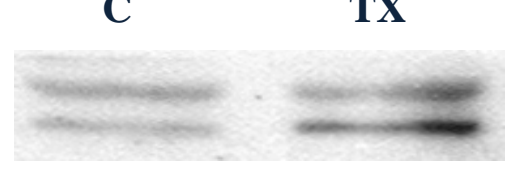

2)

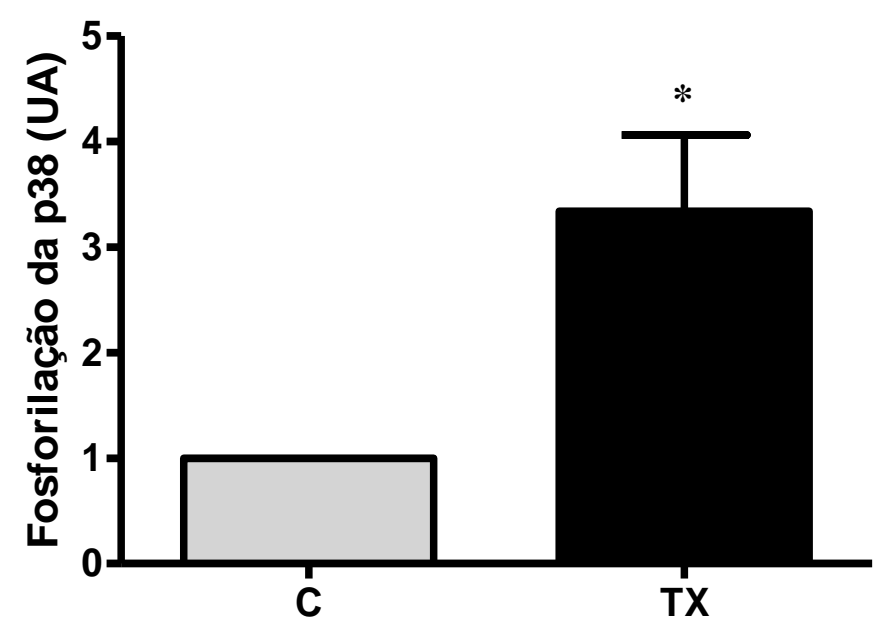

Figura 41 - 1) Imagem representativa da auto-radiografia das bandas referentes ao conteúdo da p38 total (A) e do conteúdo da p38 fosforilada (B) nas células L6-GLUT4myc controle (C) e nas células submetidas à depleção de T3 (TX). 2) Representação gráfica do conteúdo da p38 total (C) e do conteúdo da p38 fosforilada (D) nas células L6-GLUT4myc controle (C) e nas células submetidas à depleção de T3 (TX). Os dados estão expressos pela média \pm SEM e foram avaliados utilizando-se o Teste T de Student (não pareado). O valor de 1 foi atribuído à condição basal, * p< 0.05 vs TX $(\mathrm{n}=4)$. 
A)

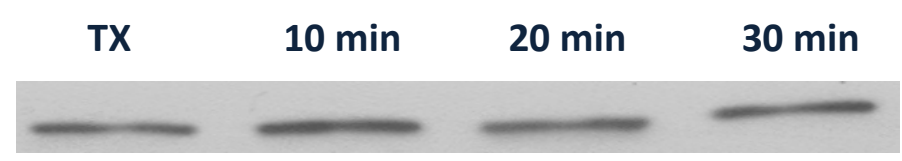

2)

C)

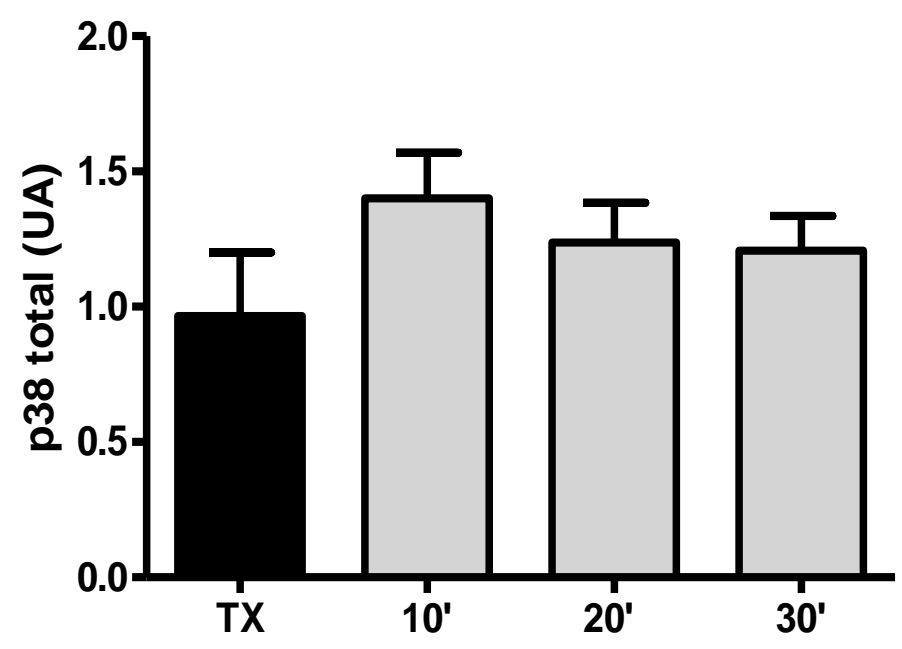

B)

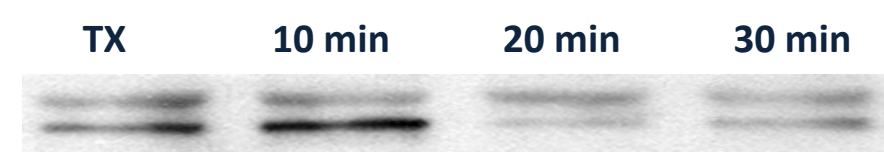

D)

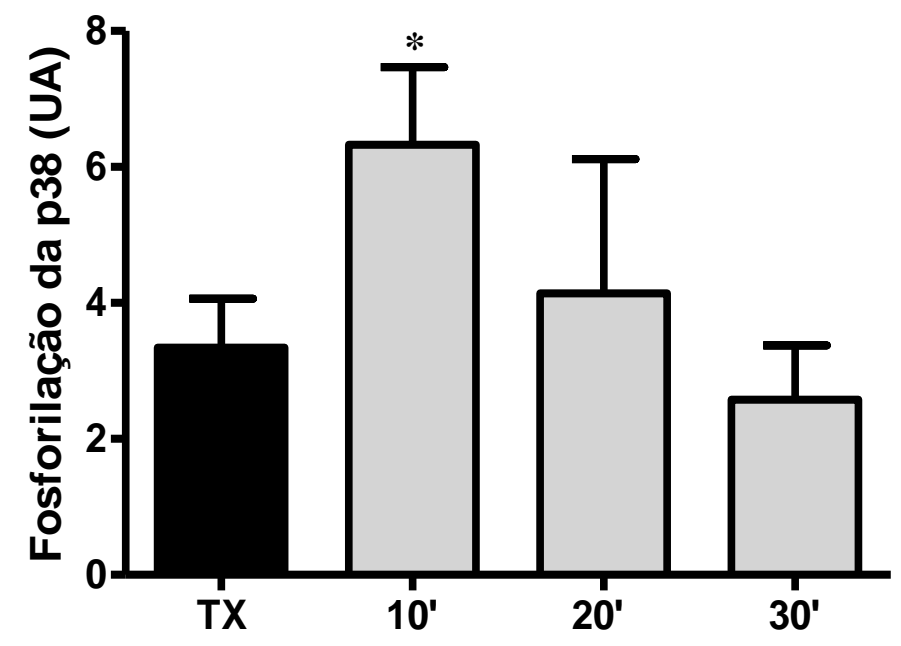

Figura 42 - 1) Imagem representativa da auto-radiografia das bandas referentes ao conteúdo da proteína p38 total (A) e do conteúdo da proteína p38 fosforilada (B) no grupo de células L6-GLUT4myc submetidas à depleção de T3 (TX) e no grupo TX que recebeu T3 na dose 10

${ }^{8}$ M por 10, 20 e 30 minutos. 2) Representação gráfica do conteúdo da proteína p38 total (C) e do conteúdo da proteína p38 fosforilada (D) no grupo de células L6-GLUT4myc submetidas à depleção de T3 (TX) e no grupo TX que recebeu T3 na dose $10^{-8} \mathrm{M}$ por 10, 20 e 30 minutos. Os dados estão expressos pela média \pm SEM e foram avaliados utilizando-se a análise de variância one-way ANOVA, seguida pelo teste de comparações múltiplas Dunnet, $* \mathrm{p}<0.05$ vs TX $(\mathrm{n}=4)$. 


\subsection{Estudo in vitro nas células 3T3-L1}

\subsubsection{Aspectos morfológicos do cultivo das células 3T3-L1}

A figura 43 apresenta em A e B as células 3T3-L1 com 10\% e 80\% de confluência respectivamente, e em $\mathrm{C}$ e $\mathrm{D}$, células diferenciadas antes e após a coloração com oil red, respectivamente. Nas células coradas com oil red, podemos observar em vermelho a presença de lipídeos, dados que as caracterizam como adipócitos.

A)

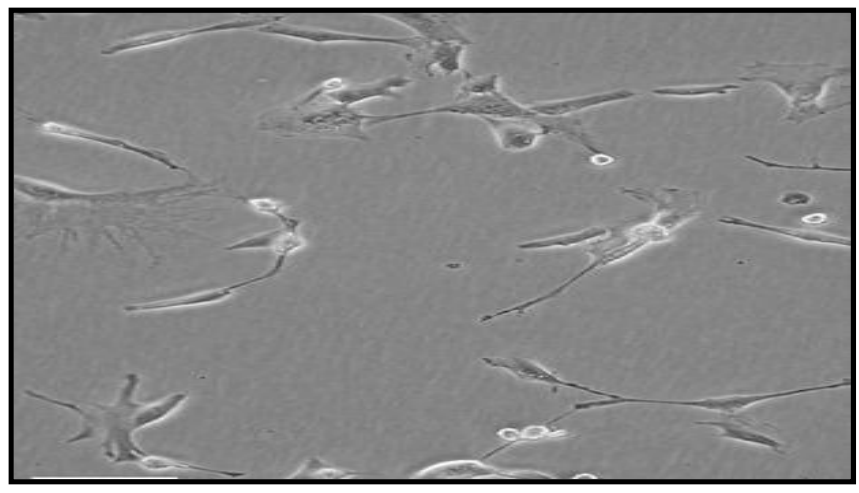

C)

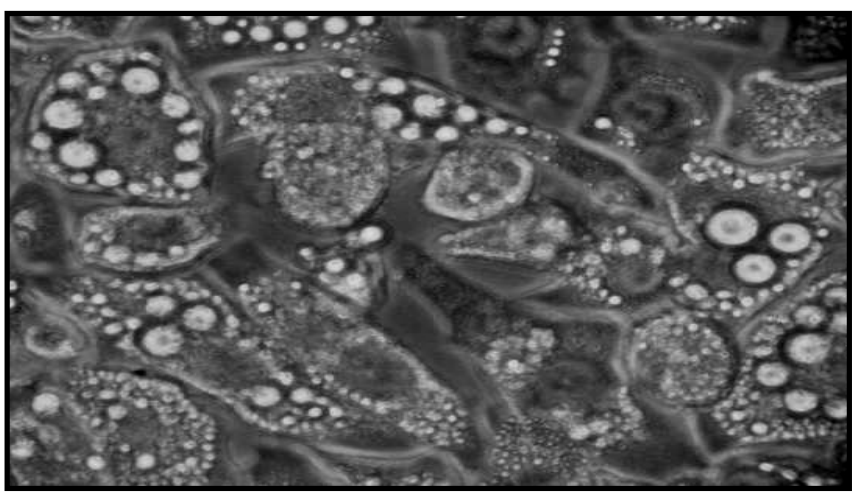

B)

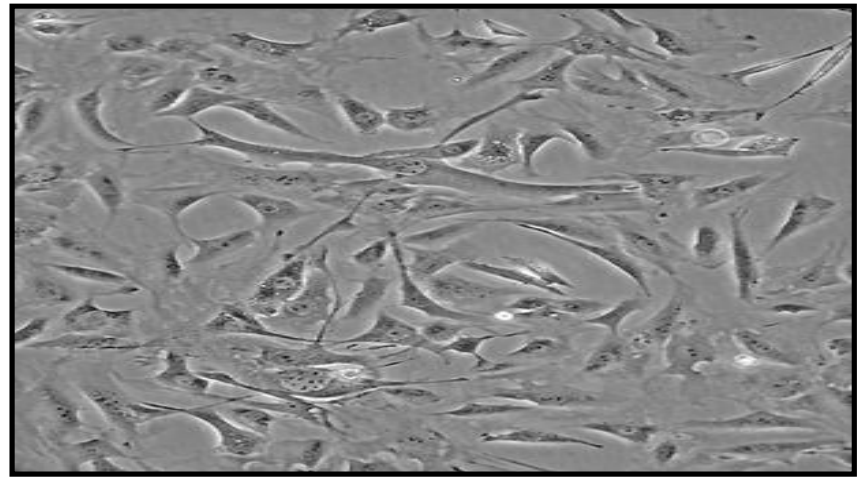

D)

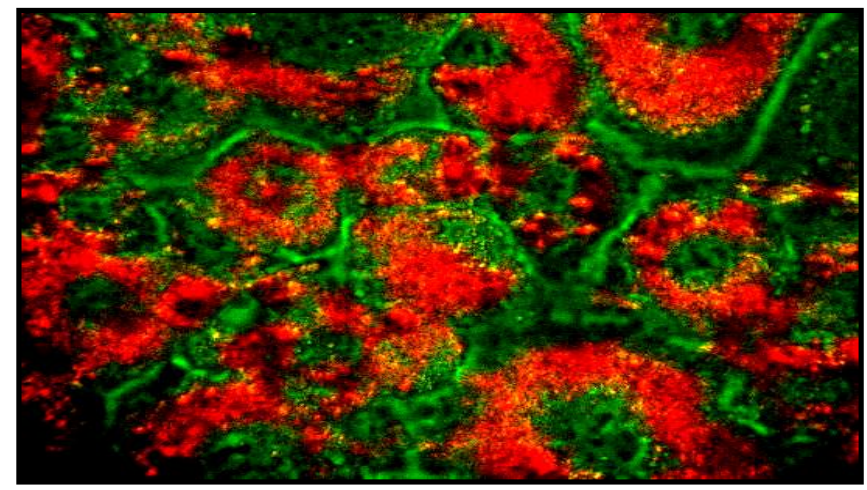

Figura 43 - Imagem das células 3T3-L1. A) Células indiferenciadas com 10\% de confluência. B) Células indiferenciadas com $80 \%$ de confluência. C) Células após 10 dias de diferenciação. D) Células coradas com oil red após 10 dias de diferenciação. 


\subsubsection{Efeito da depleção e da administração aguda de T3 sobre o conteúdo da proteína GLUT4 nas células 3T3-L1}

Neste estudo, assim como nos estudos realizados nas células L6, avaliamos o conteúdo total de GLUT4 $(\mathrm{MP}+\mathrm{M})$ e a porcentagem de GLUT4 presente na fração subcelular correspondente à Membrana Plasmática (MP) das células 3T3-L1 (adipócitos) submetidas à depleção do T3 e após 30 minutos do tratamento com este hormônio.

Observou-se que a falta do T3 reduziu significativamente tanto o conteúdo total de GLUT4 como a porcentagem dessa proteína presente na PM (figura 44 e 45). 30 minutos após a administração de doses nanomolares de T3 ocorreu um aumento no conteúdo total de GLUT4 (figura 46); contudo, a porcentagem de GLUT4 presente na membrana plasmática não foi alterada (figura 47).

A)

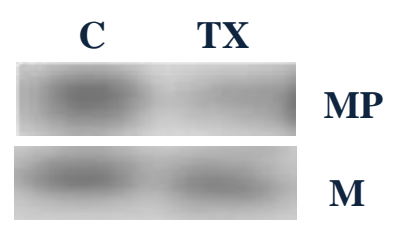

B)

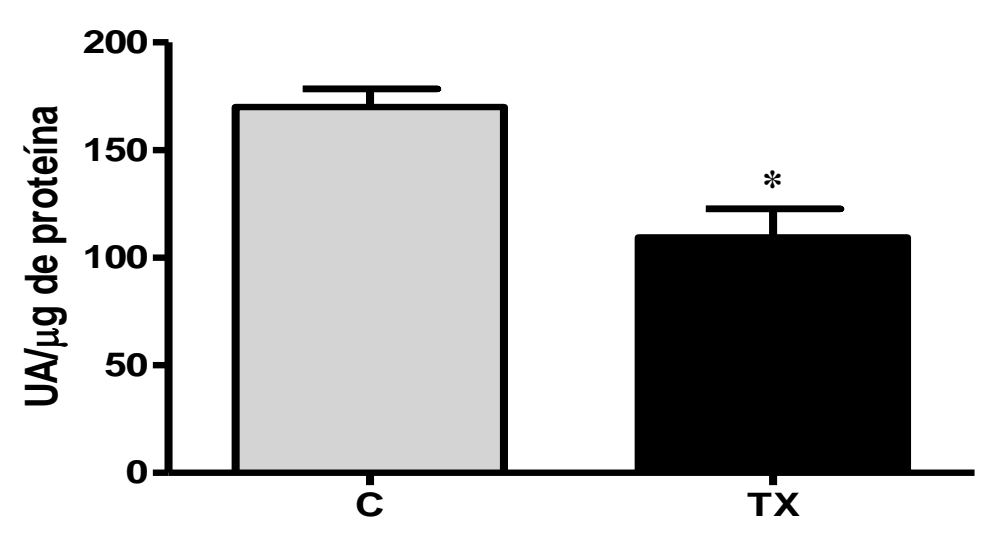

Figura 44 - A) Imagem representativa da auto-radiografia das bandas referentes ao conteúdo da proteína GLUT4 nas frações Microssomal (M) e de Membrana Plasmática (MP) nas células 3T3-L1 controle $(\mathrm{C})$ e submetidas à depleção de T3 (TX). B) Representação gráfica do conteúdo total de GLUT4 nas células 3T3-L1 controle (C) e submetidas à depleção de T3 (TX). Os dados estão expressos pela média \pm SEM e foram avaliados utilizando-se o Teste T de Student (não pareado), * $\mathrm{p}<0,05$ vs $\mathrm{C}(\mathrm{n}=8)$. 


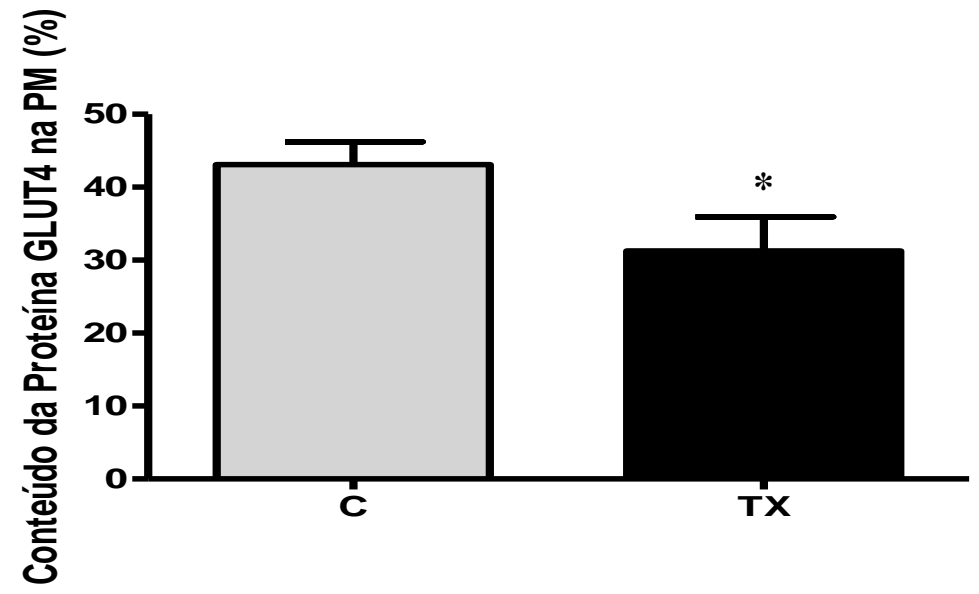

Figura 45 - Representação gráfica do conteúdo de GLUT4 na membrana plasmática das células 3T3-L1 controle (C) e submetidas à depleção de T3 (TX). Os dados estão expressos pela média \pm SEM e foram avaliados utilizando-se o Teste T de Student (não pareado), * $\mathrm{p}<$ $0,05(\mathrm{n}=8)$.

A)

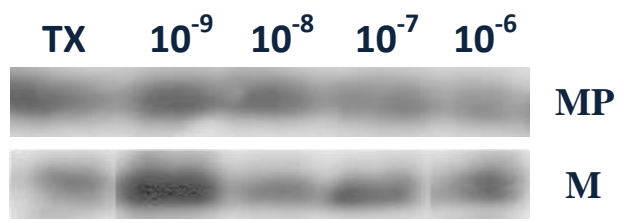

B)

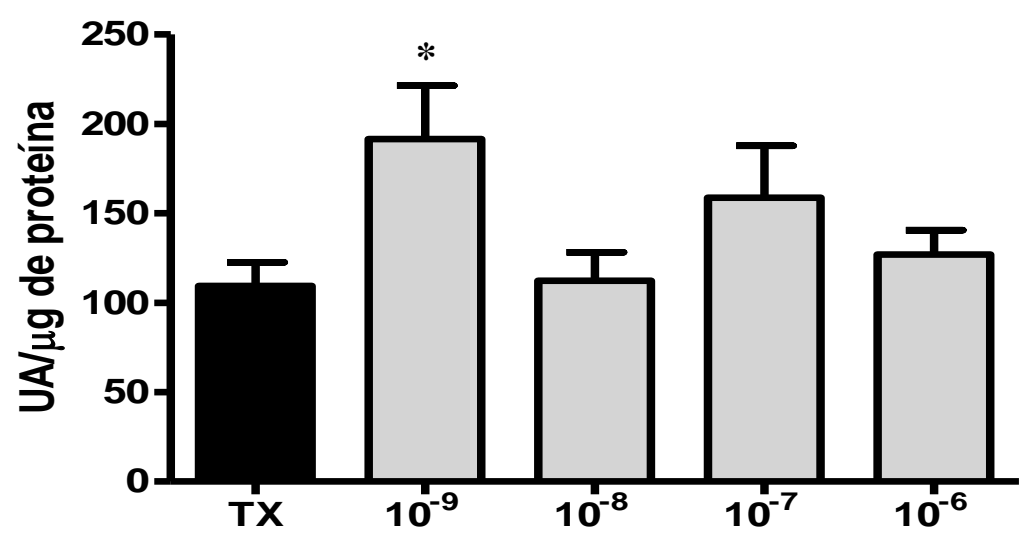

Figura 46 - A) Imagem representativa da auto-radiografia das bandas referentes ao conteúdo da proteína GLUT4 nas frações Microssomal (M) e de Membrana Plasmática (MP) nas células 3T3-L1 submetidas à depleção de T3 $(\mathrm{TX})$ e no grupo TX que recebeu T3 nas doses $10^{-9}, 10^{-8}, 10^{-7}$ e $10^{-6} \mathrm{M}$ de T3. B) Representação gráfica do conteúdo total de GLUT4 nas células 3T3-L1 submetidas à depleção de T3 (TX) e no grupo TX que recebeu T3 nas doses $10^{-9}, 10^{-8}, 10^{-7}$ e $10^{-6} \mathrm{M}$ de T3 por 30 minutos. Os dados estão expressos pela média \pm SEM e foram avaliados utilizando-se a análise de variância oneway ANOVA, seguida pelo teste de comparações múltiplas Dunnet, $* \mathrm{p}<0.05$ vs TX $(\mathrm{n}=$ 8). 


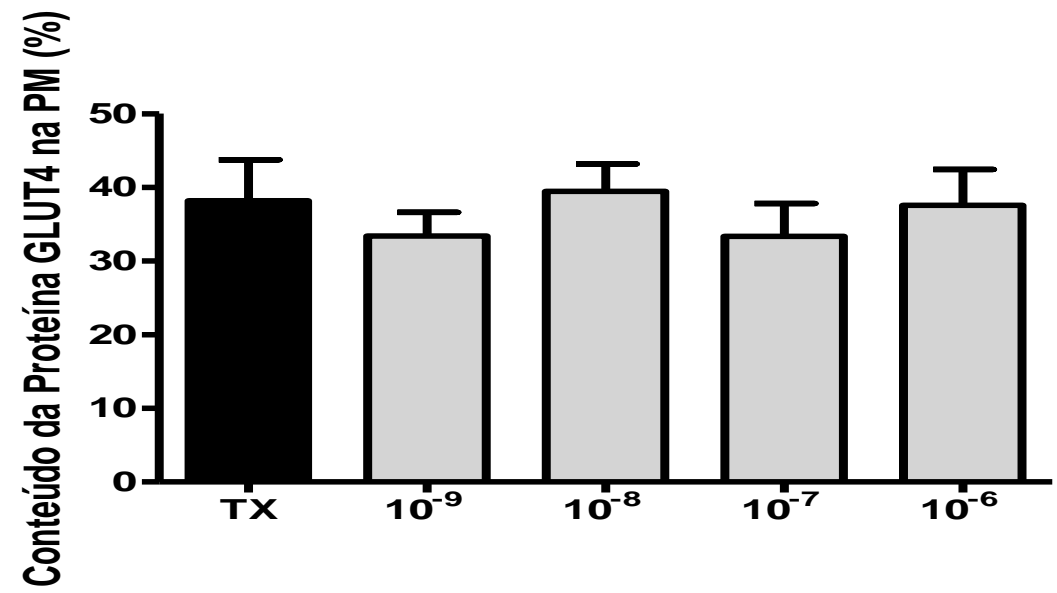

Figura 47 - Representação gráfica do conteúdo de GLUT4 na membrana plasmática das células 3T3-L1 submetidas à depleção de T3 (TX) e no grupo TX que recebeu T3 nas doses $10^{-9}$, $10^{-8}, 10^{-7}$ e $10^{-6} \mathrm{M}$ de T3 por 30 minutos. Os dados estão expressos pela média $\pm \mathrm{SEM} \mathrm{e}$ foram avaliados utilizando-se a análise de variância one-way ANOVA, seguida pelo teste de comparações múltiplas Dunnet, $(\mathrm{n}=8)$.

\subsubsection{Efeito do tratamento agudo com T3 no conteúdo total de GLU4 de células} 3T3-L1 previamente tratadas com actinomicina $D$ (bloqueador da transcrição) e cicloheximide (bloqueador da tradução)

Para avaliar se o aumento do conteúdo total de GLUT4, observado 30 minuto após a administração de T3, foi decorrente da síntese de novas proteínas, as células 3T3-L1 submetidas à depleção de T3 (TX) foram tratadas com $10^{-9} \mathrm{M}$ de $\mathrm{T} 3$ na presença de actinomicina D (ActD) ou de cycloheximide (CHX). Esses dados estão apresentados na figura 48 e mostram que o uso de ambas as drogas não foi capaz de bloquear o efeito do T3. 
A)

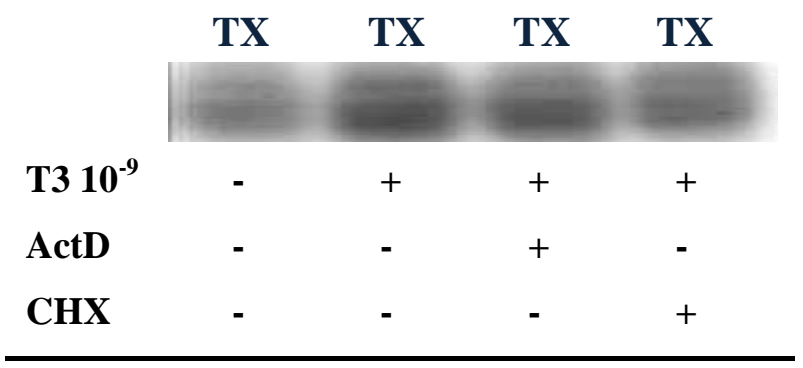

B)

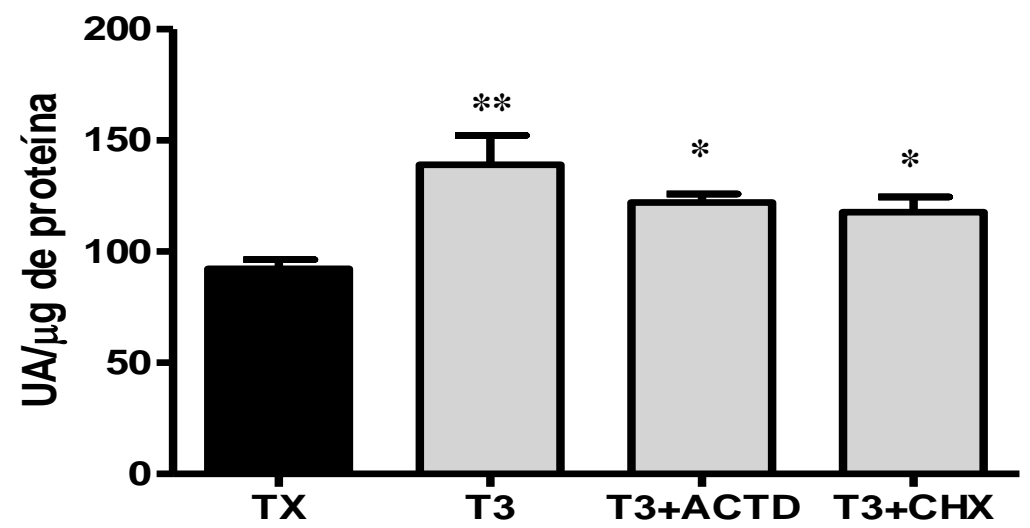

Figura 48 - A) Imagem representativa da auto-radiografia das bandas referentes ao conteúdo da proteína GLUT4 no grupo de células 3T3-L1 submetido à depleção de T3 (TX), no grupo TX que recebeu T3 nas doses $10^{-9} \mathrm{M}$ por 30 minutos (T3), e no grupo TX que recebeu $1 \mathrm{~h}$ antes da administração de T3 $2 \mu \mathrm{g} / \mathrm{ml}$ de ActD (T3+ActD) e CHX (T3+CHX) respectivamente B) Representação gráfica do conteúdo total de GLUT4 no grupo de células 3T3-L1 submetido aos seguintes tratamentos: depleção de T3 (TX); grupo TX que recebeu T3 nas doses $10^{-9} \mathrm{M}$ por 30 minutos (T3); grupo TX que recebeu $1 \mathrm{~h}$ antes da administração de T3 $2 \mu \mathrm{g} / \mathrm{ml}$ de ActD (T3+ActD) e CHX (T3+CHX) respectivamente. Os dados estão expressos pela média \pm SEM e foram avaliados utilizando-se a análise de variância one-way ANOVA, seguida pelo teste de comparações múltiplas Dunnet, ** p < 0.01 vs TX, * $\mathrm{p}<0.05$ vs $\mathrm{TX}(\mathrm{n}=8)$. 


\subsubsection{Efeito da depleção e da administração aguda de T3 sobre o conteúdo do mRNA do GLUT4 nas células 3T3-L1}

Uma vez que a actinomicina $\mathrm{D}$, bloqueador da transcrição, e a cicloheximide, bloqueador da tradução, não foram capazes de inibir o aumento no conteúdo do GLUT4 produzido pelo $\mathrm{T} 3$, resolvemos investigar se o $\mathrm{T} 3$ produziria o mesmo efeito no mRNA do GLUT4.

A figura 49 mostra os dados referentes ao efeito da depleção de T3 sobre o conteúdo do mRNA do GLUT4 nas células 3T3-L1, onde se observa redução expressiva desse transcrito. No entanto, 30 minutos após a administração de T3 ocorre um aumento significativo no conteúdo do mRNA do GLUT4, que se manteve mesmo na presença de actinomicina D (figura 50). Esses resultados indicam uma ação não genômica do T3, nunca antes descrita.

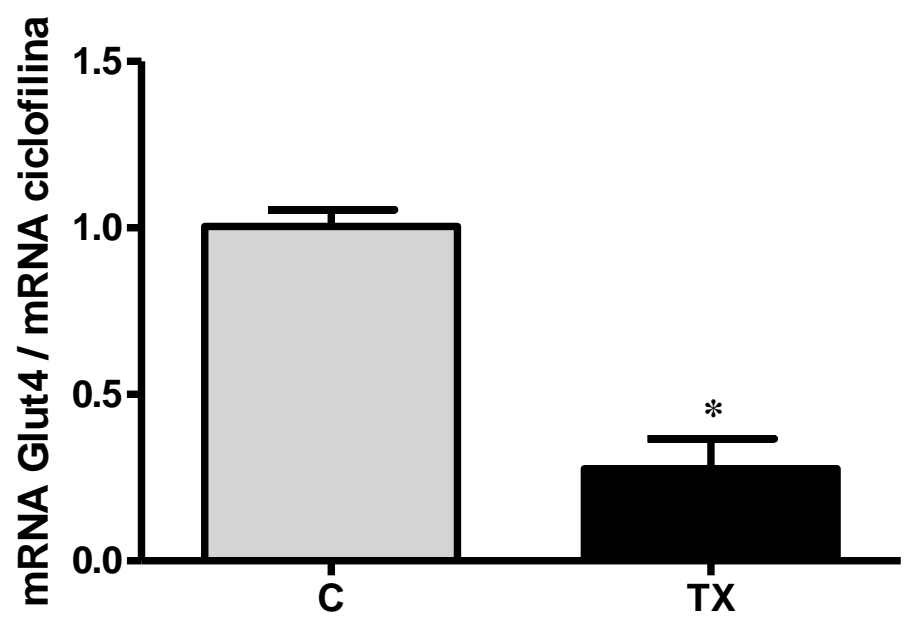

Figura 49 - Representação gráfica do conteúdo de mRNA do GLUT4 nas células 3T3-L1 controle (C) e submetidas à depleção de T3 (TX). Os dados estão expressos pela média \pm SEM e foram avaliados utilizando-se o Teste T de Student (não pareado), * $\mathrm{p}<0.05$ vs $\mathrm{C}(\mathrm{n}=6)$. 


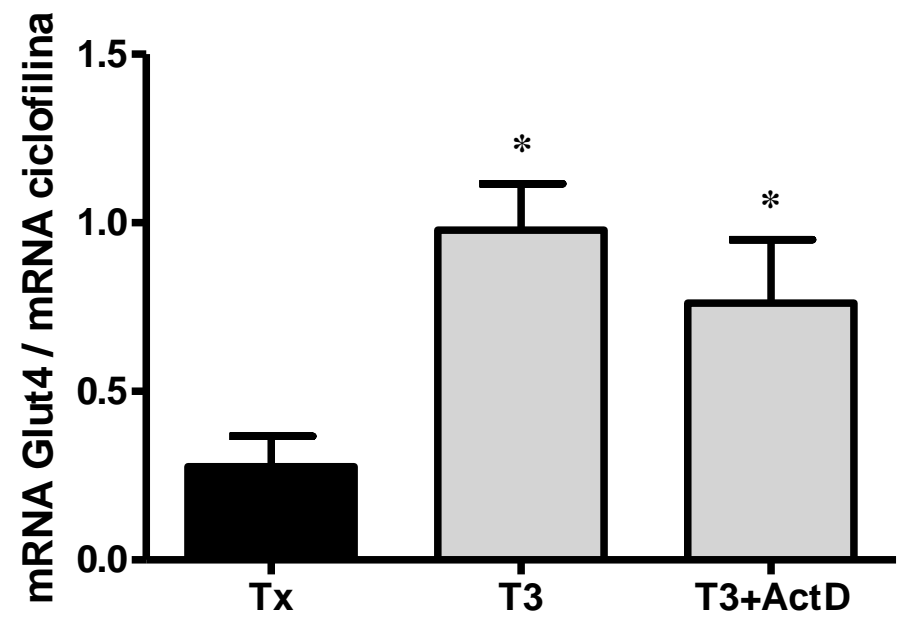

Figura 50 - Representação gráfica do conteúdo de mRNA de GLUT4 nas células 3T3-L1 submetidas aos seguintes tratamentos: depleção de T3 (TX); grupo TX que recebeu T3 nas doses $10^{-9} \mathrm{M}$ por 30 minutos (T3) e grupo TX que recebeu $1 \mathrm{~h}$ antes da administração de T3 $2 \mu \mathrm{g} / \mathrm{ml}$ de AcTD (T3+ActD). Os dados estão expressos pela média \pm SEM e foram avaliados utilizando-se a análise de variância one-way ANOVA, seguida pelo teste de comparações múltiplas Dunnet, * $\mathrm{p}<0.05$ vs TX, * $\mathrm{p}<0.05$ vs TX $(\mathrm{n}=6)$.

\subsubsection{Efeito da administração aguda de GC1 sobre o conteúdo da proteína GLUT4} nas células 3T3-L1

Nesse experimento nós avaliamos o efeito da administração aguda de GC1, um agonista específico da isoforma $\beta$ do receptor do T3 (TR $\beta$ ), no conteúdo da proteína GLUT4.

Os resultados mostram que, tal qual o próprio T3, esse análogo foi capaz de aumentar o conteúdo total de GLUT4 (figura 51). 
A)

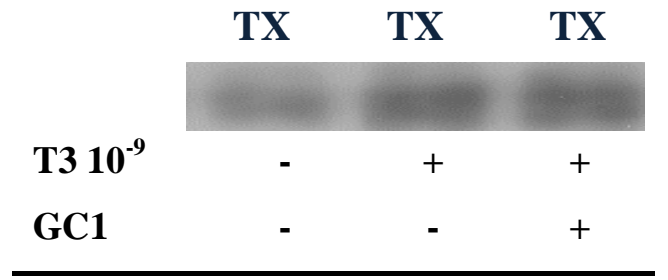

B)

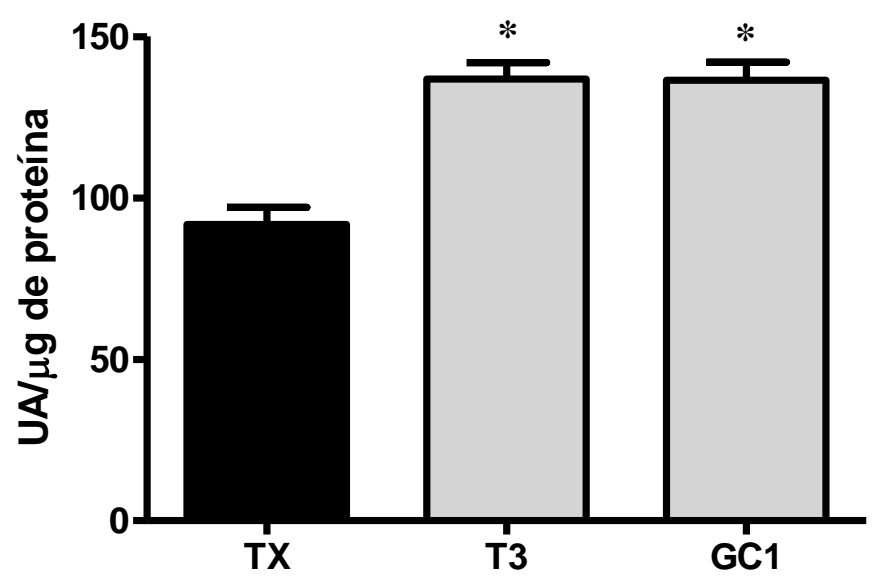

Figura 51 - A) Imagem representativa da auto-radiografia das bandas referentes ao conteúdo da proteína GLUT4 no grupo de células 3T3-L1 submetido à depleção de T3 (TX), no grupo TX que recebeu $10^{-9} \mathrm{M}$ de T3 por 30 minutos (T3), e no grupo TX que recebeu 10${ }^{9}$ M de GC1 por 30 minutos (GC1). B) Representação gráfica do conteúdo total de GLUT4 no grupo de células 3T3-L1 submetido aos seguintes tratamentos: depleção de T3 (TX); grupo TX que recebeu $10^{-9} \mathrm{M}$ de T3 por 30 minutos (T3); grupo TX que recebeu $10^{-9} \mathrm{M}$ de $\mathrm{GC} 1$ por 30 minutos (GC1). Os dados estão expressos pela média \pm SEM e foram avaliados obtidos utilizando-se a análise de variância one-way ANOVA, seguida pelo teste de comparações múltiplas Dunnet, ${ }^{*} \mathrm{p}<0.01$ vs TX $(\mathrm{n}=6)$. 


\section{DISCUSSÃO}

O tecido muscular esquelético e o adiposo desempenham papeis importantes na captação de glicose, sendo fundamentais para a manutenção da homeostase glicêmica, principalmente no período pós-prandial. Nesses tecidos a captação de glicose para o interior da célula é mediada principalmente pelo transportador de glicose GLUT4 (GOROVITS et al., 2003).

A musculatura esquelética representa cerca de $40 \%$ do peso corporal e se coloca entre os tecidos que apresentam maior utilização de glicose em resposta à insulina. Contudo, a distribuição de GLUT4 nesse tecido varia nos diferentes tipos de fibras, cujas características determinam os diferentes tipos de músculos. Dessa maneira, sabe-se que a expressão de GLUT4 é maior nos músculos oxidativos, tanto os considerados de contração lenta (tipo I), quanto os de contração rápida (tipo IIa) (MARETTE et al., 1992).

O tecido muscular esquelético é ainda um importante alvo da ação do HT, no qual este hormônio induz a expressão de genes envolvidos com o controle do metabolismo, dentre os quais o gene SLC2A4, que codifica a proteína GLUT4 (WEINSTEIN et al., 1994; CASLA; ROVIRA; WELLS, 1990). Tal qual o músculo esquelético, o tecido adiposo é um importante alvo do hormônio tireoidiano e, semelhantemente, apresenta o GLUT4 como um dos principais transportadores de glicose.

Nossos resultados demonstram que a expressão proteica e a porcentagem de GLUT4 presente na membrana plasmática estão reduzidas no músculo esquelético (Soleus e EDL) e tecido adiposo de ratos com hipotireoidismo (figura 3 e 4). Além disso, a administração de T3 rapidamente aumentou (30 minutos) o conteúdo de GLUT4 na fração correspondente à membrana plasmática, no músculo esquelético e no tecido adiposo, embora não tenha alterado seu conteúdo total (figura 7 e 8). Esses resultados aumentam as evidências de que o hormônio tireodiano atua como um componente importante para a manutenção da homeostase glicêmica, e sugerem que, em paralelo à suas ações genômicas, esse hormônio pode regular a disponibilidade de glicose para os músculos esqueléticos e tecido adiposo através de mecanismos não genômicos. As ações aqui descritas, revelam um direcionamento do GLUT4 à MP induzido pelo T3, que conforme sabido, depende da ativação de vias de sinalização intracelulares; além disso, essas ações ocorreram em um curto período de tempo (30 minutos).

Uma vez que o T4 tem sido apontado em muitos estudos como um dos principais hormônios a desencadear as ações não genômicas do HT, investigamos também se, tal qual o T3, ele é capaz de provocar um aumento agudo de GLUT4 na membrana plasmática 
(MEZOSI et al., 2005; DAVIS et al., 2000). Assim, verificamos que ratos tireoidectomizados, que apresentam uma significativa redução no conteúdo de GLUT4 na membrana plasmática em músculo esquelético (Soleus e EDL) e tecido adiposo, quando tratados agudamente com T4 não apresentaram qualquer alteração nesse parâmetro, sugerindo que a translocação do GLUT4 para a membrana plasmática seja induzida especificamente pelo T3 (figura 6). Esse resultado se soma a outros apresentados na literatura, que indicam que algumas ações não genômicas são desencadeadas pelo T3 e não pelo T4, e vice-versa (MEZOSI et al., 2005; DAVIS; LEONARD; DAVIS, 2008). Adicionalmente, ele contribui para reversão de um conceito que se firmou quando essas ações não genômicas começaram a ser identificadas e atribuídas ao T4, rT3 e T2, mas não ao T3, que desencadearia apenas ações genômicas.

Contudo, o aumento no conteúdo total de GLUT4, observado no músculo Soleus e no tecido adiposo 30 minutos após a administração de T4, sugere a possibilidade de ativação de um mecanismo não genômico distinto do envolvido na translocação do GLUT4, já que o T4 não promoveu esse último efeito. A possibilidade do efeito ser não genômico é fortalecida pelo pequeno espaço de tempo em que tal ação é desencadeada e pelo fato de que a afinidade dos receptores nucleares dos HT presentes no TRE pelo T4 é extremamente baixa para que pudéssemos esperar uma ação tão rápida (figura 5).

Estudos realizados no nosso laboratório demonstraram uma atuação do T3 na regulação pós-transcricional da expressão do gene do $\mathrm{GH}$, aumentando o grau de adenilação e da taxa de tradução deste mRNA, com consequente elevação do conteúdo de GH (DA SILVA et al., 2009; GOULART-SILVA et al., 2006). É possível que de forma semelhante ao T3, o aumento no conteúdo proteico do GLUT4, observado em reposta ao T4, decorra de uma ação deste hormônio aumentando o comprimento da cauda poli-A deste transcrito. Seu comprimento tem relação direta com a estabilidade (aumento da meia-vida) e ancoramento ao ribossomo, processos que levam a uma maior taxa de tradução do mRNA e portanto da síntese de proteínas, no caso o GLUT4 (VOLPATO et al., 2000). Sabe-se também que tanto o GLUT1 quanto o GLUT4 sofrem um processo de $N$-glicosilação durante o seu processamento, o que tem demonstrado ter um papel importante na estabilidade dessas proteínas. Assim, uma outra possibilidade seria o T4 promover um aumento no grau de glicosilação do GLUT4 e consequentemente aumentar sua meia vida, o que poderia também explicar o aumento no conteúdo total de GLUT4 observado 30 minutos após a administração desse hormônio (MCGOWAN; LONG; PEKALA, 1995; ASANO et al., 1993; ASANO et al., 1991). 
O fato do T4 ter aumentado o conteúdo de GLUT4 no músculo Soleus e no tecido adiposo sem, contudo, alterar esse parâmetro no EDL, bem como o fato de diferentes doses de T4, fisiológicas no tecido adiposo e suprafisiológicas no Soleus terem desencadeado a mesma resposta, demonstra que as ações não genômicas do HT são tecido-específicas (SHEEHAN; KUMAR; HOOD, 2004; IRRCHER et al., 2008). Ações tecido específicas foram também observada quando os animais foram tratados com T3, uma vez que o aumento no conteúdo de GLUT4 presente na fração subcelular referente à membrana plasmática foi observado no EDL a partir de doses fisiológicas e no Soleus a partir de doses cinco vezes maiores que a fisiológica. No tecido adiposo apenas a dose fisiológica de T3 foi capaz de aumentar esse parâmetro.

Os estudos relacionados às ações não genômicas dos HTs mostram que elas podem ser desencadeadas por diferentes mecanismos. Sabe-se que a integrina $\alpha v \beta 3$, o TR $\beta$ citosólico (extranuclear) e uma forma truncada do $\mathrm{TR} \alpha(\mathrm{TR} \Delta \alpha 1)$, participam dessas ações. No entanto, enquanto a integrina liga-se preferencialmente ao T4, o TR $\beta$ extranuclear é capaz de ligar-se apenas ao T3. Já o TR $\Delta \alpha 1$ interage tanto com o T4 quanto com o rT3, mostrando que os receptores ou sítios ligantes de HT envolvidos nessas ações possuem diferentes afinidades pelos análogos do HT (SHEUE-YANN; LEONARD; DAVIS, 2010). Tais diferenças podem ser as responsáveis pela resposta tecido-específica observada nesse trabalho.

O aumento de GLUT4 na fração subcelular correspondente à membrana plasmática (MP) é o resultado final da ativação de quinases intracelulares, as quais promovem a translocação de vesículas do citossol em direção à MP e a incorporação do GLUT4 na PM. No entanto, esse processo é desencadeado de maneira extremamente rápida, o que praticamente exclui a possibilidade de estar relacionado à efeitos genômicos; ou seja, esse rápido efeito do T3 sobre a translocação do GLUT4 e, portanto, sobre o seu aumento na membrana plasmática, indica que ele tenha sido desencadeado não genomicamente pelo T3.

A via da PI3-K é uma das mais conhecidas como envolvida na translocação do GLUT4. Uma vez que a ativação desta via depende do grau de atividade do receptor da insulina (IR), bem como dos substratos do receptor da insulina (IRS1/2), nós analisamos esses dois parâmetros após administração de T3. Observamos que 30 minutos após a administração de T3 ocorreu um aumento significativo da fosforilação do IR no músculo EDL e, portanto, de sua atividade (figura 9). Um aumento da fosforilação do IR no músculo Soleus foi também observado, embora não tenha sido significativo (figura 9). Esse dado é interessante e surpreendente, porque nesse período de tempo (30 minutos) a translocação já havia sido efetivada e, portanto, essa ativação do IR parece não ter sido o fator que a desencadeou. 
Adicionalmente, quando avaliamos o substrato do receptor da insulina (IRS1/2) em ambos os músculos estudados, não detectamos nenhuma alteração na sua fosforilação/atividade (figura 10). Deste modo, esses resultados indicam que a translocação do GLUT4 observada 30 minutos após a administração do T3 é independente da ativação do IR e dos IRS1/2. A administração de T3 também não provocou alteração no conteúdo da proteína p85 e da p110 nos músculos estudados (figura 11 e 12).

Sabe-se que a isoforma $\beta$ do receptor do hormônio tireoideano (TR $\beta)$ pode se ligar à subunidade regulatória $(\mathrm{p} 85 \alpha)$ da PI3-K, e que a interação do HT com esse receptor poderia levar à ativação desta quinase (CAO et al., 2005; HIROI et al., 2006), iniciando uma cascata de eventos que resultariam na fosforilação e ativação da AKT e da PKC atípica (aPKC). Essas quinases estão envolvidas na translocação do GLUT4 para a membrana plasmática (KHAN et al., 2002; PATEL et al., 2003; ISHIKI et al., 2005). Portanto, investigamos o grau de atividade da AKT após a administração do T3 e observamos redução significativa da mesma em ambos os músculos analisados (figura 13). Isso indica que o aumento na translocação do GLUT4 induzido pelo T3 é independente da via da PI3-K.

A contração muscular ativa quinases que participam da translocação do GLUT4 para membrana plasmática por meio de um mecanismo que envolve uma redução na razão ATP/AMP, sendo o aumento no conteúdo do AMP o responsável pela ativação da AMPK. É sabido que a fosforilação da AMPK aumenta o transporte de glicose no músculo esquelético por aumentar a translocação de GLUT4 para a membrana plasmática (SANTOS et al., 2008). Considerando que há estudos que mostram que o tratamento com hormônio tireoidiano aumenta a expressão da AMPK, provavelmente por um efeito transcricional (PARK et al., 2002), bem como a sua fosforilação, através de mecanismos não genômicos (IRRCHER et al., 2008), investigamos o grau de fosforilação da AMPK após administração do T3. Nossos resultados não identificaram qualquer ativação da $\mathrm{AMPK} \alpha$ pelo T3, tampouco da AMPK $\beta$, nos músculos esqueléticos estudados (figura 14 e 15).

No entanto, existem estudos que mostram um aumento na fosforilação da AMPK no músculo esquelético após 2 horas da administração do T3 e trabalhos que demonstram um aumento na fosforilação da AKT no músculo cardíaco após 5 minutos do tratamento com esse hormônio. Esses estudos reforçam que as ações do HT são tecido- específicas, o que indica que as concentrações hormonais, assim como os tempos utilizados, influenciam na capacidade de ativação dessas quinases, já que diferentes mecanismos podem ser acionados (IRRCHER et al., 2008; IORDANIDOU et al., 2010). 
As vias de sinalização da PI3-K e da AMPK não são as únicas envolvidas no processo de captação de glicose. Outros eventos, como: a ativação da via CAP-CBL, o aumento na concentração do íon cálcio no interior da célula, a ativação da óxido nítrico sintase (NOS) e o consequente aumento da geração de óxido nítrico (NO), o aumento na concentração de bradicinina ou até mesmo a hipóxia podem induzir a translocação do GLUT4 para a membrana (CHIANG et al., 2001; YOUN; GULVE; HOLLOSZY, 1991; HIGAKI et al., 2001; KISHI et al., 1998; CHOU et al., 2004). Dessa forma, embora nossos resultados tenham indicado que o T3 não utilize a via da PI3-K, tampouco a da AMPK, não podemos descartar a possibilidade da participação dessas outras vias.

Nossos estudos em células L6 corroboraram os resultados obtidos com os experimentos in vivo, uma vez que a depleção do hormônio tireoidiano provocou uma redução significativa no conteúdo de GLUT4 na fração correspondente à membrana plasmática e a administração de doses fisiológicas de T3 aumentou rapidamente esse parâmetro (figura 19 e 21). No entanto, quando células L6-GLUT4myc foram utilizadas, as quais efetivamente propiciam a identificação do GLUT4 incorporado à membrana, não detectamos aumento desta proteína na MP após administração aguda de T3 (figura 23). Essa discrepância pode ser atribuída à metodologia utilizada, uma vez que o fracionamento celular utilizado nas células L6, pode não ter sido capaz de separar o GLUT4 ancorado daquele fundido na MP. Já a metodologia empregada com as células L6-GLUT4myc detecta apenas o GLUT4 inserido na membrana e capaz de transportar a glicose. Dessa forma, apesar de termos identificado que o T3 promoveu uma migração das vesículas contendo GLUT4 em direção à MP, o que revela uma ação não genômica deste hormônio, não há indícios de que ele esteja sendo incorporado; em outras palavras, não podemos afirmar que o aumento no conteúdo de GLUT4 detectado na fração correspondente à membrana plasmática, observado em nossos estudos, produza um respectivo aumento na captação da glicose.

No entanto, embora o T3 não tenha induzido aumento do conteúdo de GLUT4myc na membrana plasmática, houve um aumento na captação da glicose, 30 minutos após a administração desse hormônio (figura 25 e 26). Isso demonstra que o T3 pode regular a disponibilidade de glicose nessas células através de mecanismos não genômicos, que não dependem de inserção de novas moléculas de GLUT4 à MP.

Adicionalmente, nossos resultados mostraram que a captação de glicose estimulada pela insulina é potencializada pelo T3 (figura 27). Ela parece ocorrer por um mecanismo independente da translocação do GLUT4, uma vez que a administração concomitante desses hormônios não aumentou o conteúdo de GLUT4 na membrana (figura 28). 
Observamos também que o tratamento com indinavir, uma droga que bloqueia especificamente o GLUT4, não bloqueou a captação de glicose (figura 29) induzida pelo T3. Além disso, quando avaliamos a porcentagem de inibição da captação de glicose pelo indinavir, observamos que, enquanto nas células controles e nas células submetidas a depleção de T3 a inibição foi de aproximadamente $25 \%$, nas células tratadas com T3 essa inibição foi de apenas $15 \%$ (figura 30). Esses resultados novamente sugerem que a captação de glicose observada, 30 minutos após a administração de T3, ocorre por um mecanismo independente da translocação do GLUT4, podendo ser devido a um processo de ativação dessa proteína ou ainda por algum mecanismo totalmente independente do GLUT4.

Uma vez que o GLUT1 é expresso no músculo esquelético e diante da demonstração feita em alguns estudos de que o T3 pode regular positivamente essa proteína através de mecanismos não genômicos (MOELLER et al., 2006), partimos para a avaliação da participação do GLUT1 no aumento da captação de glicose induzido pelo tratamento com o T3. Observamos que a falta do T3 provocou uma significativa redução na captação de glicose e no conteúdo de GLUT1myc presente na membrana plasmática (figura 31 e 32). No entanto, a administração aguda de T3 não reestabeleceu esses parâmetros (figura 33 e 34), o que demonstra que o aumento na captação de glicose descrito acima ocorreu por um mecanismo independente do GLUT1.

Em suma, os estudos in vitro demonstraram que o $\mathrm{T} 3$ promove, rapidamente (30 minutos), um aumento da captação de glicose nas células L6-GLUT4myc, sem, contudo, alterar o conteúdo de GLUT4myc presente na membrana. Diante desses resultados, investigamos o grau de fosforilação de algumas proteínas sabidamente envolvidas na mobilização de vesículas contendo GLUT4 em direção à MP (translocação do GLUT4).

A participação da via de sinalização ativada pela insulina foi investigada pela analise da proteína AKT, e do substrato da AKT/PKB (AS160). Esse substrato tem importante função na translocação das vesículas contendo o GLUT4, participando do processo de ancoragem e de inserção do GLUT4 na membrana plasmática (KANE et al., 2002; RANDHAWA et al., 2008). Avaliamos também, o grau de fosforilação da AMPK $\alpha$, proteína sabidamente envolvida com a translocação do GLUT4 que ocorre após a contração muscular. Além disso, estudamos a fosforilação da proteína p38-MAPK, uma vez que alguns estudos apontaram essa proteína como tendo papel importante na ativação do GLUT4 (SOMWAR et al., 2001).

Podemos observar na figura 38 que, apenas no grupo T3 (30 minutos), ocorreu um aumento na fosforilação da AS160, embora nenhum aumento tenha sido observado na fosforilação da AKT (figura 36). Verificamos também, que a administração de T3 não 
provocou aumento significativo da fosforilação da AMPK $\alpha$ (figura 40), contudo, aumentou rapidamente (10 minutos) a fosforilação da p38-MAPK, que se mostrou passageira (figura 42).

Esses resultados, juntamente com os apresentados anteriormente, sugerem que o aumento na captação de glicose induzido pelo T3 decorra da ativação do GLUT4 já presente na membrana, ou, possivelmente, por algum processo independente dessa proteína. Nesse sentido, é possível que o GLUT3 seja responsável por essa captação, uma vez que estudos demonstram que o HT aumenta a translocação dessa proteína (DIMITRIADIS et al., 2005).

Nos estudos realizados em células 3T3-L1, observamos também que a falta do T3 reduziu significativamente o conteúdo total de GLUT4 e a porcentagem dessa proteína presente na fração correspondente à membrana plasmática (figura 44 e 45). No entanto, 30 minutos após a administração de doses nanomolares de T3 houve um aumento no conteúdo total de GLUT4 (figura 46), sem alterações na porcentagem dessa proteína presente na membrana plasmática (figura 47).

Para comprovar que as ações do T3 evidenciadas eram não genômicas, investigamos se o aumento no conteúdo de GLUT4, observado nas células 3T3-L1 30 minutos após a administração T3, se mantinha mesmo na presença da actinomicina $\mathrm{D}$, um potente inibidor da transcrição gênica. Observou-se que a actinomicina D não previniu a ação do T3 (figura 48 e 50). Uma vez que estudos realizados previamente em nosso laboratório demonstraram um papel do T3 na regulação pós-transcricional do GH, modulando a poliadenilação deste mRNA, acreditamos que os aumentos no conteúdo proteico e do mRNA do GLUT4 observado possam ser decorrentes a uma ação do T3 incrementamdo o comprimento da cauda poli-A deste transcrito (VOLPATO et al., 2000).

Observamos também que quando as células 3T3-L1 foram tratadas previamente com cycloheximide, um forte inibidor da tradução, a ação do T3 persistiu (figura 48). É possível que o T3 tenha promovido aumento da $\mathrm{N}$-glicosilação do GLUT4 durante o seu processamento, etapa muito importante para a manutenção da estabilidade e portanto a meia vida desta proteína, o que explicaria a manutenção do seu efeito, aumentando o conteúdo total de GLUT4, mesmo na presença de cycloheximide (MCGOWAN; LONG; PEKALA, 1995; ASANO et al., 1993; ASANO et al., 1991).

Por fim, os estudos que desenvolvemos com o GC-1, um análogo do T3 tanto nas suas funções de ligação ao TR $\beta$, quanto na ativação da transcrição gênica (CHIELLINI et al., 1998) mostraram que ele, assim como o T3, promoveu aumento no conteúdo total de GLUT4 nessas células (figura 51). Esse análogo liga-se especificamente ao TR $\beta$, com afinidade ao 
GC1 semelhante à que tem ao T3, mas com uma afinidade aproximadamente 10 vezes menor pelo TR $\alpha 1$. Dessa forma, esse resultado demonstra que essa ação do T3 nas células 3T3-L1 pode ser mediada via TR $\beta$ possivelmente presente no citossol, a julgar pelo rápido estabelecimento do efeito que evidenciamos.

Ao contrário do T3, o GC1 não eleva a frequência e a massa cardíaca. No entanto, de maneira semelhante ao $\mathrm{T} 3$, ele pode reduzir o colesterol e os triglicérides plasmáticos, sugerindo um potencial efeito terapêutico desse composto no tratamento das dislipidemias (JOSSEAUME et al., 2008). Dessa forma, nossos resultados chamam a atenção também para a possibilidade do uso futuro do GC1 nas doenças que afetam a homeostase glicêmica, sem que efeitos deletérios sobre o coração sejam desencadeados, e ainda com benefícios sobre os lipídios sanguíneos. 


\section{CONCLUSÃO}

O conjunto dos dados aqui apresentados sugere que ao lado das suas reconhecidas ações genômicas, o T4 e, principalmente, o T3, atuam por mecanismos não genômicos regulando a expressão e translocação do GLUT4 em direção à MP no músculo esquelético e tecido adiposo. Adicionalmente, os nossos dados sugerem fortemente que o T3 participe, também por mecanismos não genômicos, do processo de ativação do GLUT4 já inserido na membrana, o que poderia explicar a elevação da captação de glicose por ele induzida que se mostrou ser independente da inserção de novas moléculas de GLUT4 à membrana plasmática. 


\section{REFERÊNCIAS}

ASANO, T.; KATAGIRI, H.; TAKATA, K.; LIN, J. L.; ISHIHARA, H.; INUKAI, K.; TSUKUDA, K.; KIKUCHI, M.; HIRANO, H.; YAZAKI, Y. The role of N-glycosylation of GLUT1 for glucose transport activity. J. Biol. Chem., v. 266, p. 24632-24636, 1991.

ASANO, T.; TAKATA, K.; KATAGIRI, H.; ISHIHARA, H.; INUKAI, K.; ANAI, M.; HIRANO, H.; YAZAKI, Y.; OKA, Y. The role of N-glycosylation in the targeting and stability of GLUT1 glucose transporter._FEBS Letters, v. 21, p. 258-261, 1993.

AUGUSTIN, R.; CARAYANNOPOULOS, M. O.; DOWD, L. O.; PHAY, J. E.; MOLEY, J. F.; MOLEY, K.H. Identification and characterization of human glucose transporter-like protein-9 (GLUT9): alternative splicing alters trafficking. J. Biol. Chem., v. 279, p. 1622916236, 2004.

BIRNBAUM, M. J. Identification of a novel gene encoding an insulin-responsive glucose transporter protein. Cell, v. 57, p. 305-315, 1989.

BJORNTORP, P.; DE JOUNGE, K.; SJOSTROM, L.; SULLIVAN, L. The effect of physical training on insulin production in obesity. Metabolism, v. 19, n. 8, p. 631-638, 1970.

BJORNTORP, P.; FAHLEN, M.; GRIMBY, G.; GUSTAFSON, A.; HOLM, J.; RENSTROM, P.; SCHERSTEN, T. Carbohydrate and lipid metabolism in middle-aged, physically well-trained men. Metabolism, v. 21, n. 11, p. 1037-4104, 1972.

BROZINICK, J. T. JR.; HAWKINS, E. D.; STRAWBRIDGE, A. B.; ELMENDORF, J. S. Disruption of Cortical Actin in Skeletal Muscle Demonstrates an Essential Role of the Cytoskeleton in Glucose Transporter 4 Translocation in Insulin-sensitive Tissues. J. Biol. Chem., v. 279, p. 40699-40706, 2004.

BRUNETTO, E. L.; GIANNOCCO, G.; MACHADO, U. F.; NUNES, M. T. Efeito do hormônio tireoideano aumenta a expressão gênica e a translocação do transportador de glicose (GLUT4) no músculo esquelético e cardíaco. Arq. Bras. Endocrinol. Metab., v. 50, n. 3, 2006. Suplemento 1.

"De acordo com: ASSOCIAÇÃO BRASILEIRA DE NORMAS TÉCNICAS. NBR 6023: Informação e documentação: referências: elaboração. Rio de Janeiro. 2002. 
CAO, X.; KAMBE, F.; MOELlER, L. C.; REFETOFF, S.; SEO, H. Thyroid hormone induces rapid activation of Akt/protein kinase B-mammalian target of rapamycin-p70S6K cascade through phosphatidylinositol 3-kinase in human fibroblasts. Mol. Endocribol., v. 16, p. 102-112, 2005.

CARVAlHEIRA, J. B. C.; ZECCHIN, H. G.; SAAD, M. J. A. Vias de Sinalização da Insulina. Arq. Bras. Endocrinol. Metab., v. 46, p. 419-425, 2002.

CASLA, A.; ROVIRA, A.; WELLS, J. A.; DOHM, G. L.; Increase glucose transporter (GLUT4) protein expression in hyperthyroidism. Biochem. Biophys. Res. Commum., v. 171, p. 182-188, 1990.

CHARRON, M. J.; BROSIUS, F.C; 3rd.; ALPER, S. L.; LODISH, H. F. A glucose transport protein expressed predominately in insulin-responsive tissues. Biochemistry, v. 86, p. 25352539, 1989.

CHEESEMAN, C. GLUT7: a new intestinal facilitated hexose transporter. AM. J. Physiol. Endocrinol. Metab., v. 295, p. 238-241, 2008.

CHEN-ZION, M.; BASSUKEVITZ, Y.; BEITNER, R. Rapid changes in carbohydrate metabolism in muscle induced by triiodothyronine; the role of glucose 1,6-bisphosphate. Biochem. Mol. Med., v. 56, p. 19-25, 1995.

CHIANG, S. H.; BAUMANN, C. A.; KANZAKI, M.; THURMOND, D. C.; WATSON, R. T.; NEUDAUER, C. L.; MACARA, I. G.; PESSIN, J. E.; SALTIEL, A. R. Insulin stimulated GLUT4 translocation requires the CAP-dependent activation of TC10. Nature, v. 410, p. 944-948, 2001.

CHIEllini, G.; APRILETTI, J. W.; YOSHIHARA, H. A.; BAXTER, J. D.; RIBEIRO, R. C.; SCANLAN, T. S. A high-affinity subtype-selective agonist ligand for the thyroid hormone receptor. Chem. Biol., v. 5, p. 299-306, 1998.

CHOU, S. W.; CHIU, L. L.; CHO, Y. M.; HO, H. Y.; IVY, J. L.; HO, C. F.; KUO, C. H. Effect of systemic hypoxia on GLUT4 protein expression in exercised rat heart. Jpn. J. Physiol., v. 54, p. 357-363, 2004.

CLÉMENT, K.; VIGUERIE, N.; DIEHN, M.; ALIZADEH, A.; BARBE, P.; THALAMAS, C.; STOREY, D. J.; BROWN, P. O.; BARSH, S. G.; LANGIN, D. In vivo regulation of human skeletal muscle gene expression by thyroid hormone. Genome. Res., v. 12, p. 281291, 2002. 
DA SILVA, F. G.; GIANNOCCO, G.; LUCHESSI, A. D.; CURI, R.; NUNES, M. T. T3 acutely increases $\mathrm{GH}$ mRNA translation rate and $\mathrm{GH}$ secretion in hypothyroid rats. Mol. Cell. Endocrinol., v. 317, p. 1-7, 2009.

DAVIS, J. P.; DAVIS, F. B. Nongenomic actions of thyroid hormone. Thyroid, v. 6, p. 497504, 1996.

DAVIS, J. P.; DAVIS, F. B.; CODY, V. Membrane receptors mediating thyroid hormone action. Endocrinol. Metab., v. 16, p. 429-435, 2005.

DAVIS, J. P.; LEONARD, J. L.; DAVIS, F. B. Mechanisms of nongenomic actions of thyroid hormone. Front. Neuroendocrinol., v. 29, p. 211-218, 2008.

DAVIS, P. J.; SHIH, A.; LIN, H. Y.; MARTINO, L. J.; DAVIS, F. B. Thyroxine promotes association of mitogen-activated protein kinase and nuclear thyroid hormone receptor (TR) and causes serine phosphorylation of TR. J. Biol. Chem., v. 275, p. 38032-38039, 2000.

DAWSON, P. A.; MYCHALECKYJ, J. C.; FOSSEY, S. C.; MIHIC, S. J.; CRADDOCK, A. L.; BOWDEN, D. W. Sequence and functional analysis of GLUT10: a glucose transporter in the Type 2 diabetes-linked region of chromosome 20q12-13.1. Mol. Genet. Metab., v. 74, p. 186-199, 2001.

DIMITRIADIS, G.; MARATOU, E.; ALEVIZAKI, M.; BOUTATI, E.; PSARA, K.; PAPASTERIADES, C.; RAPTIS, S. A. Thyroid hormone excess increases basal and insulinstimulated recruitment of GLUT3 glucose transporters on cell surface. Horm. Metab. Res., v. 37, p. 15-20, 2005.

DOBLADO, M.; MOLEY, K. H. Facilitative glucose transporter 9, a unique hexose and urate transporter. Am. J. Physiol. Endocrinol. Metab., v. 297, p. 831-835, 2009.

DOEGE, H.; BOCIANSKI, A.; SCHEEPERS, A.; AXER, H.; ECKEL, J.; JOOST, H. G. SCHURMANN, A. Characterization of human glucose transporter (GLUT) 11 (encoded by SLC2A11), a novel sugar-transport facilitator specifically expressed in heart and skeletal muscle. Biochem. J., v. 359, p. 443-9, 2001.

DOEGE, H.; SCHURMANN, A.; BAHRENBERG, G.; BRAUERS, A.; JOOST, H. G. GLUT8, a novel member of the sugar transport facilitator family with glucose transporte activity. J. Biol. Chem., v. 275, p. 16275-16280, 2000.

ELSHAL, M. F.; MCCOY, J. P. Multiplex bead array assays: performance evaluation and comparison of sensitivity to ELISA. Methods, v. 38, p. 317-323, 2006. 
FITTS, R. H.; WINDER, W. W.; BROOKE, M. H.; KAISER, K. K.; HOLlOSZY, J. O. Contractile, biochemical, and histochemical properties of thyrotoxic rat soleus muscle. Am. J. Physiol., v. 238, p. 15-20, 1980.

FONDELL, J. D.; GUERMAH, M.; MALIK, S.; ROEDER, R. G.; Thyroid hormone receptor associated proteins and general positive cofactors mediate thyroid hormone receptor function in the absence of the TATA box-binding protein-associated factors of TFllD. Proc. Nati. Acad. Sci. USA, v. 96, p. 1959-64, 1999.

FUJII, N.; HAYASHI, T.; HIRSHMAN, M. F.; SMITH, J. T.; HABINOWSKI, S. A.; KAIJSER, L.; MU, J.; LJUNGQVIST, O.; BIRNBAUM, M. J.; WITTERS, L. A.; THORELL, A.; GOODYEAR, L. J. Exercise induces isoform-specific increase in 5'AMPactivated protein kinase activity in human skeletal muscle. Biochem. Biophys. Res. Commun., v. 273, n. 3, p. 1150-1155, 2000.

GIANNOCCO, G.; BRUNETTO, E. L.; GOULART-SILVA, F.; MACHADO, U. F.; NUNES, M. T. O hormônio tireoideano (T3) aumenta a expressão e a translocação do transportador de glicose em músculo cardíaco de ratos por um provável mecanismo extracelular. Arq. Bras. Endocrinol. Metab., v. 50, n. 3, p. S252, Suplemento 1, 2006.

GOROVITS, N.; CHARRON, M. J. Mini-Series: Modern Metabolic Concepts. What We Know about Facilitative Glucose Transpoters. Biochem. Mol. Biol. Educ., v. 3, p. 163-172, 2003.

GOSTELI-PETER, M. A.; SCHMID, C.; ZAPF, J. Triiodothyronine Increases Glucose Transporter Isotype 4 mRNA Expression, Glucose Transport, and Glycogen Synthesis in Adult Rat Cardiomyocytes in Long-Term Culture. Biochem. Biophys. Res. v. 25, p. 521-524, 1996.

GOULART-SILVA F.; GIANNOCCO, G.; SANTOS, M. F.; NUNES, M. T. Thyroid hormone induction of actin polymerization in somatotrophs of hypothyroid rats: potential repercussions in growth hormone synthesis and secretion. Endocrinology, v. 147, p. 5777 5785, 2006.

HABER, R. S.; WEINSTEIN, S. P.; O'BOYLE, E.; MORGELLO, S. Tissue distribution of the human GLUT3 glucose transporter. Endocrinology, v. 132, p. 2538-2543, 1993.

HARDIE, D. G.; CARLING, D. The AMP-activated protein kinase--fuel gauge of the mammalian cell? Eur. J. Biochem., v. 246, n. 2, p. 259-273, 1997.

HARDIE, D. G.; SCOTT, J. W.; PAN, D. A.; HUDSON, E. R. Management of cellular energy by the AMP-activated protein kinase system. FEBS Letters, v. 546, n. 1, p. 113-120, 2003. 
HAYASHI, T.; HIRSHMAN, M. F.; FUJII, N.; HABINOWSKI, S. A.; WITTERS, L. A.; GOODYEAR, L. J. Metabolic stress and altered glucose transport: activation of AMPactivated protein kinase as a unifying coupling mechanism. Diabetes, v. 49, n. 4, p. 527-531, 2000.

HE, A.; LIU, X.; LIU, L.; CHANG, Y.; FANG, F. How many signals impinge on GLUT4 activation by insulin? Cell Signal., v. 19, p. 1-7, 2007.

HIGAKI, Y.; HIRSHMAN, M. F.; FUJII, N.; GOODYEAR, L. J. Nitric oxide increases glucose uptake through a mechanism that is distinct from the insulin and contraction pathways in rat skeletal muscle. Diabetes, v. 50, p. 241-247, 2001.

HIROI, Y.; KIM, H. H.; YING, H.; FURUYA, F.; HUANG, Z.; SIMONCINI, T.; NOMA, K.; UEKI, K.; NGUYEN, N. H.; SCANLAN, T. S.; MOSKOWITZ, M. A.; CHENG, S. Y.; LIAO, J. K. Rapid nongenomic actions of thyroid hormone. Proc. Natl. Acad. Sci. USA., v. 103, p. 14104-14049, 2006.

INCERPI, S.; LULY, P.; VITO, P. D.; FARIAS, R. N. Short-term effects of thyroid hormones on the $\mathrm{Na} / \mathrm{H}$ antiport in L-6 myoblasts: high molecular specificity for 3,3*,5triiodo-1-thyronine. Endocrinology, v. 140, p. 683-689, 1999.

IORDANIDOU, A.; HADZOPOULOU-CLADARAS, M.; LAZOU, A. Non-genomic effects of thyroid hormone in adult cardiac myocytes: relevance to gene expression and cell growth. Mol. Cell. Biochem., v. 340, p. 291-300, 2010.

IRRCHER, I.; WALKINSHAW, D. R.; SHEEHAN, T. E.; HOOD D. A. Thyroid hormone (T3) rapidly activates p38 and AMPK in skeletal muscle in vivo. J. Appl. Physiol., v. 104, p. 178-185, 2008.

ISHIKI, M.; KLIP, A. Recent developments in the regulation of glucose transporte-4 trafic: new signals, locations and partners. Endocrinology, v. 146, p. 5071-5078, 2005.

JAMES, D. E.; JENKINS, A. B.; KRAEGEN, E. W. Heterogeneity of insulin action in individual muscles in vivo: euglycemic clamp studies in rats. Am. J. Physiol., v. 248, p. E567-574, 1985.

JAMES, D. E.; STRUBE, M.; MUECKLER, M. Molecular Cloning and Characterization of an insulin-relatable glucose transporter. Nature, v. 338, p. 83-77, 1989.

JEPSEN, K.; ROSENFELD, M. G.; Biological roles and mechanistic actions of corepressor complexes. J. Cell Sci., v. 115, p. 689-698, 2002. 
JOOST, H. G.; THORENS, B. The extended GLUT-family of sugar/polyol transport facilitators: nomenclature, sequence characteristics, and potential function of its novel members. Mol. Membr. Biol., v. 18, p. 247-256, 2001.

JOSSEAUME, C.; LORCY, Y. Thyroid hormone analogs: an important biological supply and new therapeutic possibilities. Ann. Endocrinol., v. 69, p. 33-36, 2008.

KANE, S.; SANO, H.; LIU, S. C.; ASARA, J. M.; LANE, W. S.; GARNER, C. C.; LIENHARD, G. E. A method to identify serine kinase substrates. AKT phosphorylates a novel adipocyte protein with a rab GTPase-activating protein GAP domain. J. Biol. Chem., v. 277, p. 22115-22118, 2002.

KHAN, A. H.; PESSIN, J. E. Insulin regulation of glucose uptake: a complex interplay of intracellular signaling pathways. Diabetologia, v. 45, p. 1475-1483, 2002.

KISHI, K.; MUROMOTO, N.; NAKAYA, Y.; MIYATA, I.; HAGI, A.; HAYASHI, H.; EBINA, Y. Bradykinin directly triggers GLUT4 translocation via an insulin-independent pathway. Diabetes, v. 47, p. 550-558, 1998.

KROOK, A.; WALLBERG-HENRIKSSON, H.; ZIERATH, J. R. Sending the signal: molecular mechanisms regulating glucose uptake. Med. Sci. Sport. Exerc., v. 36, p. 12121217, 2004.

LEONARD, J. L.; SIEGRIST-KAISER, C. A.; ZUCKERMAN, C. J. Regulation of type II iodothyronine 5'-deiodinase by thyroid hormone. Inhibition of actin polymerization blocks enzyme inactivation in cAMP-stimulated glial cells. J. Bio.l Chem., v. 15, p. 940-946, 1990.

LIN, H-Y.; DAVIS, F. B.; GORDINIER, J. K.; MARTINO, L. J.; DAVIS, P. J. Thyroid hormone induces activation of mitogen-activated protein kinase in cultured cells. Am. J. Physiol., v. 276, p. 1014-1024, 1999.

LIU, L. Z.; HE, A. B.; LIU, X. J.; CHANG, Y. S.; FANG, F. D. Protein kinase Cל and glucose uptake. Biochemistry (Moscow), v. 71, p. 701-706, 2006.

LIVAK, K. J.; SCHMITTGEN, T. D. Analysis of relative gene expression data using realtime quantitative PCR and the 2(-delta delta C(T)) method. Methods, v. 25, p. 402-408, 2001.

LUEGMAYR, E.; VARGA, F.; FRANK, T.; ROSCHGER, P.; KLAUSHOFER, K. Effects of triiodothyronine on morphology, growth behavior, and the actin cytoskeleton in mouse osteoblastic cells (MC3T3-E1). Bone, v. 18, p. 591-599, 1996. 
MACHADO, U. F.; SAITO, M. The effect of adipose cell siza on the measurement of GLUT4 in white adipose tissue of obese mice. Braz. J. Med. Biol. Res., v. 28, p. 369-376, 1995.

MACHADO, U. F.; SCHAAN, B. D.; SERAPHIM, P. M. Transportadores de glicose na síndrome metabólica. Arq. Bras Endocrinol. Metab., v. 50, p. 177-189, 2006.

MACHADO, U. F.; SHIMIZU, Y.; SAITO, M. Decreased glucose transporter (GLUT 4) content in insulin-sensitive tissues of obese aurothioglucose- and monosodium glutamatetreated mice. Horm. Metab. Res., v. 25, p. 462-465, 1993.

MARETTE, A.; RICHARDSON, J. M.; RAMLAL, T.; BALON, T. W.; VRANIC, M.; PESSIN J. E.; KLIP, A. Abundance, localization, and insulin-induced translocation of glucose transporters in red and white muscle. Am. J. Physiol. Cell. Physiol., v. 263, p. 443$452,1992$.

MCGEE, S. L.; HOWLETT, K. F.; STARKIE, R. L; CAMERON-SMITH, D.; KEMP; M. HARGREAVES, B. E. Exercise increases nuclear AMPK alpha2 in human skeletal muscle. Diabetes, v.52, n. 4, p. 926-928, 2003.

MCGOWAN, K. M.; LONG, S. D.; PEKALA, P. H. Glucose transporter gene expression: regulation of transcription and mRNA stability. Pharmacol. Ther. v. 66, p. 465-505, 1995.

MCVIE-WYLIE, A. J.; LAMSON, D. R.; CHEN, Y. T. Molecular cloning of a novel member of the GLUT family of transporters, SLC2a10 (GLUT10), localized on chromosome 20q13.1: a candidate gene for NIDDM susceptibility. Genomics, v. 72, p. 113-117, 2001.

MEZOSI, E.; SZABO, J.; NAGY, E. V.; BORBELY, A.; VARGA, E.; PARAGH, G.; VARGA, Z. Nongenomic effect of thyroid hormone on free-radical production in human polymorphonuclear leukocytes. J. Endocrinol., v. 185, p. 121-129, 2005.

MITSUMOTO, Y.; KLIP, A. Development regulation of the subcellular distribution and glycosylation of GLUT1 and GLUT4 glucose transporters during myogenesis of L6 muscle cells. J. Biol. Chem., v. 267, p. 4957-4962, 1992.

MOELlER, L. C.; CAO, X.; DUMITRESCU, A. M.; SEO, H.; REFETOFF, S. Thyroid hormone mediated changes in gene expression can be initiated by cytosolic action of the thyroid hormone receptor beta through the phosphatidylinositol 3-kinase pathway. Nucl. Recept. Signal., v. 4, 2006.

MONDON, C. E.; DOLKAS, C. B.; REAVEN, G. M. Site of enhanced insulin sensitivity in exercise-trained rats at rest. Am. J. Physiol., v. 239, n. 3, p. E169-177, 1980. 
MUECKLER, M. Facilitative glucose transporters. Eur. J. Biochem., v. 219, p. 713-725, 1994.

MUECKLER, M.; CARUSO, C.; BADWIN, S. A.; PANICO, M.; BLENCH, I.; MORRIS, H.R.; ALLARD, W. J.; LIENHARD, G. E.; LODISH, H. F. Sequence and structure of a human glucose transporter. Science, v. 229, p. 941-945, 1985.

MUSI, N.; HIRSHMAN, M. F.; ARAD, M.; XING, Y.; FUJII, N.; POMERLEAU, J.; AHMAD, F.; BERUL, C. I.; SEIDMAN, J. G.; TIAN, R.; GOODYEAR, L. J. Functional role of AMP-activated protein kinase in the heart during exercise. FEBS Letters, v. 579, n. 10, p. 2045-2050, 2005.

NEMETH, P.; PETTE, D. Succinate dehydrogenase activity in fibres classified by myosin ATPase in three hind limb muscles of rat. J. Physiol., v. 320, p. 73-80, 1981.

NUNES, M. T.; BIANCO, A. C.; MIGALA, A.; AGOSTINI, B.; HASSELBACH, W. Thyroxine induced transformation in sarcoplasmic reticulum of rabbit soleus and psoas muscles. Z. Naturforsch., v. 40, p. 726-734, 1985.

NYSTROM, F. H.; QUON, M. J. Insulin signallig: metabolic pathways and mechanisms for specificity. Cell. Signal., v. 11, p. 563-574, 1999.

OPPENHEIMER, J. H.; SCHWARTZ, H. L.; MARIASH C. N.; KINLAW, W. B.; WONG, N. C. W.; FREAKE, H. C. Advances in our understanding of thyroid hormone action at the cellular level. Endocr. Rev., v. 8, p. 288-308, 1987.

PARK, S. H.; PAULSEN, S. R.; GAMMON, S. R.; MUSTARD, K. J.; HARDIE, D. G.; WINDER, W. W. Effects of thyroid state on AMP-activated protein kinase and acetyl-CoA carboxylase expression in muscle. J. Appl. Physiol., v. 93, p. 2081-2088, 2002.

PATEL, N.; RUDICH, A.; KHAYAT, Z. A.; GARG, R.; KLIP, A. Intracelular Segregation Of Phosphatidylinositol-3,4,5-Trisphophate by Insulin-Dependentactin Remodeling in L6 Skeletal Muscle Cells. Mol. Cell. Biol., v. 23, p. 4611-4626, 2003.

PHAY , J. E.; HUSSAIN, H. B.; MOLEY, J. F. Cloning and expression analysis of a novel member of the facilitative glucose transporter family, SLC2A9 (GLUT9). Genomics, v. 66, p. 217-20, 2000.

PUPO, A. A.; MARREIRO, D. Dosage of insulin levels using radioimmunoassay with double antibodies. AMB Rev. Assoc. Med. Bras. v. 16, p. 153-156, 1970. 
RANDHAWA, V. K.; ISHIKURA, S.; TALIOR-VOLODARSKY, I.; CHENG, A. W.; PATEL, N.; HARTWIG, J. H.; KLIP, A. GLUT4 vesicle recruitment and fusion are differentially regulated by Rac, AS160, and Rab8A in muscle cells. J. Biol. Chem., v. 3, p. 27208-27219, 2008.

RICHTER, E. A.; HANSEN, B. F.; HANSEN, S. A. Glucose-induced insulin resistance of skeletal-muscle glucose transport and uptake. Biochem. J., v. 252, p. 733-77, 1988.

ROHER, D.; DILLMANN, W. H. Thyroid hormone markedly increases the mRNA coding for sarcoplasmic reticulum Ca2+-ATPase in the rat heart. J. Biol. Chem., v. 263, p. 69416944, 1988.

SALTIEL, A. R.; KAHN, C. R. Insulin signaling and the regulation of glucose and lipid metabolism. Nature, v. 414, p. 799-806, 2001.

SAMUELS, H. H.; STANLEY, F.; CASANOVA, J. Depletion of L-3,5,3'-triiodothyronine and L-thyroxine in euthyroid calf serum for use in cell culture studies of the action of thyroid hormone. Endocrinology, v. 105, p. 80-85, 1979.

SANTOS, J. M.; RIBEIRO, S. B.; GAYA, A. R.; APPELL, H. J.; DUARTE, J. A. Skeletal muscle pathways of contraction-enhanced glucose uptake. Int. J. Sports. Med., v. 29, p. 785794, 2008.

SANTOS, R. A.; GIANNOCCO, G.; NUNES, M. T. Thyroid hormone stimulates myoglobin expression in soleus and extensorum digitalis longus muscles of rats: Concomitant alterations in the activities of krebs cycle oxidative enzymes. Thyroid, v. 11, p. 545-550, 2001.

SCHEEPERS, A.; JOOST, H. G., SCHÜRMANN, A. The glucose transporter families SGLT and GLUT: molecular basis of normal and aberrant function. JPEN. J. Parenter. Enteral Nutr., v. 28, p. 364-371, 2004.

SCHEEPERS, A.; SCHMIDT, S.; MANOLESCU, A.; CHEESEMAN, C. I.; BELL, A.; ZAHN, C.; JOOST, H. G.; SCHURMANN, A.; Characterization of the human SLC2A11 (GLUT11) gene: alternative promoter usage, function, expression, and subcellular distribution of three isoforms, and lack of mouse orthologue. Mol. Membr. Biol., v. 4, p. 339-351, 2005.

SEGAL, J. Acute effect of thyroid hormone on the heart: an extranuclear increase in sugar uptake. J. Mol. Cell. Cardiol., v. 21, p. 323-34, 1989a. 
SEGAL, J.; INGBAR, S. H. Evidence that an increase in cytoplasmic calcium is the initiating event in certain plasma membrane-mediated responses to 3,5,3_- triiodothyronine in rat thymocytes. Endocrinology, v. 124, p. 1949-1955, 1989 b.

SHEEHAN, T. E.; KUMAR, P. A.; HOOD, D. A. Tissue-specific regulation of cytochrome c oxidase subunit expression by thyroid hormone. Am. J. Physiol. Endocrinol. Metab., v. 286, p. 968-974, 2004.

SHEUE-YANN, C.; LEONARD J. L.; DAVIS P. J. Molecular Aspects of Thyroid Hormone Actions. Endocr. Rev., v. 31, p. 139-170, 2010.

SHIMIZU, Y.; SHIMAZU, T. Thyroid hormone augments GLUT4 expression and insulinsensitive glucose transport system in differentiating rat brown adipocytes in culture. J. Vet. Med. Sci. v. 64, p. 677-681, 2002.

SOMWAR, R.; KIM, D. Y.; SWEENEY, G.; HUANG, C.; NIU, W.; LADOR, C.; RAMLAL, T.; KLIP, A. GLUT4 translocation precedes the stimulation of glucose uptake by insulin in muscle cells: potential activation of GLUT4 via p38 mitogen-activated protein kinase. Biochem. J., v. 359, p. 639-649, 2001.

STUART, C. A.; WEN, G.; JIANG, J. GLUT3 protein and mRNA in autopsy muscle specimens. Metabolism, v. 48, p. 876-880, 1999.

TORRANCE, C. J.; DEVENTE, J. E.; JONES, J. P.; DOHM, G. L. Effects of Thyroid Hormone on GLUT4 Glucose Transporter Gene Expression and NIDDM in Rats. Endocrinology, v. 138, p. 1204-1214, 1997a.

TORRANCE, C. J.; USALA, S. J.; PESSIN, J. E.; DOHM, G. L.; Characterization of a low affinity thyroid hormone receptor binding site within the rat GLUT4 gene promoter. Endocrinology, v. 138, p. 1215-1223, 1997 b.

ULDRY, M.; THORENS, B. The SLC2 family of facilitated hexose and polyol transporters. Pflugers Arch., v. 448, p. 250-260, 2004.

VAVVAS, D.; APAZIDIS, A.; SAHA, A. K.; GAMBLE, J.; PATEL, A.; KEMP, B. E.; WITTERS, L. A.; RUDERMAN, N. B. Contraction-induced changes in acetyl-CoA carboxylase and 5'-AMP-activated kinase in skeletal muscle. J. Biol. Chem., v. 272, n.20, p. 13255-13261, 1997.

VIGUERIE, N.; MILlET, L.; AVIZOU, S.; VIDAL, H.; LARROUY, D.; LANGIN, D. Regulation of human adipocyte gene expression by thyroid hormone. J. Clin. Endocrinol. Metab., v. 87, p. 630-634, 2002. 
VOLPATO, C. B.; SHIRAISHI, E. M.; LATRONICO, A. C.; NUNES, M. T. Thyroid hormone modulates the polyadenylation of growth hormone mRNA in rats. Endocr. J. v. 47, p. 169, 2000 (Abstract).

WATSON, R. T.; PESSIN, J. E. Intracellular organization of insulin signaling and GLUT 4 translocation. Recent Prog. Horm. Res., v. 56, p. 175-194, 2001.

WEINSTEIN, S. P.; O'BOYLE, E.; HABER, R. S.; Thyroid hormone increase basal and insulin-stimulated glucose transport in skeletal muscle. The role of GLUT4 glucose transporter expression. Diabetes, v. 43, p. 1185-1189, 1994.

WINDER, W. W.; HARDIE, D. G.; MUSTARD, K. J.; GREENWOOD, L. J.; PAXTON, B. E.; PARK, S. H.; RUBINK, D. S.; TAYLOR, E. B. Long-term regulation of AMP-activated protein kinase and acetyl-CoA carboxylase in skeletal muscle. Biochem. Soc. Trans., v. 31, p. 182-185, 2003.

WOOD, I. S.; TRAYHURN, P. Glucose transporters (GLUT and SGLT): expanded families of sugar transport proteins. Br. J. Nutr., v. 89, p. 3-9, 2003.

WRIGHT, E.M. Renal Na ${ }^{+}$-glucose cotransporters. Am. J. Physiol., v. 280, p. 10-18, 2001.

YONEMITSU, N.; TODA, S.; TAKATORI, O.; MIYABARA, S.; SUGIHARA, H. Morphological and functional comparison of subcapsular small cells, subcapsular large cells and inner layer cells of bovine adrenal cortex. Acta. Pathol. Jpn. v. 41, p. 428-436, 1991.

YOUN, J. H.; GULVE, E. A.; HOLLOSZY, J. O. Calcium stimulates glucose transport in skeletal muscle by a pathway independent of contraction. Am. J. Cell. Physiol., v. 260, p. 555-561, 1991.

ZAID, H.; ANTONESCU, C. N.; RANDHAWA, V. K.; KLIP, A. Insulin action on glucose transporters through molecular switches, tracks and tethers. Biochem. J., v. 413, p. 201-215, 2008.

ŽDYCHOVÁ, J.; KOMERS, R. Emerging role of Akt kinase/protein kinase B signaling in pathophysiology of diabetes and its complications. Physiol. Res., v. 54, p. 1-16, 2005.

ZINMAN, T.; SHNEYVAYS, V.; TRIBULOVA, N.; MANOACH, M.; SHAINBERG, A. Acute, nongenomic effect of thyroid hormones in preventing calcium overload in newborn rat cardiocytes. J. Cell. Physiol., v. 207, p. 220-231, 2006. 